UNIVERSIDADE DE SÃO PAULO

ESCOLA DE ENGENHARIA DE SÃO CARLOS

DEPARTAMENTO DE EGENHARIA MECÂNICA

\title{
MICROFRESAMENTO DE AÇOS COM GRÃOS ULTRAFINOS
}

\section{CLEITON LAZARO FAZOLO DE ASSIS}

Tese apresentada à Escola de Engenharia de São Carlos da Universidade de São Paulo, como parte dos requesitos para obtenção do título de Doutor em Engenharia Mecânica.

ORIENTADOR: PROF. DR. RENATO GOULART JASINEVICIUS COORIENTADOR: PROF. DR. ALESSANDRO ROGER RODRIGUES

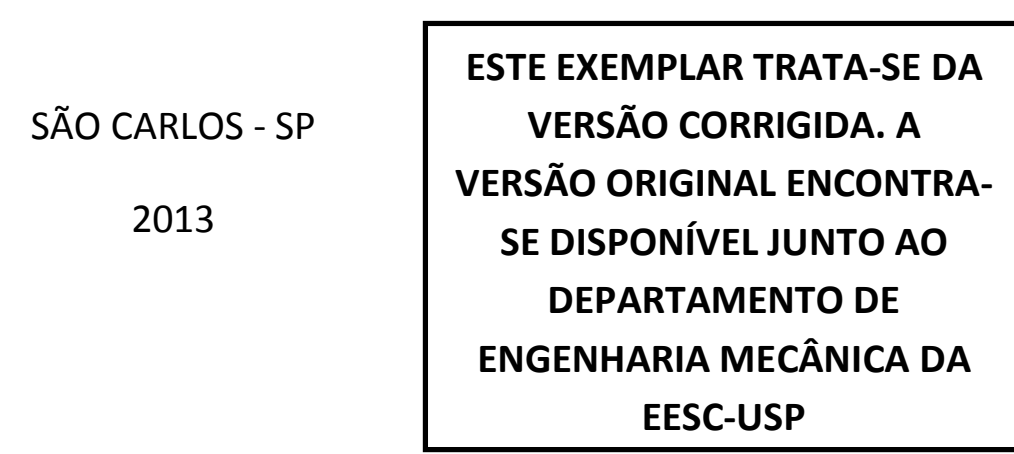


AUTORIZO A REPRODUÇÃO TOTAL OU PARCIAL DESTE TRABALHO, POR QUALQUER MEIO CONVENCIONAL OU ELETRÔNICO, PARA FINS DE ESTUDO E PESQUISA, DESDE QUE CITADA A FONTE.

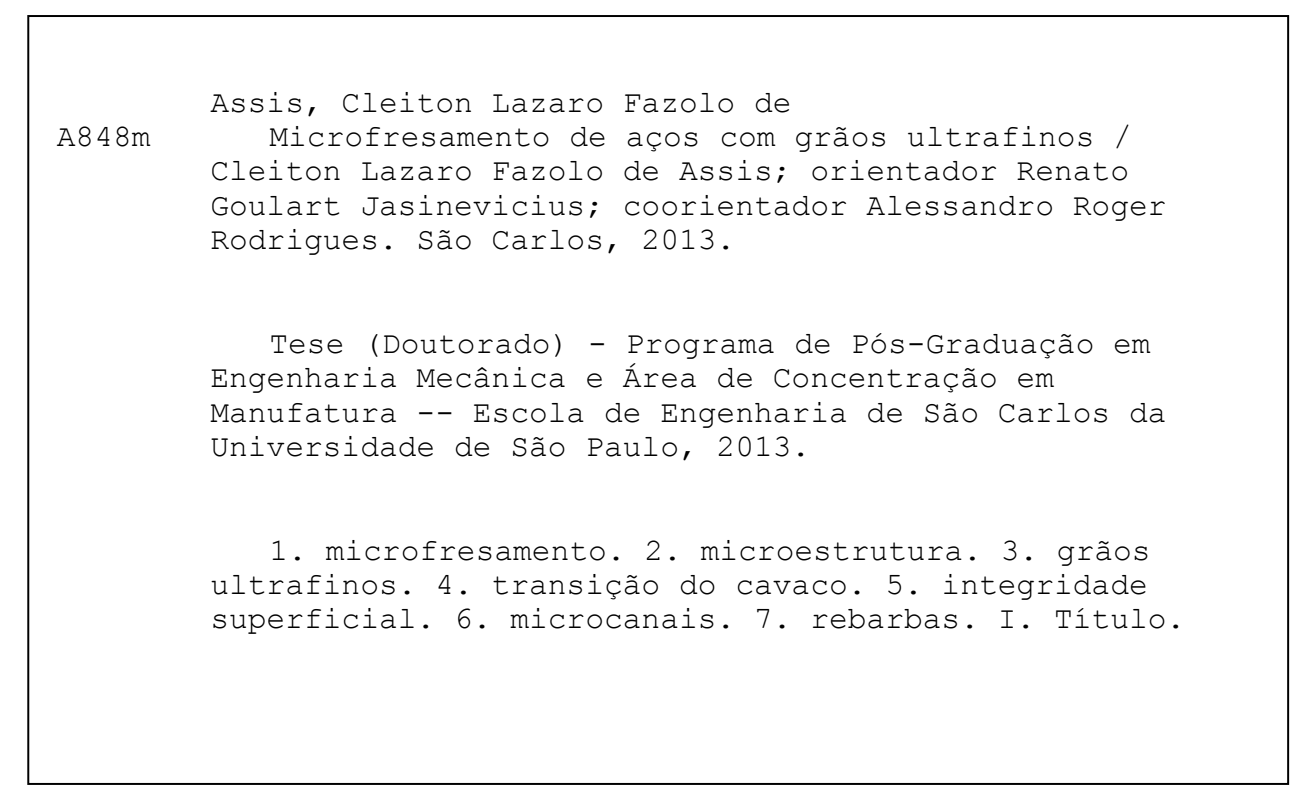




\section{FOLHA DE IULGAMENTO}

Candidato: Engenheiro CLEITON LAZARO FAZOLO DE ASSIS.

Título da tese: "Microfresamento de aços com grãos ultrafinos".

Data da defesa: 20/09/2013

\section{Comissão Julgadora:}

Prof. Associado Renato Goulart Jasinevicius (Orientador)

(Escola de Engenharia de São Carlos/EESC)

Prof. Dr. Alessandro Roger Rodrigues

(Escola de Engenharia de São Carlos/EESC)

Prof. Dr. Eduardo Carlos Bianchi

(Universidade Estadual Paulista "Júlio de Mesquita Filho"/UNESX-Bauru)

Prof. Dr. Hidekasu Matsumoto

APNOUADO

(Universidade Estadual Paulista "Júlio de Mesquita Filho"/UNESP - Ilha Solteira)

Prof. Dr. Adriano Fagali de Souza

(Universidade Federal de Santa Catarina/UFSC)

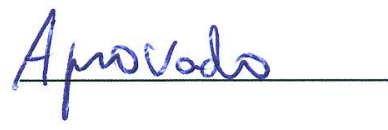

Coordenador do Programa de Pós-Graduação em Engenheira Mecânica:

Prof. Associado Marcelo Areias Trindade

Presidente da Comissão de Pós-Graduação:

Prof. Titular Denis Vinicius Coury 


\section{DEDICATÓRIA}

Dedico este trabalho a minha mãe Eurides pelos princípios e virtudes passados a mim durante minha vida. Ao meu pai Lazaro e irmãos Cristiane e Cleber, e a minha pequena Sahra pela inocência e amor que somente a infância provê. 


\section{AGRADECIMENTOS}

Agradeço a todos aqueles que de alguma forma contribuíram para minha formação pessoal, profissional e intelectual. Sou grato pelos desafios, momentos de reflexão, conquistas e vitórias. Um homem não se constrói apenas por si só, o trabalho árduo e o companheirismo são as ferramentas para desbravar horizontes e encontrar seu espaço no mundo. Sem essas contribuições eu não seria quem eu aprendi a ser, e tenho orgulho de ter convivido com tão sábias pessoas.

A minha família, tios e primos pela companhia durante estes anos de luta e emprenho. Obrigado por sempre demonstrarem o orgulho que sentem de mim.

Ao meu inquieto orientador Professor Dr. Renato Goulart Jasinevicius, pelas contribuições para o desenvolvimento desta pesquisa, confiança e parceria. Agradeço por cada oportunidade, pelas discussões e ensinamentos.

Ao meu coorientador Professor Dr. Alessandro Roger Rodrigues pela oportunidade, amizade e confiança depositada em mim desde a iniciação científica.

Ao meu supervisor canadense Professor Dr. Yusuf Altintas por me conceder a oportunidade de realizar o meu estágio de doutorado sanduíche junto à University of British Columbia em Vancouver (Canadá). Agradeço pela sabedoria, ensinamentos e filosofias.

Ao Professor Dr. Reginaldo Teixeira Coelho pela oportunidade de desenvolver este trabalho de pesquisa no Laboratório de Processos Avançados e Sustentabilidade. Agradeço pelo apoio, confiança e por ter intermediado meu estágio de pesquisa no Canadá.

Ao Professor Dr. Oscar Balancin por ceder o laboratório de tratamentos termomecânicos do Departamento de Engenharia de Materiais da UFSCar para o refino de grão dos corpos de prova utilizados nos ensaios de usinagem. Agradeço ao técnico Rover Belo por acompanhar e auxiliar no tratamento do material.

Ao Professor Dr. Rubens Caram Júnior do Departamento de Engenharia Mecânica da Unicamp pelo uso do nanodurômetro, e a Nathália Verríssimo por acompanhar e auxiliar nas medições de nadodureza.

Aos Professores Doutores Alberto Moreira, Eraldo Janone, Jaime Duduch, João Fernando de Oliveira, João Rollo, Juno Gallego, Leopoldo Oliveira, Luciana Montanari, Luiz Casteletti, Maíra Silva, Roberto Tsunaki e Waldek Filho pelas contribuições para com esta pesquisa, seja pelo apoio, amizade, uso de equipamentos ou discussões sobre os resultados. Agradeço por dedicarem parte de vosso tempo ao meu trabalho.

Ao Engenheiro MSc. Aldo Yoshida Rigatti pela amizade, parceria e contribuições para a elaboração e execução dos ensaios de usinagem, e tratamento e análise dos resultados. 
Aos alunos de iniciação científica Danilo Barbosa, Henrique Massaoka, Jonathan Francciesco, Otávio Ponce, Pedro Mantegazza, Renata Grass, Sofia Cravo e Vlademir Alves pela participação direta na construção deste trabalho. Agradeço a amizade, parceria, entusiasmo, dedicação e momentos de descontração e alegria. Não teriam sido possíveis tantos bons resultados sem vosso empenho e minúcia na investigação proposta por esta tese de doutorado.

Aos demais membros do Laboratório de Processos Avançados e Sustentabilidade (LAPRAS) da Escola de Engenharia de São Carlos pela amizade e apoio durante meus anos como doutorando. Agradeço também aos antigos e atuais membros do Grupo de Pesquisa em Usinagem (GPU) da Faculdade de Engenharia de Ilha Solteira (FEIS/UNESP) pela participação na construção deste trabalho.

Aos Técnicos de laboratório Adolfo Ferrarin, Diego Coimbrão, Douglas Bon, Eliezer Francisco, João Bernardi, José Lima, Marcio de Paula, Pedro Lorenzo, Ricardo Pereira, Vinícius Mariano e Vitor Sacramento. Agradeço pelo auxílio na realização de ensaios mecânicos, preparação e análise das amostras.

A Fundação de Amparo a Pesquisa do Estado de São Paulo (FAPESP) pelo fomento a pesquisa e concessão das bolsas de Doutorado (Processo 2010/06140-0) e de Estágio de Pesquisa no Exterior (2012/13363-1).

Agradeço também ao CNPq e a CAPES pelos auxílios às viagens para congressos e realização de pesquisas de campo.

A Arotec pelo uso do microscópio laser para medição dos raios de aresta das ferramentas. Agradeço também a Açobril pelo desconto na compra do aço para os corpos de prova.

Aos amigos Aline Frederico, Edilson Souza, Felipe Custódio, Ítalo Assis, Júlio César, Marcos Assis, Neyane Marini, Silvia Kelly e Vitor Franco pela amizade e companheirismo durante minha estadia no Canadá. Vossa companhia, apoio, incentivo e motivação eram sempre bem vindas durante aquele inverno canadense.

Aos amigos estrangeiros Ahmet Yildz, Alex Yuen, Amirhossein Hadi, Byron Reynolds, Chen Fan, Fan Liquig, Ke Zhang, Keivan Ahmadi, Mark Dyck, Mohamemmad Kroshdarregi, Mohit Law, Mustafa Kaymakci, Niccolò Grossi, Oguzhan Tuysuz, Sneha Tulsyan, Yang Jixiang, Zekai Kilic e em especial a Jin Xioliang pelo acolhimento, receptividade e apoio ao meu trabalho realizado no Manufacturing Automation Laboratories (MAL) da University of British Columbia em Vancouver (Canadá).

Para finalizar, agradeço aos sempre presentes amigos Adimara Colturato, Adriana Norcino, Alessandro Silva, Alex Bottene, Aruan Assis, Bruna Aroca, Bruno Vendramin, Carla Santos, Carlos Gomes, Cassio Basile, Cláudia Nascimento, Daniel Maia, Daniel Suyama, Danilo Silva, Douglas Honório, Elisangela Fazolo, Fabio Leite, Fernando Brandão, Gustavo Banhato, Hícaro 
Adriano, Joana Mezanini, José Eduardo, Juliana Lukiantchuki, Juliana Paganelli, Marcel Dib, Marcelo Filardi, Marieli Lukiantchuki, Michel Peres, Naiana Bazanini, Natália Assis, Paulo Manoel, Ricardo Campos, Ricardo Hildebrand, Ricardo Arai, Rodolfo Manera, Rodrigo Silva, Wiviane Valério e Yao Luo. 
Esta tarde senti o aroma dos campos Em um doce momento da minha vida As vozes dos anjos ecoaram Entoando uma sonata única e intensa Logo termino de escrever outro verso Para a inspiração ganhar liberdade

Os ventos correm velozes Para retornar sinais de esperança

Quando pouco for sentido Perante um mundo desconhecido

Então as portas se abrem A luz adentra e toma o espaço

Notei que começamos a partir do fim Mostre-me os meios para mudar tudo E fazer melhor, como nunca faríamos E assim reconstruir uma parte de nós Pois quero que isto tenha significado

Dance comigo seguindo meus passos Daremos vida a esta aridez de almas Criaremos chuva neste vasto deserto Assim dominamos esta força interior Para reaver nosso instante de glória

As flores ainda germinam nos campos A beleza não se despede deste abrigo O céu revela algo mais Pois muito mais existe além do que vemos Nós contribuímos com o sentimento Para que sejamos parte do universo

Encontrei a razão por trás da criação A existência única do espírito humano o pulsar que sinto em tudo o que toco

As águas se revoltam Trazendo sinais da tempestade Junto à mudança dos eventos Simbolizando a falta da palavra

Então a perfeição se desfaz E começamos do fim outra vez (Espírito Humano - Cleiton Assis) 


\section{Resumo}

ASSIS, C. L. F. Microfresamento de aços com grãos ultrafinos. 2013. 82 p. Tese (Doutorado) Escola de Engenharia de São Carlos, Universidade de São Paulo, São Carlos, 2013.

A micromanufatura via usinagem apresenta algumas dificuldades, principalmente aquelas relacionadas à formação do cavaco, pois a espessura de corte passa a ter a dimensão do tamanho de grão do material da peça e da microgeometria da aresta de corte. Em operações de microcorte, a microestrutura do material é um fator importante no controle da geração da superfície da peça, mecanismo de formação de cavaco, etc. Este trabalho de pesquisa avaliou o efeito do tamanho ultrafino dos grãos do material da peça sobre os fenômenos inerentes ao corte no microfresamento. As variáveis de usinagem investigadas foram avanço por dente $\left(f_{z}\right)$, velocidade de corte $\left(v_{c}\right)$, diâmetro da microfresa $\left(d_{\phi}\right)$ e raio de aresta de corte $\left(r_{e}\right)$, visando avaliar o mecanismo de formação do cavaco, acabamento da peça e integridade superficial. Os materiais utilizados nos experimentos foram um aço bifásico (ferrita-perlita) com tamanho de grão ferrítico de $11 \mu \mathrm{m}$ e outro de microestrutura homogênea de grãos ultrafinos com 0,7 $\mu \mathrm{m}$, ambos com mesma composição química e baixo-carbono. Dois grupos de ensaios foram propostos: (1) macro e microfresamento e (2) microfresamento de canais. O tipo de usinagem foi o de fresamento de topo, sem emprego de fluido de corte. Os ensaios de usinagem foram executados em centros de usinagem CNC. As ferramentas de corte foram de metal duro com recobrimentos, diâmetro $16 \mathrm{~mm}$ na escala macro de usinagem, 200 e $800 \mu \mathrm{m}$ na escala micro. A adequação da microestrutura do material da peça à redução da escala de usinagem, através do mecanismo de refino de grão, gerou alguns aspectos favoráveis à microusinagem, como melhor acabamento $\left(S_{\mathrm{sk}} \approx 0\right.$ e $\left.S_{\mathrm{ku}} \approx 3\right)$, formação de cavaco contínuo e menor formação de rebarbas com a redução da espessura de corte $\left(f_{z} \leq r_{e}\right)$, possibilitando aplicações em microfabricação por corte com ferramenta de geometria definida utilizando aços baixo carbono, antes limitadas à estruturas na construção civil e peças obtidas por conformação mecânica.

Palavras-chave: microfresamento, microestrutura, grãos ultrafinos, formação do cavaco, integridade superficial, microcanais e rebarbas. 
Abstract

ASSIS, C. L. F. Micromilling of ultrafine grained steels. 2013. 82 p. Thesis (Ph.D.) - School of Engineering at São Carlos, Sao Paulo University, Sao Carlos, 2013.

Micro manufacturing by means of machining presents difficulties, mainly those related to chip formation, since chip thickness become as small as normal material grain size, as well as the cutting edge radius. At such micro cutting operations material microstructure ascends as a very important issue in terms of machining output, i.e. surface roughness, subsurface damages, cutting forces, etc. This research evaluated the effect of the intervention on the metallurgical microstructure of the material on the cutting phenomena inherent in micromachining. The variables investigated were the feed per tooth $\left(\mathrm{f}_{\mathrm{t}}\right)$, cutting speed $\left(\mathrm{v}_{\mathrm{c}}\right)$, micro end-mill diameter $\left(d_{\phi}\right)$ and cutting edge radius $\left(r_{e}\right)$. The materials used in the experiments were a steel two-phase (ferrite-pearlite) with ferritic grain size of $11 \mu \mathrm{m}$ and similar one with homogeneous microstructure and ultrafine grains $(0.7 \mu \mathrm{m})$, both low carbon. The mechanism of chip formation, surface finish and surface integrity were investigated and correlated with the studied variables. Two groups of machining experiments were proposed: (1) macro and micro end-milling and (2) microchannels. Overall, the type of machining was the end milling, without using cutting fluid. The machining tests were carried on a CNC machining center. The cutting tools are coated, diameter $16 \mathrm{~mm}$ in macro scale of machining, 200 and $800 \mu \mathrm{m}$ in micro scale. the adequacy of the microstructure of the workpiece material to the reduce the scale of machining generated some favorable aspects to micromachining, such as better finishing $\left(\mathrm{S}_{\mathrm{sk}} \approx 0 \mathrm{e}\right.$ $\left.S_{k u} \approx 3\right)$, continuous chip formation and lesser burr formation by reducing the cutting thickness $\left(f_{z} \leq r_{e}\right)$, enabling micromanufacturing applications for low carbon steels, once limited to structures in the civil construction and pieces obtained by mechanical forming.

Key-words: micro end-milling, microstructure, ultrafine grained, chip formation, surface integrity, microchannels and burrs. 
Figura 2.1 - Interação cavaco-ferramenta na microusinagem (Nakayama \& Tamura, 1968). .. 7 Figura 2.2 - Formação esquemática de Poisson burr, tear burr e rollover burr (Gillespie \&

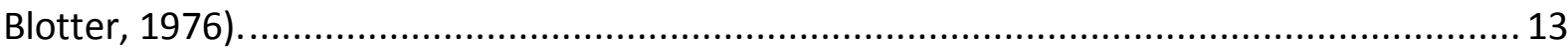

Figura 2.3 - Tipos de rebarba encontrados no fresamento (Chern, 1993). ........................... 13

Figura 2.4 - Formação de rebarbas em canais microfresados (Schueler et al., 2009). ........... 14

Figura 2.5 - Imagens de rebarbas em microusinagem de canais: (a) rebarba primária, (b) rebarba agulha, (c) rebarba pena e (d) rebarba menor (Chern et al., 2007). A direção do avanço é da esquerda para direita.

Figura 2.6 - Efeito do aumento do ângulo de conicidade $\left(\theta_{T}\right)$ da microfresa na formação de rebarbas.

Figura 2.7 - Cavaco de quasi-cisalhamento-extrusão em (a) micrografia e (b) simulação numérica. Os grãos A mais duros estão comprimindo o grão B mais dúctil (Simoneau, Ng, \&

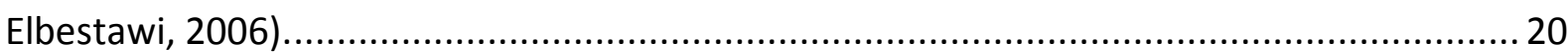

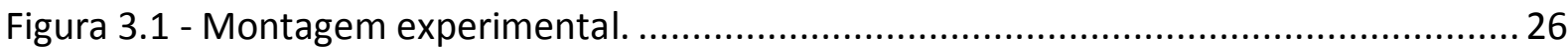

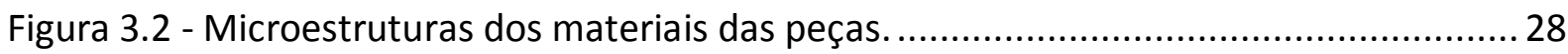

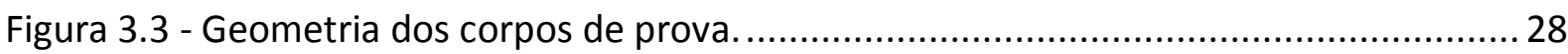

Figura 3.4 - Imagens das arestas obtidas por (a) MEV do inserto e (c) microscopia ótica laser da microfresa, e medições do raio de aresta do (b) inserto e (d) microfresa.

Figura 3.5 - Vista superior da trajetória das microfresas pela microestrutura dos materiais das peças

Figura 3.6 - (a) superfície de picos com $S_{\mathrm{sk}}=3,20$ e $S_{\mathrm{ku}}=18,71$, e (b) textura periódica com $\mathrm{S}_{\mathrm{sk}}=0,16$ e $\mathrm{S}_{\mathrm{ku}}=1,63$.

Figura 3.7 - Gráfico da recuperação elástica das endentações com a variação da carga

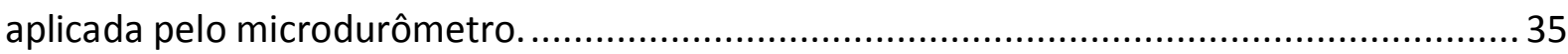

Figura 3.8 - Sistema para coleta dos cavacos na microusinagem. ....................................... 35

Figura 3.9 - Medição da espessura do cavaco para cálculo do grau de recalque. ................... 36

Figura 4.1 - Micrografias de MO do cavaco formado com $\mathrm{f}_{\mathrm{z}} \approx \mathrm{r}_{\mathrm{e}}$ (ataque Nital 2\%)................ 38

Figura 4.2 - Micrografias de MO do cavaco formado com $f_{z}>r_{e}$ (ataque Nital 2\%)................ 39

Figura 4.3 - Imagens de MEV do (a) cavaco de quasi-cisalhamento-extrusão na macrousinagem com $\mathrm{f}_{\mathrm{z}} \approx \mathrm{r}_{\mathrm{e}}$ do material $\mathrm{CR}$ e (b) detalhe das lamelas (ataque Nital $2 \%$ )........ 40 Figura 4.4 - Imagens de MEV do cavaco do material CR fresado em diferentes condições. $\mathrm{FC}=$ frente de cisalhamento e MTD = mudança da taxa de deformação.

Figura 4.5 - Imagens de MEV do cavaco do material GUF fresado em diferentes condições. FC = frente de cisalhamento e MTD = mudança da taxa de deformação.

Figura 4.6 - Gráficos do grau de recalque medidos na macrousinagem.

Figura 4.7 - Efeito do raio de aresta na formação do cavaco no fresamento para $f_{z} \leq r_{e}$ e $f_{z}>r_{e}$.

Figura 4.8 - Face de escorregamento do cavaco formado em (a) GUF5 e (b) GUF18............ 45

Figura 4.9 - Imagens 3D das superfícies micro e macrofresadas. 
Figura 4.10 - Microestrutura da subsuperfície das peças micro e macrofresadas (ataque Nital $2 \%)$. As setas indicam a direção da velocidade de avanço (vf) da ferramenta.

Figura 4.11 - Subsuperfície no microfresamento do material CR com $5 \mu \mathrm{m} / z\left(f_{z} \approx r_{e}\right)$. Em (a) a distribuição periódica dos fluxos de deformação e em (b) a ampliação de um dos fluxos de deformação.

Figura 4.12 - Imagens de MEV da superfície usinada do material CR. vf = direção do avanço da ferramenta.

Figura 4.13 - Imagens de MEV da superfície usinada do material GUF. vf = direção do avanço da ferramenta.

Figura 4.14 - Imagens de MEV e análise química por EDX da superfície de folga das ferramentas para $\mathrm{f}_{\mathrm{z}} \approx \mathrm{r}_{\mathrm{e}}$ na macrousinagem. 54

Figura 4.15 - Avaliação da formação de superfície pelo parâmetro de rugosidade $S_{z} \ldots \ldots \ldots . . . .56$

Figura 4.16 - Microdureza superficial e imagens de MO das endentações. 58

Figura 4.17 - Imagens de MEV da superfície da base dos canais para microfresa de $200 \mu \mathrm{m}$ de diâmetro e 10000 rpm. As setas indicam a direção da velocidade de avanço e de rotação da ferramenta.

Figura 4.18 - Imagens de MEV das rebarbas para microfresa de $200 \mu \mathrm{m}$ de diâmetro e 10000 rpm. As setas indicam a direção da velocidade de avanço e de rotação da ferramenta. 61 Figura 4.19 - Imagens de MEV da superfície da base dos canais para microfresa de $800 \mu \mathrm{m}$ de diâmetro e 10000 rpm. As setas indicam a direção da velocidade de avanço e de rotação da ferramenta.

Figura 4.20 - Imagens de MEV das rebarbas para microfresa de $800 \mu \mathrm{m}$ de diâmetro e 10000 rpm. As setas indicam a direção da velocidade de avanço e de rotação da ferramenta. Figura 4.21 - Imagens de MEV da superfície da base dos canais para microfresa de $800 \mu \mathrm{m}$ de diâmetro e 54000 rpm. As setas indicam a direção da velocidade de avanço e de rotação da ferramenta.

Figura 4.22 - Imagens de MEV das rebarbas para microfresa de $800 \mu \mathrm{m}$ de diâmetro e 54000 rpm. As setas indicam a direção da velocidade de avanço e de rotação da ferramenta.

Figura 4.23 - Rugosidade média Sa para (a) microfresas de diferentes diâmetros e rotação do eixo árvore de 10000 rpm e (b) microfresas de diâmetro de 800 um e rotação do eixo-árvore de $54000 \mathrm{rpm}$.

Figura 4.24 - Imagens em 3D das superfícies da base dos canais do material GUF microfresados com ferramentas de $800 \mu \mathrm{m}$ de diâmetro na condição de $\mathrm{f}_{\mathrm{z}} \approx \mathrm{r}_{\mathrm{e}}$, e velocidades de rotação do eixo-árvore de 10000 rpm em (a) e 54000 rpm em (b).

Figura 4.25 - Formação de rebarbas na usinagem com microfresa de $200 \mu \mathrm{m}$. (a) deformação, (b) fratura, (c) remoção do material e (d) rebarbas na lateral do canal. As setas circulares indicam o sentido de giro da microfresa. A direção do avanço da ferramenta é de baixo para cima.

Figura A.1 - Medição do raio de aresta de uma das pastilhas utilizadas no macrofresamento. 
Figura A.2 - Medição do raio de aresta de uma das microfresas utilizadas no microfresamento. 


\section{Lista de Tabelas}

Tabela 2.1 - Espessura mínima de corte para alguns materiais metálicos. 8

Tabela 2.2 - Principais defeitos de superfície em peças microusinadas.

Tabela 3.1 - Parâmetros de usinagem e microestrutura dos corpos de prova (macro e

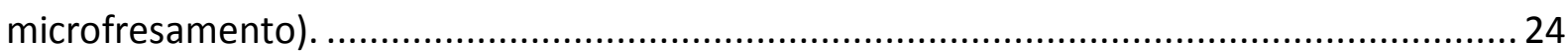
Tabela 3.2 - Parâmetros de usinagem e microestrutura dos corpos de prova (microfresamento de canais) ........................................................................................ 25 Tabela 3.3 - Composição química do material utilizado nos ensaios de usinagem (\% em peso). 27

Tabela 3.4 - Características metalúrgicas e mecânicas dos corpos de prova. 27

Tabela 4.1 - Nomenclatura aplicada à identificação dos resultados e discussão. 37

Tabela 4.2 - Avaliação da formação de picos e vales nas peças micro e macrofresadas. 46 
A: $\quad$ Ponto de estagnação do cavaco

$a_{e}: \quad$ Largura de usinagem [mm]

$a_{p}$ : Profundidade de usinagem [mm]

b: $\quad$ Altura da rebarba

c: Microcavidades

$d_{\varnothing}$ : Diâmetro das microfresas [ $\left.\mu \mathrm{m}\right]$

f: $\quad$ Avanço da ferramenta [mm/volta]

$F_{c}: \quad$ Força de corte [N]

$F_{T}$ : Força de avanço [N]

$f_{z}: \quad$ Avanço por dente [N]

g: Grooves

gi: Grooves de microcavacos

h: Espessura de material não removido

$h^{\prime}: \quad$ Espessura do cavaco

$h_{m}$ : Mínima espessura do cavaco

$h_{r e}$ : Recuperação elástica do material

i: Formação incompleta do cavaco

mr: Microrebarbas

n: $\quad$ Coeficiente de encruamento

$\eta$ : $\quad$ Ângulo de microestrutura do cavaco [ [ ]

p: Largura da rebarba

ps: $\quad$ Fluxo plástico severo

$r: \quad$ Restos de material depositados

$r_{e}: \quad$ Raio de aresta da ferramenta [ $\left.\mu \mathrm{m}\right]$

re: $\quad$ Repasse da ferramenta

$R_{\text {HSC: }}$ High Spot Count

$R_{p c}$ : Peak Count

$R_{s m}: \quad$ largura média dos elementos do perfil

s: $\quad$ Smeared material

$S_{a}$ : $\quad$ Rugosidade média avaliada sobre a superfície 3D completa 
sb: $\quad$ Smeared material em forma de ondas

$S_{k u}: \quad K u r t o s i s$ da textura da superfície 3D

$S_{q}$ : Desvio médio quadrático da rugosidade avaliada sobre a superfície $3 D$ completa

$S_{s k}: \quad$ Skewness da textura da superfície 3D

St: $\quad$ Steps

$S_{Z}$ : $\quad$ Rugosidade média dos maiores afastamentos pico vale avaliada sobre a superfície 3D completa

$v_{c}$ : Velocidade de corte $[\mathrm{m} / \mathrm{min}]$

$v_{f}: \quad$ Velocidade de avanço $[\mathrm{mm} / \mathrm{min}]$

$\gamma_{e}: \quad$ Ângulo de saída efetivo da ferramenta $\left[{ }^{\circ}\right]$

$\varepsilon: \quad$ Deformação

$\theta_{m}: \quad$ Ângulo crítico ou de estagnação [ [ ]

$\theta_{T}: \quad$ Ângulo de conicidade $\left[{ }^{\circ}\right]$

$\sigma_{o}: \quad$ Limite de escoamento

$\phi: \quad$ Ângulo de cisalhamento 


\section{Lista de Siglas}

AISI: $\quad$ American Iron and Steel Institute

ARBL: $\quad$ Aços de alta resistência e baixa-liga

CAPES: $\quad$ Coordenação de Aperfeiçoamento de Pessoal de Nível Superior

CNC: $\quad$ Controle numérico computadorizado

CNPq: $\quad$ Conselho Nacional de Desenvolvimento Científico e Tecnológico

CR: $\quad$ Material com microestrutura bifásica ferrita-perlita

DEMa: Departamento de Engenharia de Materiais

EDM: $\quad$ Electrical discharge machine

EDX: $\quad$ Energy-dispersive X-ray spectroscopy

EESC: $\quad$ Escola de Engenharia de São Carlos

FAPESP: $\quad$ Fundação de Amparo à Pesquisa do Estado de São Paulo

FC: $\quad$ Frente de cisalhamento

FEIS: $\quad$ Faculdade de Engenharia de llha Solteira

GPU: $\quad$ Grupo de Pesquisa em Usinagem

GUF: Material com microestrutura ferrítica homogênea com grãos ultrafinos

HSLA: High-Strength, Low-Alloy

LAPRAS: Laboratório de Processos Avançados e Sustentabilidade

MAL: $\quad$ Manufacturing Automation Laboratories

MEV: $\quad$ Microscopia eletrônica de varredura

MET: $\quad$ Microscopia eletrônica de transmissão

MTD: $\quad$ Mudança da taxa de deformação

MO: $\quad$ Microscopia Óptica

PVD: $\quad$ Physical vapor deposition

TG: $\quad$ Tamanho médio de grão ferrítico de acordo com a norma ASTM E112-96

UFSCar: $\quad$ Universidade Federal de São Carlos

UNESP: $\quad$ Universidade Estadual Paulista

UNICAMP: Universidade de Campinas

USP: $\quad$ Universidade de São Paulo 
ÍNDICE

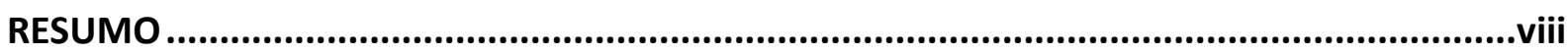

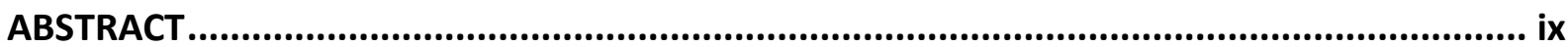

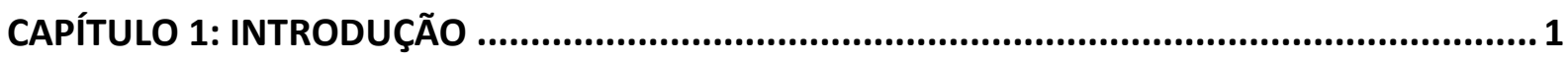

1.1. Justificativa ................................................................................................ 3

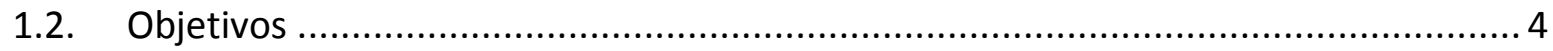

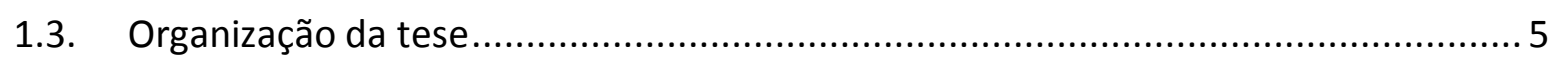

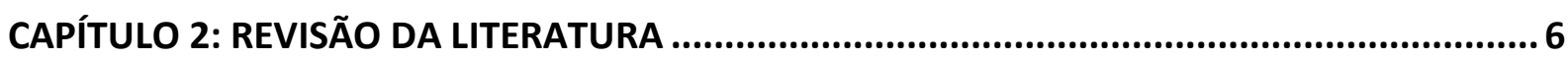

2.1. Efeito da microgeometria da aresta de corte .............................................. 6

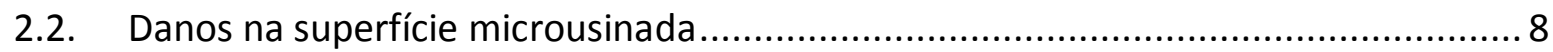

2.3. Mecanismo de formação de cavaco ............................................................... 18

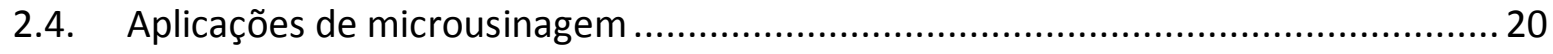

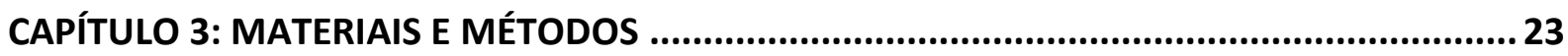

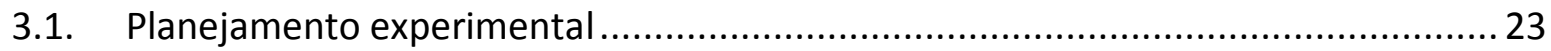

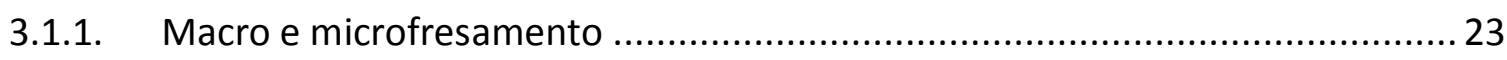

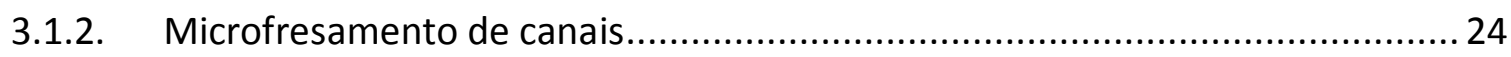

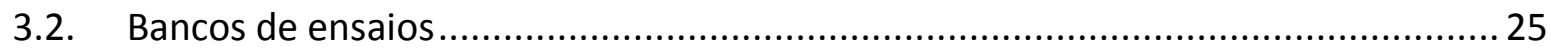

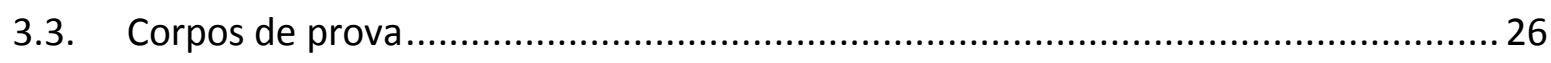

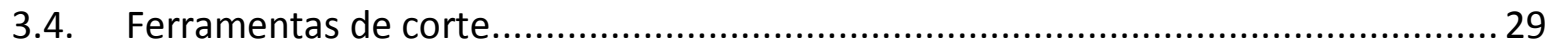

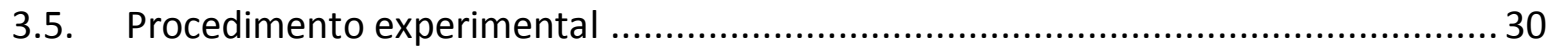

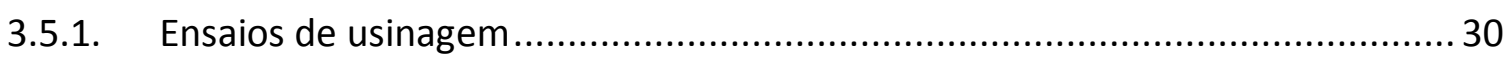

3.5.2. Rugosidade, ferramentas, borda usinada e rebarbas .................................. 32

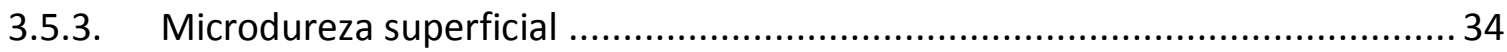

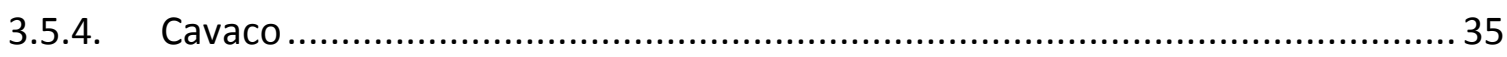

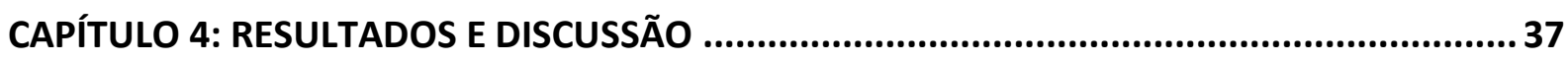

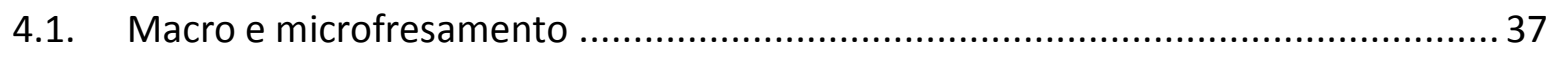

4.1.1. Mecanismo de formação de cavaco ............................................................. 37

4.1.2. Acabamento da peça e defeitos de superfície ........................................... 45

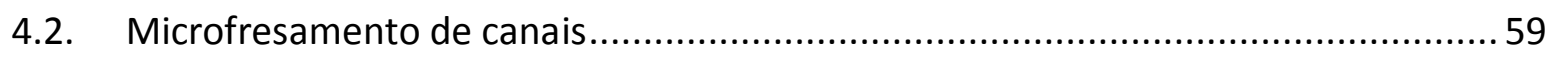




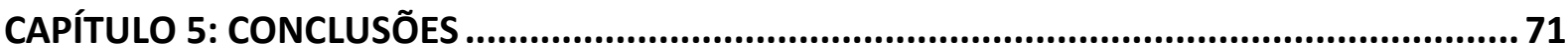

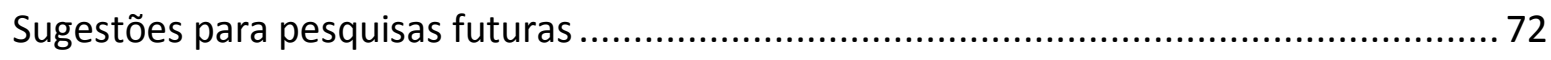

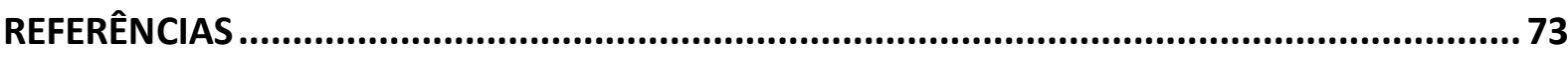

APÊNDICE A - MEDIÇÃO DO RAIO DE ARESTA DAS FERRAMENTAS ................................ 80 


\section{Capítulo 1}

\section{INTRODUÇÃO}

Aços baixo-carbono são normalmente aplicados na fabricação de chapas finas para a indústria automobilística e folhas de flandres para confecção de utensílios domésticos e objetos de arte. Outras aplicações típicas são perfis estruturais, vagões, comportas, tubos, construção civil e latas. Em geral são aplicações que não envolvem solicitações mecânicas severas, devido à baixa resistência mecânica e alta ductilidade e tenacidade. Estes aços são de baixo custo, facilmente usináveis e soldáveis, e não são tratáveis termicamente para endurecimento (Weng, 2009).

Um modo de expandir a aplicação dos aços baixo-carbono é a intervenção na microestrutura do material com auxílio de técnicas de refino de grão. A redução do tamanho de grão até a ordem de alguns micrometros ou inferior a $1 \mu \mathrm{m}$ gera um incremento significativo na resistência mecânica (Okitsu, Takata, \& Tsuji, 2009). Aços baixo-carbono com microestrutura constituída pelas fases ferrita (ultrafina) e bainita favorecem alta resistência mecânica e baixa tenacidade. Por outro lado, a presença das fases ferrita (ultrafina) e particulados de cementita globular nos contornos de grão geram menor incremento de resistência mecânica, porém asseguram boa tenacidade (Weng, 2009).

O controle do tamanho dos grãos e das fases presentes na microestrutura expandem aplicações antes restritas, com fator econômico favorável. Componentes para automóveis, parafusos e micropeças com paredes finas podem ser fabricados com o emprego de aços baixo-carbono com grãos ultrafinos, pois o balanço entre resistência mecânica e tenacidade pela intervenção metalúrgica na microestrutura abre um novo campo de possibilidades. Além disso, superfícies de materiais com grãos ultrafinos, submetidas a solicitações de fadiga, desgaste e corrosão apresentaram resultados superiores aos respectivos materiais de mesma composição química, porém com maior tamanho de grão (Wang et al., 2008).

Dando ênfase à usinagem, a microestrutura da peça possui uma influência significante nos fenômenos inerentes ao corte, independente da escala de usinagem, em especial quando relacionado à redução do avanço por dente da ferramenta até a ordem de dimensão do raio de aresta (Mian, Driver, \& Mativenga, 2011). Nessa condição a baixa razão do cavaco e fluxo plástico indesejado, tal como efeito de ploughing podem causar 
significantes danos na superfície usinada, e o escoamento de material na camada afetada pode aumentar a dureza na superfície da peça (Rodrigues et al., 2010).

A resposta mecânica de um material pode ser fortemente influenciada pelo efeito de escala na usinagem (Fang, 2003). Quando a espessura de corte está na dimensão do raio de aresta da ferramenta, mudanças no estado de tensões e na taxa de deformação ocorrem, pois o escoamento lateral muda o estado de tensão de compressivo para trativo (Fang, 2003). Como resultado, há mudanças no mecanismo de formação do cavaco e surgimento de defeitos indesejáveis na superfície da peça. Isto se deve à redução do volume de material à frente da ferramenta e a quantidade de material que escoa sob a ferramenta, na zona terciária de cisalhamento, a qual aumenta proporcionalmente com a redução da espessura de corte, principalmente para materiais com mais de uma fase (Simoneau, Ng, \& Elbestawi, 2006). Nestes casos, a usinagem é favorecida quando a quantidade de uma fase mais dura é reduzida na microestrutura do material, como a perlita, e a microestrutura torna-se mais homogênea (Rodrigues et al., 2012).

A maior diferença entre as características da usinagem de um material com microestrutura homogênea e com diferentes fases é a mudança na formação do cavaco de contínuo para descontínuo, e sua influência na formação da superfície da peça (Vogler, DeVor, \& Kapoor, 2004). Microestruturas refinadas retardariam este efeito, mantendo os cavacos contínuos mesmo quando na usinagem com espessuras de corte inferiores ao raio de aresta da ferramenta. Isso por que na redução da escala de usinagem a ferramenta pode usinar um dado grão de uma fase mais dura e em seguida um grão dúctil, alterando o processo de formação da superfície (Liu et al., 2004). Tendo como base este argumento, o refinamento da microestrutura para outras classes de materiais é uma alternativa viável para solucionar problemas relacionados à qualidade da superfície usinada e desempenho do componente quando submetido a solicitações mecânicas. 


\subsection{Justificativa}

A redução da escala de usinagem tem gerado a necessidade de melhor compreensão dos fenômenos inerentes ao corte. No microfresamento, com o uso de microfresas com diâmetros menores que $1 \mathrm{~mm}$, tornou-se necessária a aplicação de avanços por dente cada vez menores, com razões entre espessura de material não removido e raio de aresta de corte inferiores a $1 \mu \mathrm{m} / \mu \mathrm{m}$. A redução deste parâmetro de usinagem deve-se a busca por

menor força de corte e de avanço, visando manter a integridade da ferramenta, principalmente com o aumento da velocidade de corte. Porém, nessa condição há a ocorrência de transição entre cisalhamento e ploughing, afetando significativamente a qualidade da superfície microusinada.

O aumento da velocidade de corte também tem sido relatada como fator de influência na microusinagem, afetando os mecanismos presentes no efeito de raio de aresta no processo de corte, diminuindo a formação de rebarbas e melhorando o acabamento da peça (Mian, Driver, \& Mativenga, 2011). Se o aumento da velocidade de corte for mesmo significativo na melhora do processo de corte e da integridade superficial da peça na microusinagem, com o uso de microfresadas de diâmetros cada vez menores, altas rotações de eixo-árvore serão necessárias para viablizar este processo, possivelmente superiores a 500 mil rpm (Robinson \& Jackson, 2005).

Com relação ao material da peça, a existência de diferentes fases ou alterações na orientação cristalográfica resultam em uma forte variação na força de usinagem, espessura do cavaco e ângulo de cisalhamento, levando a mudanças do mecanismo de corte enquanto a ferramenta passa pelo interior de uma fase ou quando a direção de usinagem encontra-se em diferentes alinhamentos com a orientação cristalográfica dos grãos (Porto et al., 2004).

Uma textura cristalina favorável do material em relação à direção da usinagem e uma distribuição homogênea do tamanho médio dos grãos poderiam conduzir à melhorias no acabamento da peça. E um caminho viável seria através do refinamento de grãos da microestrutura do material (Popov et al., 2006). Além disso, seria possível averiguar o quanto a intervenção metalúgica no material da peça pode favorecer usinagens com avanço por dente inferiores ao raio de aresta da ferramenta, e a real necessidade de altos incrementos de velocidade de corte para melhoria do acabamento da peça. 


\subsection{Objetivos}

O principal objetivo deste trabalho é avaliar o efeito da intervenção metalúrgica na microestrutura do material da peça na fabricação de microcomponentes, em particular as geradas pelo processo de microfresamento. Neste trabalho são considerados como principais aspectos a homogeneidade da microestrutura, o tamanho ultrafino dos grãos e o raio de aresta de corte. Os objetivos específicos são:

- Estudar o efeito da microestrutura da peça no mecanismo de formação do cavaco com a redução da espessura de corte até a ordem de tamanho do raio de aresta de corte;

- Analisar a formação de defeitos na superfície e subsuperfície da peça usinada com avanços por dente da ordem da microgeometria da aresta de corte;

- Avaliar o acabamento das peças associando diferentes parâmetros de rugosidade e com imagens 3D da superfície usinada;

- Avaliar o efeito do macro e microfresamento nas mudanças nas propriedades mecânicas da superfície usinada, utilizando como parâmetro a variação da microdureza na superfície da peça;

- Estudar a formação de rebarbas e superfície no microfresamento de canais, considerando como parâmetros a variação da velocidade de corte, espessura de corte, diâmetro das microfresas e microgeometria da aresta de corte. 


\subsection{Organização da tese}

Este trabalho de pesquisa está dividido em quatro partes distintas. A primeira parte trata da revisão da literatura, com a abordagem dos principais aspectos relacionados ao tema, tendo como palavras chave inter-relacionadas: microusinagem, raio de aresta de corte, mecanismo de formação de cavaco, integridade superficial e microestrutura da peça. O texto está organizado em quatro tópicos, com clara seleção e enfoque aos resultados apresentados por esta tese de doutorado. O efeito da microgeometria da aresta da ferramenta na usinagem, em particular com a redução da escala de usinagem, formação de superfície e principais efeitos da redução da espessura de corte, mecanismo de formação de cavaco com a mudança de escala macro para micro de usinagem e efeito da microestrutura da peça, e para finalizar as aplicações do processo de microusinagem, em particular o microfresamento.

A segunda parte trata dos materiais e métodos adotados nesta pesquisa, com a apresentação dos equipamentos e ferramentas, tanto para execução dos ensaios de usinagem quanto para a obtenção e análise dos resultados. Uma caracterização mecânica e microestrutural dos materiais de estudo, e também uma descrição dos procedimentos aplicados aos ensaios e respectivo tratamento dos resultados.

A terceira parte apresenta os principais resultados gerados nesta pesquisa, na forma de figuras autoexplicativas, com indicações e medições. A análise qualitativa e quantitativa dos resultados embasa a discussão, visando, na medida do possível, realizar comparações com a literatura, buscando respostas coerentes e com critério investigativo científico, explicações demonstradas e sem preposições.

A quarta parte encerra o trabalho de pesquisa com as principais conclusões e sugestões para futuros trabalhos de pesquisa. 


\section{Capítulo 2}

\section{REVISÃO DA LITERATURA}

\subsection{Efeito da microgeometria da aresta de corte}

Com a redução da escala de usinagem, surgem problemas de ordem prática para fabricação de microcomponentes. No microfresamento, as fresas passam a ter diâmetros inferiores a $1 \mathrm{~mm}$, e com dimensões tão pequenas a aplicação inadequada dos parâmetros de usinagem tende a causar desgaste e/ou quebra da ferramenta, prejudicando o acabamento e precisão dimensional da peça (Kim, Mayor, \& Ni, 2004; Kang et al., 2007). Para tanto, baixos avanços por dente tem sido considerados com propósito de reduzir a força de avanço e também melhorar o acabamento da peça (Lee \& Dornfeld, 2005). Muitas vezes a razão $f_{z} / r_{e}$ é menor que $1 \mu \mathrm{m} / \mu \mathrm{m}$, e o ângulo de saída efetivo da ferramenta $\left(\gamma_{\mathrm{e}}\right)$ aumenta consideravelmente. Com base nestes apontamentos, o aprofundamento na compreensão dos mecanismos inerentes ao corte na redução da escala de usinagem, adequação de parâmetros de usinagem e efeito da microestrutura da peça são fatores a serem considerados na redução da escala de corte.

Dois aspectos tem adquirido grande importância na compreensão de fenômenos inerentes ao corte: o efeito de escala com a redução da espessura de corte até a ordem de tamanho do raio de aresta e a significante influência da microestrutura da peça (Dornfeld, Min, \& Takeuchi, 2006). Melhor rugosidade tem sido obtida com valores de avanço por dente próximos ao valor de raio de aresta da ferramenta (Mian, Driver, \& Mativenga, 2010). No entanto, nessa condição a baixa razão do cavaco e fluxo plástico indesejado, tal como efeito de ploughing ou fluxo lateral podem causar significantes danos na superfície usinada e aumentar a dureza na superfície da peça (Rodrigues et al., 2010).

Em microusinagem, conforme Figura 2.1, o raio de aresta da ferramenta $\left(r_{e}\right)$ é comparável com a espessura de material não removido (h). A redução substancial na razão entre a espessura de material não removido e o raio de aresta tem uma profunda influência sobre a energia específica de corte, formação do cavaco e integridade superficial da peça (Ding, Shen, \& Shin, 2012). Os cavacos não podem se formar quando a espessura de material não removido é inferior à espessura crítica do cavaco. Isto devido a efeitos elásticos, o que 
também pode gerar instabilidade do corte. Efeitos de vibração regenerativos também precisam ser considerados, mas a avaliação dinâmica exata entre a ferramenta e a peça de trabalho é extremamente desafiadora (Chae, Park, \& Freiheit, 2006).

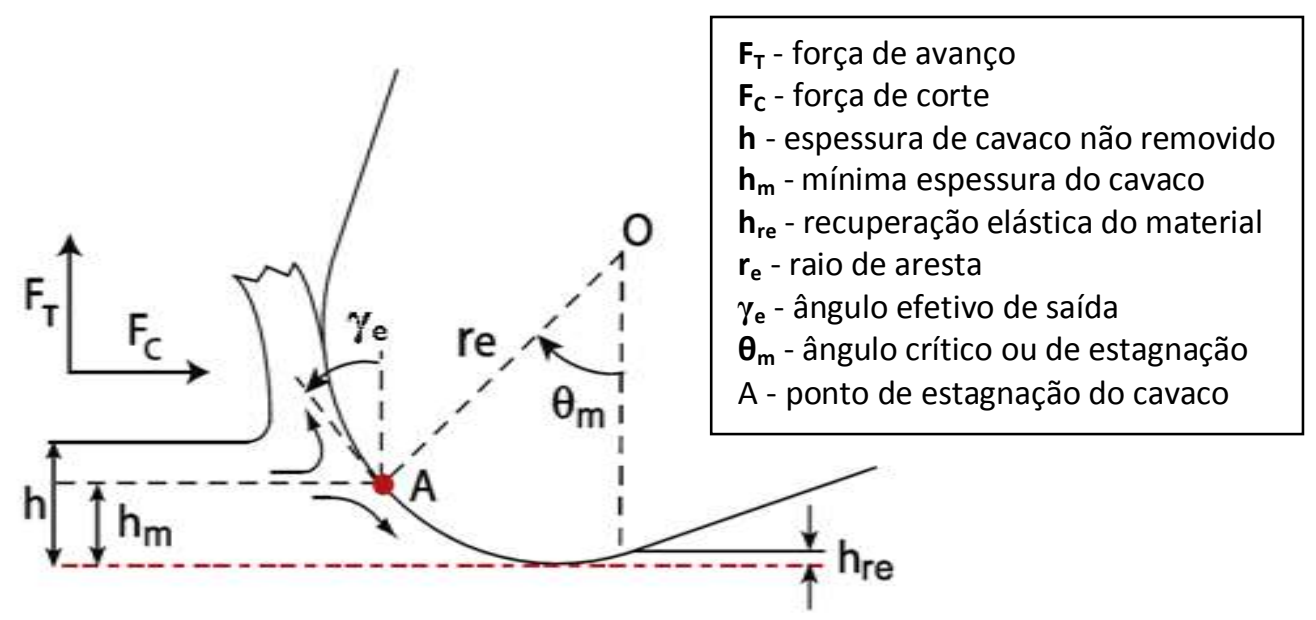

Figura 2.1 - Interação cavaco-ferramenta na microusinagem (Nakayama \& Tamura, 1968).

No microfresamento, a ferramenta pode rotacionar várias vezes sem remover material da peça, especialmente quando o avanço por dente é menor que a espessura mínima do cavaco, causando o efeito de ploughing (Cuba Ramos et al., 2012). As forças de corte podem flutuar periodicamente com o número de passes por dente, influenciando fortemente os mecanismos de formação de superfície, resposta dinâmica da ferramenta e consequente desgaste ou fratura de ferramentas com dimensão reduzida (Kim, Mayor, \& Ni, 2004).

Quando a espessura de corte está na dimensão do raio de aresta da ferramenta, mudanças no estado de tensões e na taxa de deformação ocorrem (Fang, 2003). Como resultado, há mudanças no mecanismo de formação do cavaco e surgimento de defeitos indesejáveis na superfície da peça, principalmente para materiais multifásicos (Simoneau, $\mathrm{Ng}$, \& Elbestawi, 2006). Nestes casos, a usinagem é favorecida quando a quantidade de uma fase mais dura é reduzida na microestrutura do material, como a perlita (Mocellin, Melleras, \& Guesser, 2004).

Conforme verificado na Tabela 2.1, a interação entre a geometria de corte e a microestrutura do material da peça é relevante, pois na microusinagem o cavaco pode variar de níveis submicrométricos para alguns micrometros, e a espessura de corte pode ser da 
ordem de alguns micrometros. Assim, a geometria do corte e o tamanho dos grãos do material da peça tornam-se comparáveis em tamanho. Como resultado, no corte de materiais ferrosos, a ferramenta em dado momento pode estar usinando apenas ferrita e em seguida perlita, alterando significativamente os mecanismos de corte e a resposta do processo associado, como a força de corte e a rugosidade da superfície (Liu et al., 2004).

Tabela 2.1 - Espessura mínima de corte para alguns materiais metálicos.

\begin{tabular}{l|l|l|l}
\hline \multicolumn{1}{c|}{ AUTOR } & h MíNIMO & MATERIAL DA PEÇA & \multicolumn{1}{c}{ MÉTODO } \\
\hline Vogler, DeVor e Kapoor (2004) & $\begin{array}{l}\text { 0,2r } \text { (ferrita) }_{\text {) }} \\
0,3 r_{e} \text { (perlita) }\end{array}$ & $\begin{array}{l}\text { Aço ferrítico } \\
\text { Aço perlítico }\end{array}$ & Elementos finitos \\
\hline Kim, Mayor e Ni (2004) & $0,3 r_{e}$ & Latão & Modelo mecânico/matemático \\
\hline Lai et al. (2008) & $0,25 r_{e}$ & Cobre & Elementos finitos \\
\hline Kang, Kim e Seo (2010) & $0,3 r_{e}$ & Aço AISI 1045 & Análise da força de corte \\
\hline
\end{tabular}

Para compreensão dos processos envolvendo a usinagem com espessura de corte na ordem de grandeza do raio de aresta da ferramenta ou ainda menores, é relevante avaliar os fatores mais influentes no processo (Mian, Driver, \& Mativenga, 2011). O efeito das propriedades da microestrutura da peça, o raio de aresta da ferramenta e espessura de corte podem se associar durante a usinagem, afetando a qualidade do componente e seu desempenho (Wu \& Liu, 2009). A maior diferença entre as características da usinagem de um material com microestrutura homogênea e com diferentes fases é a mudança da formação do cavaco de contínuo para descontínuo, e sua influência na formação da superfície da peça (Vogler, DeVor, \& Kapoor, 2004).

\subsection{Danos na superfície microusinada}

A integridade superficial descreve e controla todas as possíveis alterações produzidas numa superfície e até mesmo subsuperfície durante a fabricação, incluindo seus efeitos sobre as propriedades do material e o comportamento da superfície em serviço (Davim, 2010). O prévio conhecimento das propriedades superficiais e subsuperficiais do material da peça é um fator de grande relevância devido às respectivas influências no comportamento funcional da superfície, precisão dimensional e também o conhecimento sobre o mecanismo de remoção de material (Daymi, 2011). 
Superfícies usinadas possuem características subdividas em quatro diferentes níveis: rugosidade, ondulações, marcas de avanço e falhas (Machado et al., 2009). As marcas de avanço são o reflexo do movimento relativo entre a peça e a ferramenta, durante o processo de usinagem. São marcas correspondentes as direções predominantes das irregularidades superficiais. As falhas são interrupções não intencionais, inesperadas e indesejáveis da topografia típica da superfície de uma peça (Machado et al., 2009).

Por vezes, a rugosidade na usinagem parece ser aleatória, o que sinaliza outras influências além das meramente geométricas entre a forma da ferramenta e os parâmetros de corte. Decorrente desta observação, a rugosidade pode ser dividida em duas componentes: cinemática e de processo (Davim, 2010).

A rugosidade cinemática é originada da ação combinada entre a geometria da ponta da ferramenta e respectivo avanço por dente, podendo ser expressa por equações teóricas para vários processos de usinagem (Davim, 2010). De outra forma, a rugosidade de processo decorre de outros fatores além do processo de remoção de material durante a usinagem, e está relacionada ao comportamento dinâmico do sistema peça-máquina-fixação. Em outras palavras, a rugosidade de processo é gerada por vibrações e deflexões da peça oriundas das forças e variações de temperaturas envolvidas no corte (Machado et al., 2009).

A rugosidade sobrepõe a ondulação, que por sua vez sobrepõe as imperfeições de forma, formando o perfil de textura superficial, podendo ser entendida como irregularidades finas de menor espaçamento, resultantes da ação inerente ao processo de corte causado pela ferramenta (Davim, 2010).

A caracterização da superfície, subsuperfície (borda usinada), e condições da ferramenta (desgaste) são importantes para o monitoramento do processo de usinagem e no caso de materiais dúcteis, ainda requerem maiores estudos (Sreejith \& Ngoi, 2000). A influência do raio de aresta da ferramenta e a mudança no coeficiente de atrito entre a superfície de flanco da ferramenta e a superfície livre da peça são determinantes no aumento da quantidade de defeitos na superfície usinada (Son, Lim, \& Ahn, 2005).

Com relação à microestrutura da peça, quanto maior o tamanho de grão do material e a existência de uma segunda fase, mais sensível ele se torna a formação de defeitos na superfície e subsuperfície da peça (Rodrigues et al., 2012). Para materiais multifásicos a formação da superfície é fortemente dependente dos efeitos da geometria da ferramenta e 
da mínima espessura de corte com a redução da relação entre avanço por dente e raio de aresta de corte (Vogler, DeVor, \& Kapoor, 2004).

Os defeitos típicos encontrados em superfícies microusinadas são apresentados pela Tabela 2.2 (Bailey, 1977; Gillibrand, 1979; Brinksmeier et al., 1982; Schaller et al., 1999; Hasnaoui et al., 2003; Rech \& Moisan, 2003; Bissacco, Hansen \& De Chiffre, 2006; Simoneau \& Elbestawi, 2006). São em geral caracterizados por falhas na superfície da peça gerada pela interação peça-ferramenta. Os prows, dimples, vazios e microtrincas são associados com a existência de uma segunda fase no aço, geralmente a perlita (Gillibrand, 1979).

O tamanho e forma do dimple dependem do tipo de carregamento e extensão de coalescência do microvazio, não estando particularmente relacionados com o tamanho do grão (Hasnaoui et al., 2003). A formação de dimples foi estudada em materiais com estrutura dual fase (ferrita-perlita), surgindo apenas nos grãos de ferrita localizados entre dois grãos de perlita, e sua formação foi relacionada à mudança no mecanismo de formação do cavaco (Gillibrand, 1979). No entanto, dimples podem compreender mais de um grão e terem maior extensão na superfície da peça (Bailey, 1977; Hasnaoui et al., 2003). Há poucos trabalhos sobre o mecanismo de formação de dimples, portanto ainda carece de mais investigações, especialmente quando afetam a qualidade da superfície usinada (Simoneau \& Elbestawi, 2006).

O smeared material tende a ser formado quando o raio de aresta da ferramenta está na mesma ordem de grandeza da espessura de material não removido (Bissacco, Hansen, \& De Chiffre, 2006). Nesta condição uma parcela do material da peça é empurrada para o lado, onde a deformação é feita facilmente por causa da falta de material, removido na passagem anterior da ferramenta (Bissacco, Hansen, \& De Chiffre, 2006). Esse defeito gera na aresta de corte o mesmo efeito da aresta postiça de corte na usinagem, causando oscilações na força e altos valores de coeficiente de atrito (Puls, Klocke, \& Lung, 2012).

Os grooves comuns e os grooves de microcavacos são encontrados nas regiões onde o processo de formação de cavaco é contínuo (Bailey, 1977; Gillibrand, 1979). Estes sulcos ou asperezas penetram a superfície da peça devido à alta tensão normal transmitida pelo contato na interface peça-ferramenta, e é conhecido por produzir considerável efeito de ploughing (Bailey, 1977). 
Tabela 2.2 - Principais defeitos de superfície em peças microusinadas. As setas indicam a direção do corte.

\begin{tabular}{|c|c|c|}
\hline DEFEITO DE SUPERFICÍE & CARACTERÍSTICA & CAUSA \\
\hline Cavidades & $\begin{array}{l}\text { Descontinuidades na superfície } \\
\text { usinada. }\end{array}$ & $\begin{array}{l}\text { Devido à natureza das condições de atrito } \\
\text { na região de contato da peça com a aresta } \\
\text { de corte. }\end{array}$ \\
\hline Debris & $\begin{array}{l}\text { Descontinuidades na superfície } \\
\text { usinada. }\end{array}$ & $\begin{array}{l}\text { Nucleação e propagação de trincas à } \\
\text { frente da aresta de corte, com } \\
\text { consequente remoção de material. }\end{array}$ \\
\hline Dimples & $\begin{array}{l}\text { Pequenas depressões } \\
\text { superfície da peça. }\end{array}$ & $\begin{array}{l}\text { Formação e coalescência de microvazios } \\
\text { ao longo do caminho da fratura, processo } \\
\text { que envolve um considerável nível de } \\
\text { deformação plástica localizada. }\end{array}$ \\
\hline Fluxo plástico s & $\begin{array}{l}\text { Material severamente deformado } \\
\text { com fluxo orientado na direção } \\
\text { do corte. }\end{array}$ & $\begin{array}{l}\text { Material plasticamente deformado, } \\
\text { pertencente à última parte do cavaco. }\end{array}$ \\
\hline Ploughing & $\begin{array}{l}\text { Fluxo lateral de material na } \\
\text { superfície da peça. }\end{array}$ & $\begin{array}{l}\text { Ocorre principalmente quando o avanço } \\
\text { por dente é inferior ao raio de aresta da } \\
\text { ferramenta. }\end{array}$ \\
\hline Grooves & $\begin{array}{l}\text { Riscos ou asperezas ao longo da } \\
\text { superfície da peça em } \\
\text { decorrência da passagem da } \\
\text { aresta de corte. }\end{array}$ & $\begin{array}{l}\text { Têm origem no polimento causado pela } \\
\text { superfície de flanco da ferramenta. }\end{array}$ \\
\hline $\begin{array}{l}\text { Grooves de } \\
\text { microcavacos }\end{array}$ & $\begin{array}{l}\text { Ranhuras mais profundas que as } \\
\text { de gooves, também paralelas à } \\
\text { direção do corte. }\end{array}$ & $\begin{array}{l}\text { Semelhante à formação de grooves, } \\
\text { porém com geração de microcavacos que } \\
\text { podem vir a aderir à superfície da peça. }\end{array}$ \\
\hline Marcas de chatter & $\begin{array}{l}\text { Ranhuras retas, paralelas entre si } \\
\text { e perpendiculares à direção do } \\
\text { corte. }\end{array}$ & $\begin{array}{l}\text { Relacionadas à interação peça-ferramenta } \\
\text { com o aumento da velocidade de corte e } \\
\text { desgaste da ferramenta. }\end{array}$ \\
\hline Prows & $\begin{array}{l}\text { Pequenas saliências na superfície } \\
\text { usinada. }\end{array}$ & $\begin{array}{l}\text { Formados na usinagem com baixa } \\
\text { velocidade de corte, sendo associados à } \\
\text { aresta postiça de corte. }\end{array}$ \\
\hline Rebarbas & $\begin{array}{l}\text { Porção de material da peça } \\
\text { deslocada para a direção axial da } \\
\text { ferramenta. }\end{array}$ & $\begin{array}{l}\text { Relacionado às propriedades mecânicas } \\
\text { do material, com mecanismo de formação } \\
\text { dependente do tipo da rebarba. }\end{array}$ \\
\hline Recuperação elástica & $\begin{array}{l}\text { Elevações na superfície não } \\
\text { relacionadas à rugosidade gerada } \\
\text { pela usinagem e/ou a efeitos } \\
\text { dinâmicos da máquina } \\
\text { ferramenta. }\end{array}$ & $\begin{array}{l}\text { Consequência dos diferentes níveis de } \\
\text { resistência à deformação entre os grãos } \\
\text { da microestrutura da peça. }\end{array}$ \\
\hline Restos de material & $\begin{array}{l}\text { Material aderido à superfície da } \\
\text { peça. }\end{array}$ & $\begin{array}{l}\text { Originário da formação de debris, } \\
\text { cavidades ou vazios. }\end{array}$ \\
\hline Smeared material & 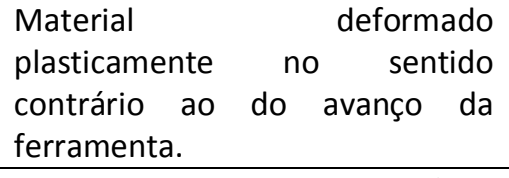 & $\begin{array}{l}\text { Surge devido ao aumento da razão entre a } \\
\text { força de avanço e a força de corte. }\end{array}$ \\
\hline Steps & $\begin{array}{l}\text { Ondulações sensíveis } \\
\text { subsequentes a fluxos plásticos } \\
\text { severos. }\end{array}$ & $\begin{array}{l}\text { Sua ocorrência está relacionada à } \\
\text { formação de fluxo plástico severo. }\end{array}$ \\
\hline Trincas & $\begin{array}{l}\text { Fissuras que penetram na } \\
\text { superfície da peça. }\end{array}$ & $\begin{array}{l}\text { Mudança das propriedades mecânicas } \\
\text { entre os grãos, tensões residuais e fadiga } \\
\text { na superfície da peça. }\end{array}$ \\
\hline Vazios & $\begin{array}{l}\text { Descontinuidades na superfície } \\
\text { usinada. }\end{array}$ & $\begin{array}{l}\text { Diferenças no limite de escoamento entre } \\
\text { as fases da microestrutura. }\end{array}$ \\
\hline
\end{tabular}


Na formação de cavidades, a adesão da aresta de corte com o material da peça produz fluxo plástico na região de contato, a qual sofre de acúmulo de discordâncias com posterior formação de microtrincas (Bailey, 1977). A tensão de cisalhamento excede a resistência local causando fratura e a porção de material é removida, produzindo a cavidade na superfície (Bailey, 1977). Em contrapartida, vazios são formados pela interação entre um grão dúctil em torno de um grão mais duro, associado à deformação plástica severa, em geral entre grãos de ferrita e perlita (Simoneau \& Elbestawi, 2006).

O fluxo plástico severo surge na última parte do cavaco que tende a um valor de espessura zero. Neste ponto, a ferramenta começa a perder o contato com a peça e o material remanescente da formação do cavaco é deformado pela aresta de corte, produzindo um fluxo de deformação plástica na direção do corte (Bissacco, Hansen, \& De Chiffre, 2006). Este fenômeno é análogo ao encontrado na usinagem com espessuras de corte inferiores ou na ordem do raio de aresta da ferramenta, com adesão de material da peça na ferramenta pelo escoamento de material do cavaco pela superfície de folga da ferramenta (Bailey, 1977; Kishawy \& Elbestwi, 1999).

No escoamento lateral ou formação incompleta do cavaco, uma grande parte do material da peça é submetida à alta pressão e temperatura no instante do corte, produzindo uma completa plastificação do material, o qual passa a escoar pela lateral da ferramenta (Fernández-Abia et al., 2011). Os debris são associados com a transição parcial ou completa do cavaco e com a aplicação de baixas velocidades de corte (Bailey, 1977). Para todos os defeitos que envolvam remoção de pequenas porções de material da superfície recémusinada, pode haver aderência desse material à aresta da ferramenta e posteriormente ser depositado na superfície da peça, e ter um valor de dureza de 3 a 5 vezes a dureza normal do material (Gillibrand, 1979).

As rebardas são consideradas um dos principais problemas na microusinagem de componentes, e o controle da sua formação está relacionado à especificação dos parâmetros de usinagem e propriedades mecânicas do material da peça (Dornfeld et al., 2009). De modo geral, as rebarbas são classificadas em quatro tipos, sendo as três primeiras apresentadas na Figura 2.2 com tradução livre (Gillespie, 1975):

- Rebarba de fluxo lateral: formada pela tendência do material a gerar uma protuberância para os lados quando comprimida pela aresta da ferramenta até que a deformação plástica seja permanente; 
- Rebarba de rompimento: acontece quando o material se desprende da peça por rasgamento ao invés de cisalhamento puro;

- Rebarba de flexão: uma rebarba de cavaco que é dobrada ao invés de cortada, também conhecida como rebarba de saída por se formar no fim do corte no fresamento;

- Rebarba sem corte: ocorre na separação da porção de material sendo removida da peça antes que a separação por corte seja concluída.

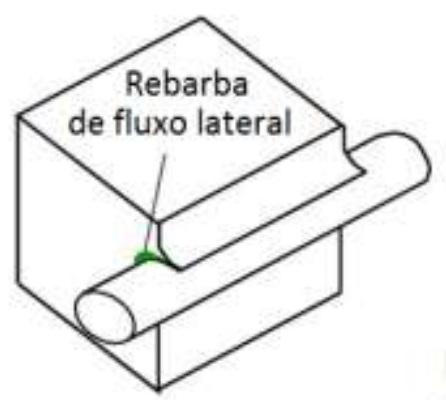

Rebarba de rompimento

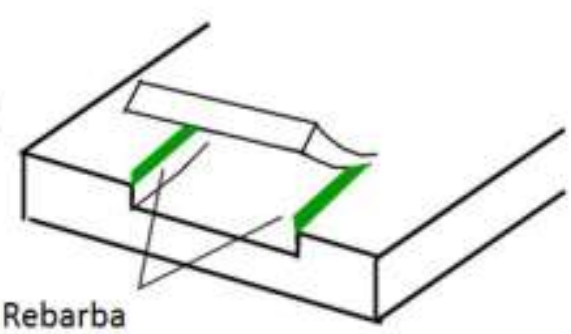

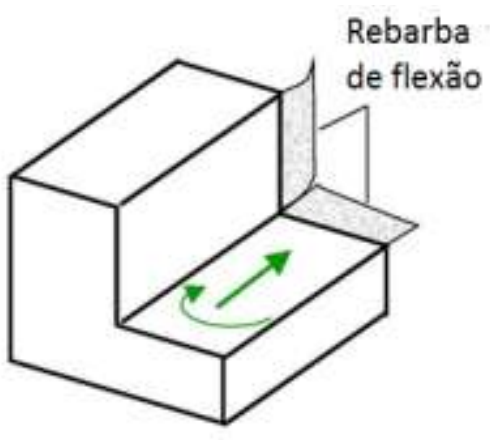

Figura 2.2 - Formação esquemática de Poisson burr, tear burr e rollover burr (Gillespie \& Blotter, 1976).

No fresamento cinco tipos de rebarbas foram identificados, conforme mostrado na Figura 2.3, com tradução livre: rebarba tipo faca, rebarba tipo enrolada, rebarba secundária, rebarba tipo onda e quebra de aresta (Chern, 1993). Na mesma figura, $b$ corresponde à altura e $p$ à largura da rebarba.

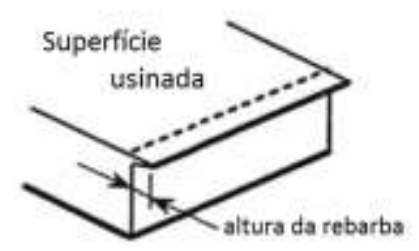

(a) rebarba tipo faca

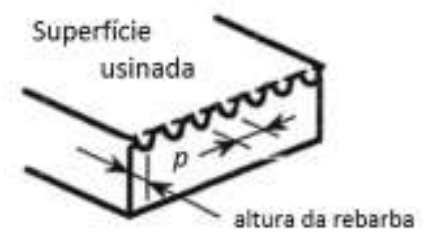

(d) rebarba tipo onda

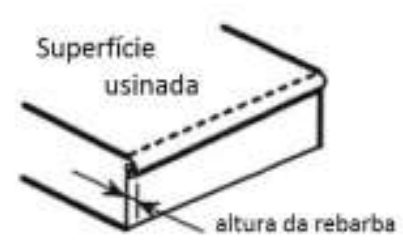

(b) rebarba tipo enrolada

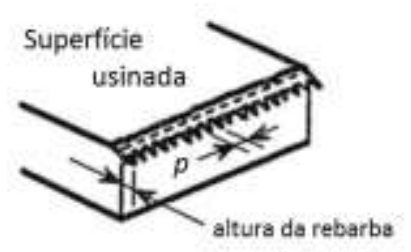

(e) quebra de aresta

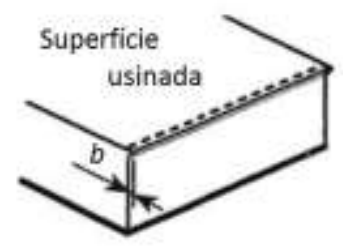

(c) rebarba secundária

Figura 2.3 - Tipos de rebarba encontrados no fresamento (Chern, 1993). 
No microfresamento de canais, as rebarbas podem se formar em diferentes pontos da peça. A Figura 2.4 ilustra a formação de rebarbas no ponto de entrada e saída da ferramenta, e também nas laterais do canal.

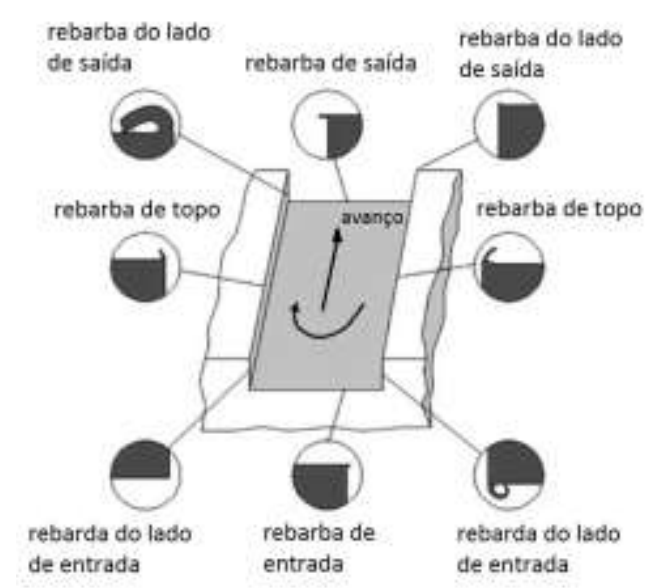

Figura 2.4 - Formação de rebarbas em canais microfresados (Schueler et al., 2009).

Ainda com relação ao microfesamento de canais, quatro formas de rebarbas de topo têm sido relatadas. São elas: rebarba primária, rebarba agulha, rebarba pena e rebarba menor (Chern et al., 2007). A Figura 2.5 apresenta, com tradução livre, as formas de rebarbas encontradas na microusinagem de canais em uma liga de alumínio com microfresa de $500 \mu \mathrm{m}$ de diâmetro e velocidade de rotação do eixo-árvore de 10000 rpm (Chern et al., 2007). 

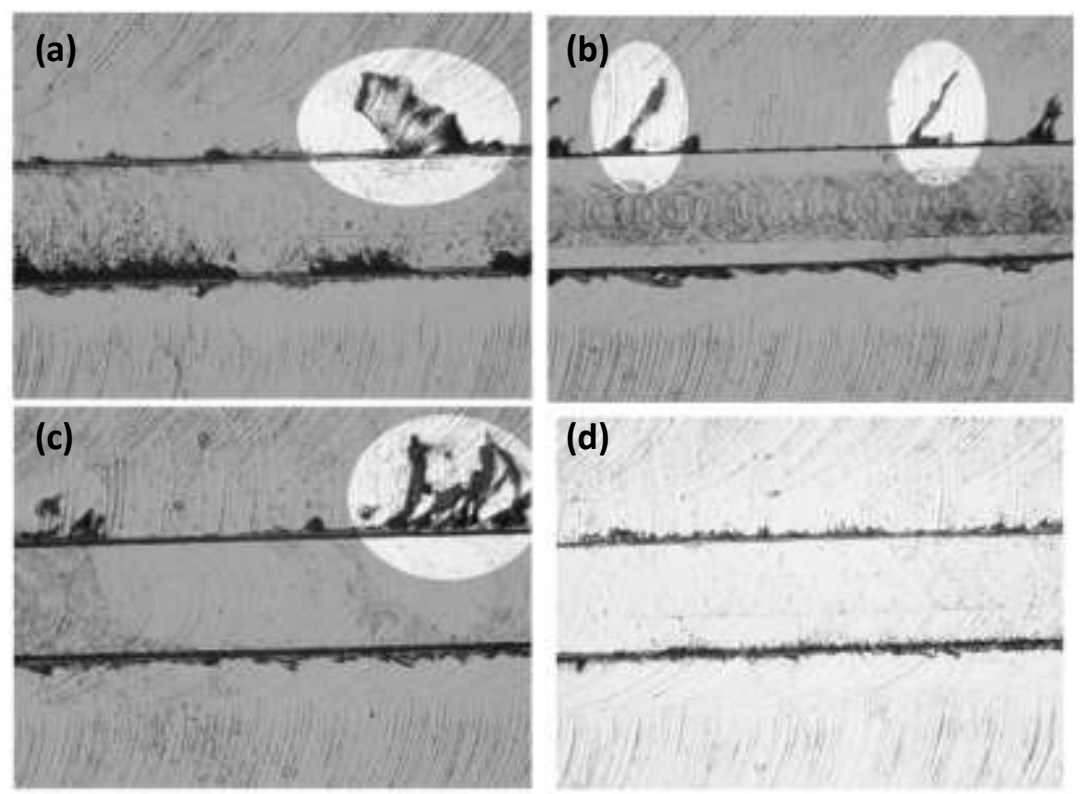

Figura 2.5 - Imagens de rebarbas em microusinagem de canais: (a) rebarba primária, (b) rebarba agulha, (c) rebarba pena e (d) rebarba menor (Chern et al., 2007). A direção do avanço é da esquerda para direita.

O aumento da profundidade de usinagem resulta em aumento da formação de rebarbas, pois a porção de material empurrada para o topo da peça é maior (Lee, Stirn, \& Essel, 2000). Por outro lado, o aumento da profundidade de usinagem aliada à redução do avanço por dente teve reflexo na diminuição da formação de rebarbas (Li \& Chou, 2010). O aumento da velocidade de corte favorece o aumento das rebarbas, desde que a taxa de deformação seja alta o suficiente para aumentar o endurecimento por deformação no material da peça (Biermann \& Steiner, 2012). Considerando apenas o avanço por dente, há menos formação de rebarbas quando a relação $f_{z} / r_{e}$ é igual ou maior que $1 \mu \mathrm{m} / \mu \mathrm{m}$ (Jin et al., 2009). Porém, a redução do avanço por dente, associado ao aumento da velocidade de corte tem gerado menos formação de rebarbas (Jahanmir, 2011). No geral, o aumento dos parâmetros de usinagem causa maior desgaste da ferramenta, tendo como resultado o aumento na formação de rebarbas ao longo do comprimento de usinagem (Li \& Chou, 2010).

Com relação à geometria das microfresas, o aumento do ângulo de saída diminui a tensão de compressão sobre o material a frente da ferramenta, favorecendo a redução da formação de rebarbas (Komanduri, 1971; Jahanmir, 2011). E com relação à redução do diâmetro da microfresa, maiores rebarbas têm sido relatadas com o incremento de avanço por dente, possivelmente devido a acúmulo de calor na zona de corte (Lekkala et al., 2011; Jahanmir, 2011). A Figura 2.6 apresenta o efeito do aumento do ângulo de conicidade $\left(\theta_{T}\right)$ de 
microfresas cônicas de $500 \mu \mathrm{m}$ de diâmetro na formação de rebarbas durante o microfresamento de alumínio 6061 (Saptaji, Subbiah, \& Dhupia, 2012). O aumento do ângulo de conicidade $\left(\theta_{T}\right)$ da ferramenta favoreceu a redução das rebarbas, isto devido ao aumento do ângulo efetivo de saída da ferramenta, medido no vetor de velocidade de corte e a direção do fluxo do cavaco.

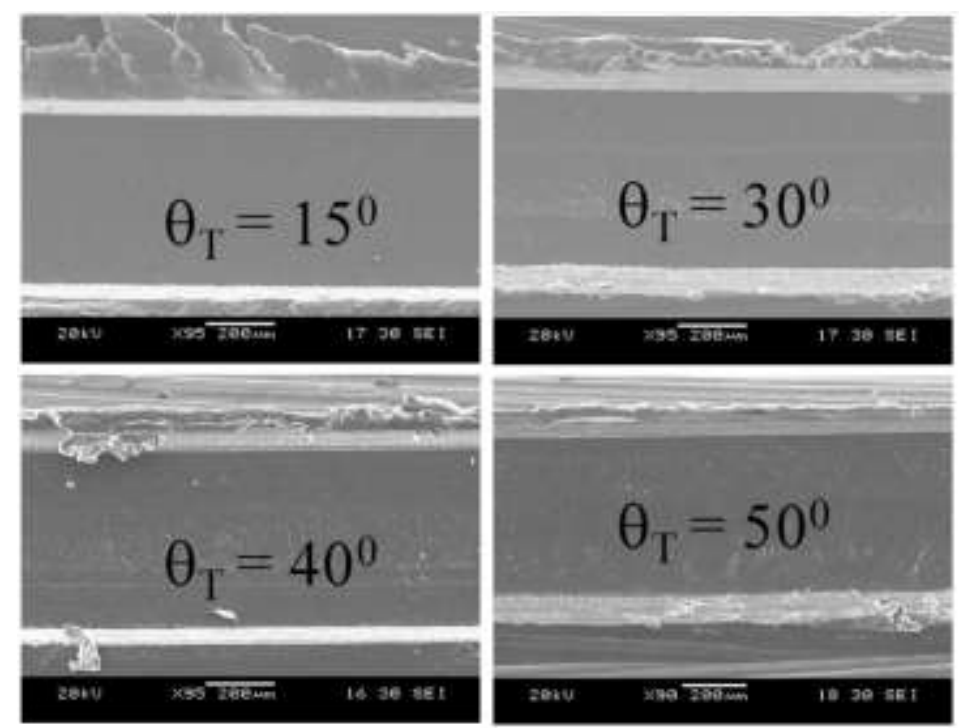

Figura 2.6 - Efeito do aumento do ângulo de conicidade $\left(\theta_{T}\right)$ da microfresa na formação de rebarbas.

A formação de rebarbas também é dependente do material da peça. Materiais dúcteis tendem a formar menos rebarbas, devido menor resistência mecânica, a qual antecipa a fratura, gerando menos material para a rebarba (Lekkala et al., 2011). Em materiais multifásicos há formação de microrebarbas com espaçamento equivalente ao espaçamento entre os grãos do material (Vogler, DeVor, \& Kapoor, 2004). Este efeito é causado pela mudança no mecanismo de formação de cavaco enquanto a ferramenta passa pelos grãos de diferentes fases do material (Bailey, 1977; Vogler, DeVor, \& Kapoor, 2004).

Com a redução do diâmetro da ferramenta, a aresta de corte passa a cortar menos grãos, e em alguns casos, um grão de cada vez. A modificação da microestrutura do material da peça seria uma ferramenta para solução de problemas relacionados à formação de rebarbas (Komatsu et al., 2012). Uma microestrutura homogênea e com grãos de tamanho inferior ao do raio de aresta da ferramenta, retardaria possíveis mudanças no mecanismo de formação do cavaco em microusinagens com baixo avanço por dente, minimizando as microrebarbas formadas em materiais multifásicos (Bissacco, Hansen, \& De Chiffre, 2006). 
Com base nestes principais aspectos da literatura, para aplicações requerendo um acabamento da peça crítico e com menos defeitos, o efeito da microestrutura do material não pode ser negligenciado. A possibilidade de minimizar os efeitos da microestrutura seria modificações metalúrgicas da microestrutura da peça, tal como o uso de materiais com tamanho de grão menores que o raio de aresta da ferramenta ou de estrutura amorfa (Zhou et al., 2001; Weule, Hüntrup, \& Tritschler, 2001). Materiais multifásicos oferecem um desafio adicional, devido a diferenças nas propriedades das fases, por exemplo, perlita e ferrita, no caso de aços (Câmara et al., 2012).

Um material ferrítico apresenta uma espessura mínima de cavaco menor do que o material perlítico (Vogler, DeVor, \& Kapoor, 2004). Durante a usinagem de um material com diferentes fases, essa variação na espessura mínima de cavaco afeta o ângulo de cisalhamento, o qual aumenta com o aumento da espessura de corte, independentemente da velocidade de corte (Wu \& Liu, 2010). No fresamento, um material com microestrutura que se comporte como um cristal único seria desejável para reduzir a variação no ângulo de cisalhamento, com consequente melhor acabamento da peça (Lee \& Zhou, 1993).

Para um material com grãos ultrafinos, a superfície macrousinada surge com ranhuras relativamente suaves, uniformes e ordenadas na direção do avanço, enquanto para um material multifásico, a superfície apresenta irregularidades na superfície como ondulações gerando maior diferença de altura entre os picos e vales da superfície usinada (Liu et al., 2004). Conforme a espessura de corte diminui, a diferença entre a rugosidade teórica e o valor medido na superfície da peça aumenta (Bernardos \& Vosniakos, 2003). Esta diferença é devido à adesão na interface cavaco-ferramenta, transição entre ploughing e cisalhamento do metal, e variação local do módulo de Young (Komanduri, 1971; Zhou et al., 2001).

Com relação aos parâmetros de usinagem, melhor rugosidade tem sido obtida com valores de avanço próximos do raio de aresta da ferramenta, sugerindo que o acabamento da peça é mais sensível ao raio de aresta do que ao tamanho de grão do material da peça (Mian, Driver, \& Mativenga, 2010). De acordo com alguns pesquisadores, a velocidade de corte é outro fator dominante na redução da escala de usinagem, afetando os mecanismos presentes no efeito do raio de aresta no processo de corte, sugerindo a hipótese de que o aumento da velocidade de corte reduz a formação de rebarbas e melhora o acabamento da peça (Mian, Driver, \& Mativenga, 2011). 


\subsection{Mecanismo de formação de cavaco}

O mecanismo de formação de diferentes cavacos é relacionado ao movimento da aresta de corte determinado por diferentes condições de usinagem (Ning, Rahman, \& Wong, 2001). Para diferentes velocidades de corte materiais dúcteis tendem a gerar cavacos contínuos, enquanto materiais endurecidos podem gerar cavacos descontínuos com o aumento da velocidade de corte (Davies, Buns, \& Evans, 1997). No entanto, esta transição também é dependente da redução da espessura de material não removido (Davies, Buns, \& Evans, 1997). Sendo assim, a seleção de parâmetros de usinagem deve levar em consideração os efeitos destas zonas de transição, as quais podem influenciar o processo de usinagem (Bissacco, Hansen, \& De Chiffre, 2005).

Para materiais endurecidos a mudança no mecanismo de formação do cavaco ocorre devido à oscilação do fluxo de material e cisalhamento adiabático na zona primária de cisalhamento (Davies, Buns, \& Evans, 1997). Em materiais dúcteis com diferentes fases, a transição ocorre com a mudança na taxa de deformação devido à redução de escala de usinagem, comportamento mecânico de cada fase e o resultado da interação entre as fases do material da peça durante o processo de corte (Fleck \& Hutchinson, 1993; Simoneau, Ng, \& Elbestawi, 2006).

A teoria macroscópica de deformação plástica de materiais policristalinos repousa na hipótese simplificada de que o material é localmente homogêneo durante o processo de corte (Zhou et al., 2001). No entanto, a redução da espessura de corte tende a ser uma fonte de acúmulo de discordâncias durante o corte de metais, favorecendo mudanças no grau de deformação do cavaco (Liu, Li, \& Liang, 2007; Lai et al., 2008). Estas mudanças são particularmente significativas na usinagem de metais com diferentes graus de dureza na microestrutura do material, geralmente associado à presença de diferentes fases ou grãos com diferentes orientações cristalográficas (Zhou et al., 2001; Simoneau, Ng, \& Elbestawi, 2006).

Com relação à influência do raio de aresta da ferramenta, quando a espessura de material a ser removido é menor que o raio de aresta, o ângulo efetivo de saída da ferramenta é sempre negativo, o qual tende a gerar uma severa tensão de compressão na 
região da aresta de corte, colaborando com a transição de contínuo para um cavaco descontínuo (Enahoro \& Oxley, 1961).

A mudança no mecanismo de formação do cavaco com a redução da escala de usinagem para materiais bifásicos (ferrita-perlita) tem sido encontrada na usinagem com espessura de corte menor que o maior tamanho de grão do material (Simoneau, $\mathrm{Ng}$, \& Elbestawi, 2006). Este cavaco descontínuo, chamado de quasi-cisalhamento-extrusão é formado pelo cisalhamento de grãos mais duros, e a extrusão de grãos mais dúcteis entre dois grãos mais duros (Simoneau, Ng, \& Elbestawi, 2006). Sua formação tem sido verificada em operações de usinagem de microescala e mesoescala, condições nas quais a espessura de corte manteve-se sempre menor que o maior tamanho de grão do material da peça (Simoneau, Ng, \& Elbestawi, 2006). Esta formação de cavaco não foi encontrada na usinagem em macroescala com espessura de corte maior que o maior tamanho de grão do material (Weule, Hüntrup, \& Tritschler, 2001; Simoneau, Ng, \& Elbestawi, 2006).

Quando o comprimento do plano de cisalhamento reduz, a taxa de deformação aumenta, liderando um aumento da resistência de cisalhamento (Joshi \& Melkote, 2004). As tensões de fluxo são sensíveis à taxa de deformação, passando a serem dominadas pela densidade de discordâncias e dureza do material a frente da aresta de corte (Wu \& Liu, 2010). Quanto maior a taxa de deformação imposta, maior é o grau de endurecimento do material (Fleck et al., 1994). Nestas condições, o comportamento mecânico de cada fase irá exercer diferentes contribuições aos níveis de deformação e consequentemente alterar o mecanismo de formação de cavaco (Simoneau, Ng, \& Elbestawi, 2006).

A seção de material a ser cortada é tão pequena que a quantidade de energia envolvida no processo gera uma grande tensão no material, comprimindo o grão de ferrita (B) contra os grãos de perlita (A), conforme apresentado pela Figura 2.7 (Simoneau, Ng, \& Elbestawi, 2006). A perlita age como uma barreira de alta dureza durante o processo de corte, causando a extrusão do grão de ferrita que é mais dúctil, e o processo é repetido sucessivamente durante o corte (Simoneau, Ng, \& Elbestawi, 2006). 

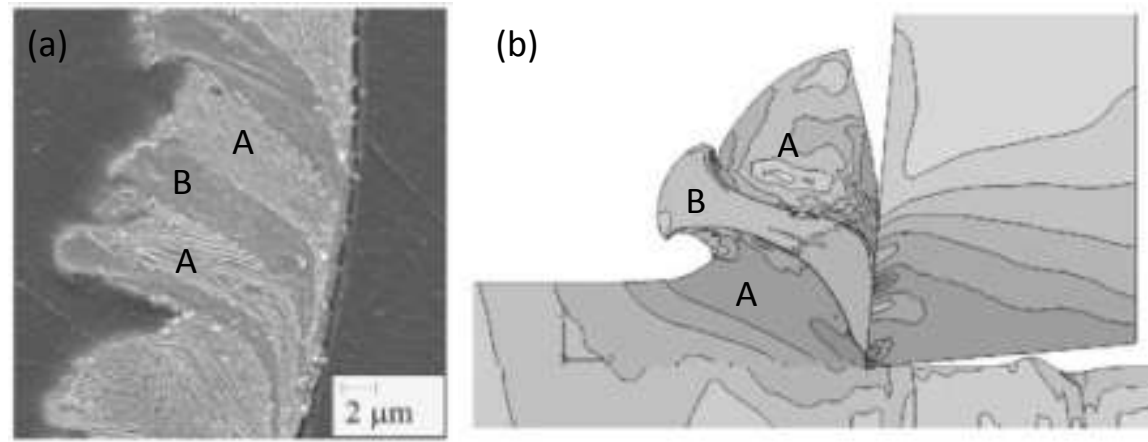

Figura 2.7 - Cavaco de quasi-cisalhamento-extrusão em (a) micrografia e (b) simulação numérica. Os grãos A mais duros estão comprimindo o grão B mais dúctil (Simoneau, Ng, \& Elbestawi, 2006).

Quando o avanço por dente diminui, a tensão de fluxo aumenta, e este fenômeno é associado ao efeito de escala (Brown \& Armarego, 1964). As tensões de fluxo durante a formação do cavaco são sensíveis à taxa de deformação. Em um baixo range de taxa de deformação, a tensão de fluxo é dominada pela densidade de discordâncias e dureza influenciada pela taxa de deformação (Porto et al., 2004). Quanto maior a taxa de deformação imposta, maior é o grau de endurecimento (Fleck \& Hutchinson, 1993). Uma pequena parcela de volume de material de alguns micrometros eleva dramaticamente a taxa de endurecimento do metal durante o trabalho de deformação (Fleck et al., 1994).

A existência do efeito de escala na plasticidade, em pesquisa realizada por Flecke e Hutchinson (1993) e análises numéricas de Simoneau, Ng e Elbestawi (2006) para o fenômeno de deformação durante o corte com a redução da espessura de corte, evidenciaram a diferença do comportamento entre a ferrita e a perlita durante o processo de deformação e a ação que um grão mais duro exerce sobre um grão mais dúctil. Para grãos mais duros nos quais as tensões na interface cavaco-ferramenta são maiores, a zona de material da peça em contato com a aresta da ferramenta atua como uma forte fonte de discordâncias, favorecendo o cisalhamento (Lee \& Zhou, 1993). Em sequência, para os grãos de ferrita, as tensões na interface cavaco-ferramenta decaem e o material escorrega ao longo da face de saída da ferramenta, sendo parcialmente cisalhado e/ou extrudado quando localizado entre dois grãos de perlita (Simoneau, Ng, \& Elbestawi, 2006).

\subsection{Aplicações de microusinagem}

Por algumas centenas de anos, as peças de relógios de bolso eram basicamente os únicos microprodutos industriais fabricados. Com o decorrer da evolução tecnológica, os 
bens de consumo foram se tornando otimizados, contendo mais funções em um espaço menor, além de diversificar as soluções para produtos e processos de fabricação (Masuzawa, 2000).

Nessa linha, a miniaturização tornou necessária a introdução de microcomponentes nos mais diversos produtos industriais. Por exemplo, após a introdução de dispositivos semicondutores, circuitos elétricos tornaram-se extremamente compactos. Pacotes de circuitos integrados são obrigados a conter dispositivos com microdimensões. A placa de circuito deve conter microcanais (Masuzawa, 2000). Não apenas dispositivos elétricos, mas também peças mecânicas, tais como interruptores, motores e até parafusos foram miniaturizados durante esta mudança (Masuzawa \& Töshoff, 1997).

Microcomponentes estão no dia a dia das pessoas, como o bico de injeção de combustível dos automóveis. Regulamentações severas decorrentes de problemas ambientais instigaram a melhora do projeto do bico para menores dimensões e com maior precisão. Um forte candidato à miniaturização é o campo da biotecnologia, uma vez que o objeto de trabalho são células biológicas e genes, e as ferramentas para sua manipulação muitas vezes são micromanipuladores, tais como micropinças, microbisturis, microagulhas etc (Masuzawa, 2000).

As aplicações médicas também são importantes. Inspeções e cirurgias menos invasivas são de grande interesse, e neste caso, a miniaturização de instrumentos médicos é uma das abordagens eficazes para se chegar a essa meta (Masuzawa, 2000). Algumas outras aplicações incluem motores e turbinas em miniatura, microsatélites, implantes, robótica e componentes para aeronaves de missões de reconhecimento (drones) (Filiz et al., 2007).

Criar estruturas de silício em micro ou nanoescala é importante para a indústria de semicondutores, a qual gera bilhões de dólares a cada ano. Especificações geométricas é uma exigência para os métodos de manufatura utilizados para confeccionar estas estruturas com altos requisitos de precisão. Nesse quesito, há necessidade de técnicas mais rápidas e eficazes para a usinagem de estruturas de silício, além de outros materiais de engenharia, como ligas ferrosas, alumínio e cobre. Para estes materiais, a microusinagem se torna um processo adequado para atender os requisitos de velocidade de produção e precisão (Jackson, 2006).

Para atender as demandas de manufatura de componentes miniaturizados e com geometria complexa, buscou-se o desenvolvimento de tecnologias para processamento de 
materiais de engenharia de alta resistência, incorrendo em boa resistência ao desgaste e considerável precisão. O microfresamento tem sido aplicado como uma importante ferramenta para gerar geometrias tridimensionais com precisão, isto devido a grande flexibilidade do processo (Huo \& Cheng, 2010).

Além desse aspecto, outra vantagem do microfresamento, em contraste com outros processos, tais como decapagem de silício, plasma e químicos, usados na manufatura de microdispositivos, é a menor restrição aos tipos de materiais que podem ser utilizados (Vázques et al., 2010). Alguns microcomponentes requerem geometria complexa e aplicabilidade variada e diferenciada. Seguindo este escopo, geometrias tridimensionais precisam ser plausíveis a partir de uma vasta variedade de materiais de engenharia (Huo \& Cheng, 2010).

As exigências estão aumentando para micro lentes anesféricas como componente em diversos dispositivos ópticos, tais como câmeras digitais, dispositivos laser e de transmissão óptica (Suzuki et al., 2007). Estas micro lentes são geralmente produzidos por injeção sob alta pressão em moldes de cerâmica, carbeto de tungstênio ou carbeto de silício. Para tanto, atender as diminutas tolerâncias e devida qualidade da superfície usinada tem sido uma tarefa que envolve diversas áreas do conhecimento (engenharia, química, materiais etc) (Özel \& Altan, 2000). Esta necessidade tem aberto margem para aplicação do microfresamento com fresas de arestas cortantes de diamante capazes de produzir moldes de injeção com as mais variadas configurações, o que possibilita expandir o campo de aplicação para além da produção de lentes (Masuzawa, 2000).

O processo de EDM (electrical discharge machine) com microfios tem revelado avanço significativo na confecção de microfresas com raio de aresta controlado (Dimov et al., 2004). Esta técnica abre campo para a fabricação de microfresas com raios de aresta em dimensões capazes de favorecer o corte e reduzir efeitos de escoamento lateral de material para determinadas aplicações, principalmente quando do uso de microfresas de diâmetros extremamente pequenos (Chern et al., 2007). Ferramentas mais resistentes à quebra e desgaste, e com geometria controlada, aliadas a boas estratégias de usinagem para microfresamento e materiais adequados, representam um importante fator na fabricação de micromoldes e paredes finas (Dimov et al., 2004). 


\section{Capítulo 3}

\section{MATERIAIS E MÉTODOS}

As informações sobre a etapa experimental são descritas na sequência: planejamento experimental, bancos de ensaios, especificações dos corpos de prova, ferramentas de corte e procedimento experimental. Os ensaios de usinagem foram divididos em dois grupos, cujos resultados estão estreitamente correlacionados. Sendo estes grupos: (1) macro e microfresamento e (2) microfresamento de canais. O primeiro grupo trata de estudos sobre mecanismo de formação de cavaco e defeitos na superfície e borda usinada, variando o avanço por dente e considerando o raio de aresta da ferramenta. O segundo grupo tratou de estudos de formação de superfície e rebarbas, tendo como variáveis o avanço por dente, a velocidade de corte e o raio de aresta da ferramenta.

\subsection{Planejamento experimental}

\subsubsection{Macro e microfresamento}

Para os ensaios de usianagem foi proposto o fresamento de topo reto em centro de usinagem vertical CNC. Os parâmetros de usinagem adotados como variáveis de entrada foram velocidade de corte $\left(v_{c}\right)$, profundidade de usinagem $\left(a_{p}\right)$, avanço por dente $\left(f_{z}\right)$ e raio de aresta da ferramenta $\left(r_{e}\right)$. Os ensaios foram realizados em corte concordante, sem fluido de corte, com largura de usinagem $\left(\mathrm{a}_{\mathrm{e}}\right)$ constante e igual a $2 \mathrm{~mm}$ para o macrofresamento e $0,130 \mathrm{~mm}$ para o microfresamento.

A faixa de exploração das variáveis de entrada foi determinada conforme o fabricante das ferramentas de corte e os conceitos de usinagem em macro e microescala. Sendo assim, a Tabela 3.1 apresenta os parâmetros de usinagem e as microestruturas dos corpos de prova, com respectivos tamanho médio de grão ferrítico, aplicados aos experimetnos. Cada ensaio de usinagem foi realizado duas vezes. Todas as médias foram calculadas considerando uma confiabilidade estatística de $95 \%$. 
Tabela 3.1 - Parâmetros de usinagem e microestrutura dos corpos de prova (macro e microfresamento).

\begin{tabular}{lc|c}
\hline \multicolumn{1}{c}{ PARÂMETROS DE USINAGEM } & MACROFRESAMENTO & MICROFRESAMENTO \\
\hline Velocidade de corte $[\mathrm{m} / \mathrm{min}]$ & 800 & 135 \\
Profundidade de usinagem $[\boldsymbol{\mu m}]$ & 500 & 32 \\
Largura de usinagem $[\mathrm{mm}]$ & 2 & 0,130 \\
Raio de aresta de corte $[\boldsymbol{\mu \mathrm { m }}]$ & 25 & 5 \\
Avanço por dente $[\boldsymbol{\mu \mathrm { m }}]$ & 25 e 300 & 5 e 18 \\
\hline \multicolumn{2}{l}{ Microestrutura e TG* } & Ferrita-perlita com $11 \mu \mathrm{m}$ \\
& Ferrita ultrafina com $0,7 \mu \mathrm{m}$ \\
\hline TG - Tamanho médio de grão ferrítico &
\end{tabular}

A velocidade de corte e a profundidade de usinagem foram fixadas. Com relação ao avanço por dente, foi proposto adotar como avanço mínimo, o valor do raio de aresta das ferramentas. Um material de mesma composição química foi empregado nos ensaios, porém apresentando microestruturas com caracterísitcas diferentes. O material nomeado CR é constituído de microestrutura bifásica (ferrita-perlita) e o material nomeado GUF possui microestrutura ferrítica homogênea com grãos ultrafinos. Além dos estudos do efeito dos parâmetros de usinagem indicados anteriormente, foi verificado o efeito da microestrutura dos materiais nos ensaios, em especial a homogeneidade e granulado refinado nas variáveis de estudo propostas.

\subsubsection{Microfresamento de canais}

Os ensaios de microfresamento de canais também foram realizados em centro de usinagem vertical CNC. Os parâmetros de usinagem adotados como variáveis de entrada foram velocidade de corte $\left(v_{c}\right)$, profundidade de usinagem $\left(a_{p}\right)$, avanço por dente $\left(f_{z}\right)$, diâmetro das microfresas $\left(d_{\varnothing}\right)$ e raio de aresta da ferramenta $\left(r_{e}\right)$. Todos os ensaios foram realizados sem emprego de fluido de corte, na condição de corte discordante na entrada da aresta de corte e concordante na saída da aresta de corte, com largura de usinagem $\left(\mathrm{a}_{\mathrm{e}}\right)$ dependente do diâmetro das microfresas, constantes ao longo de toda o comprimento de usinagem e iguais a 200 e $800 \mu \mathrm{m}$.

A faixa de exploração das variáveis de entrada foi determinada conforme o fabricante das ferramentas de corte e os conceitos de microusinagem. Sendo assim, a Tabela 3.2 apresenta as variáveis de entrada (fatores de controle). Cada ensaio de usinagem foi 
realizado duas vezes, visando confirmar os efeitos gerados pela relação entre velocidade de corte $\left(v_{c}\right)$, avanço por dente $\left(f_{z}\right)$, raio de aresta da ferramenta $\left(r_{e}\right)$ e microestrutura dos materiais no acabamento da peça e formação de rebarbas. Todas as médias foram calculadas considerando uma confiabilidade estatística de 95\%. Para este grupo de ensaios a velocidade de corte será identificada pela rotação do eixo-árvore em rpm, visando facilitar as análises.

Tabela 3.2 - Parâmetros de usinagem e microestrutura dos corpos de prova (microfresamento de canais).

\begin{tabular}{l|c}
\hline \multicolumn{2}{c}{ PARÂMETROS DE USINAGEM } \\
\hline Velocidade de rotação do eixo-árvore $[\mathrm{rpm}]$ & 10000 e 54000 \\
Profundidade de usinagem $[\mu \mathrm{m}]$ & 32 \\
Largura de usinagem $[\mu \mathrm{m}]$ & 200 e 800 \\
Raio de aresta de corte $[\mu \mathrm{m}]$ & 3 \\
Avanço por dente $[\mu \mathrm{m}]$ & 0,$5 ; 3$ e 10 \\
\hline Microestrutura e TG* & Ferrita-perlita com $11 \mu \mathrm{m}$ \\
\hline
\end{tabular}

*TG - Tamanho médio de grão ferrítico

A profundidade de usinagem foi fixada. Com relação ao avanço por dente, foi proposto adotar um avanço menor, aproximado e maior que o raio de aresta das ferramentas, conforme apresentado na Tabela 3.2. Para este grupo de ensaios foram aplicados os mesmos materiais empregados nos ensaios de macro e microusinagem.

\subsection{Bancos de ensaios}

Na macrousinagem, a preparação dos corpos de prova, assim como os ensaios, foram conduzidos em um centro de usinagem CNC Hermle, modelo C800U, com rotação máxima de $24000 \mathrm{rpm}$ e 3 eixos com precisão de deslocamento de $5 \mu \mathrm{m}$ (Figura 3.1). Na microusinagem, a preparação dos corpos de prova, assim como os ensaios, foram conduzidos em um centro de microusinagem CNC Mikrotools, modelo MPM4020L, 3 eixos com precisão de deslocamento de 0,3 $\mu \mathrm{m}$ para trajetória máxima de $25 \mathrm{~mm}$ (Figura 3.1). 0 eixo-árvore de alta rotação para processos de microusinagem possui range de velocidade de 10000-60000 rpm com sistema de mudança de ferramenta pneumático, e potência de 1,3 kW à 60000 rpm. 


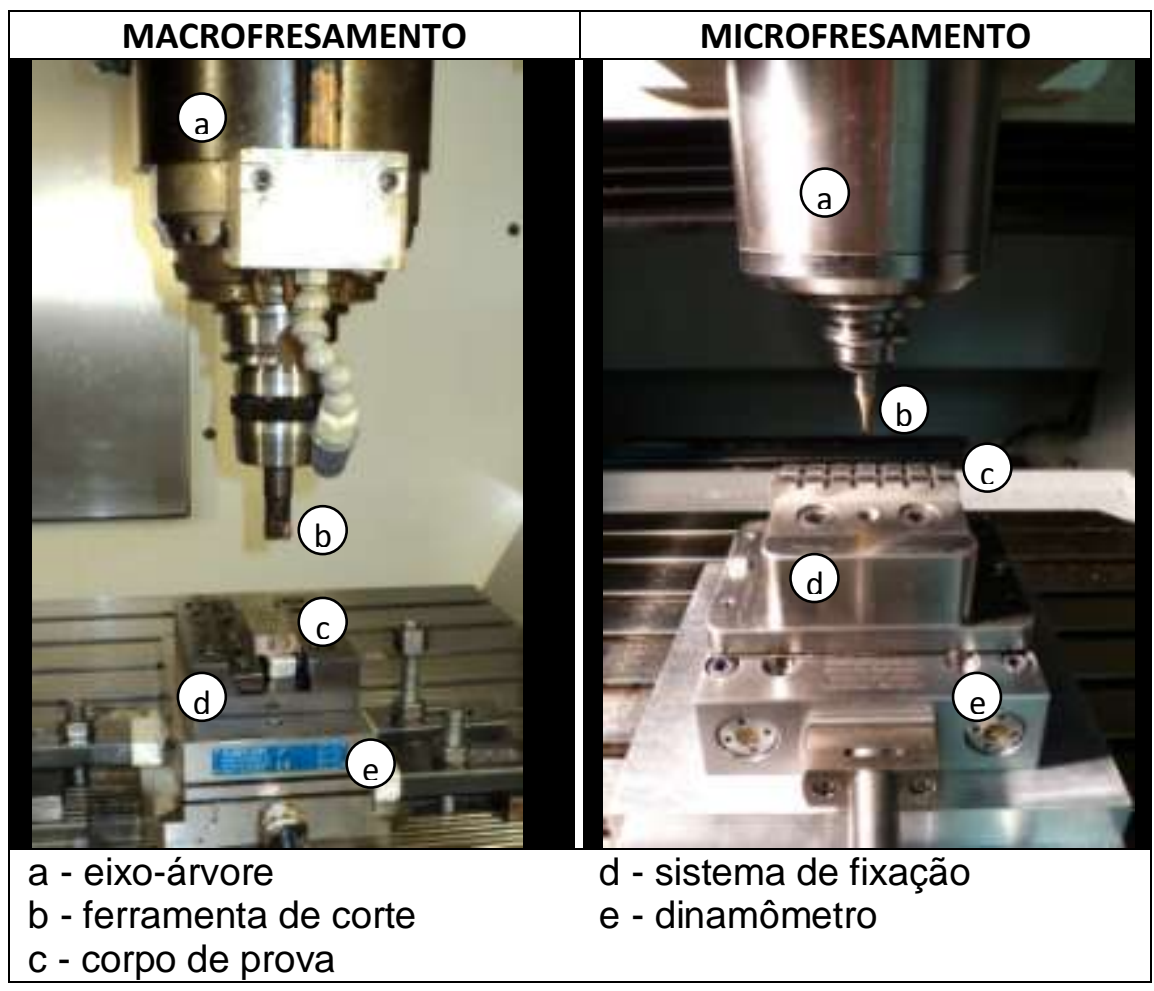

Figura 3.1 - Montagem experimental.

A caracterização dos cavacos, rebarbas, superfície e borda usinada dos corpos de prova foi feita em um microscópio eletrônico de varredura (MEV) da marca Philips, modelo XL30-TMP. As medidas de microdureza na superfície usinada foram feitas com auxílio de microdurômetro da marca Leica, modelo VMHT MOT, empregando carga de 100 gf.

As rugosidades médias das superfícies usinadas foram medidas com um perfilômetro ótico Veeco, modelo Wyko NT1100, assim como as imagens 3D das superfícies. As medidas de raio de aresta dos insertos e microfresas foram feitas com um microscópio laser de medição 3D Olympus, modelo OLS4000 LEXT.

\subsection{Corpos de prova}

Os corpos de prova foram provenientes de uma parceria entre o Laboratório de Processos Avançados e Sustentabilidade (LAPRAS) e o Departamento de Engenharia de Materiais (DEMa), da Universidade Federal de São Carlos (UFSCar). O material, fornecido pela Usiminas-Cubatão S/A na forma de chapa grossa laminada, denomina-se comercialmente como COS AR60. 
Parte dos corpos de prova foi submetida a um tratamento termomecânico para obtenção de uma estrutura de grãos ultrafinos. Os corpos de prova de dimensões $25 \times 25 \times 100$ $\mathrm{mm}$, extraídos da chapa grossa, foram submetidos ao processamento termomecânico de laminação a morno para refino de grão. Uma redução de $50 \%$ na espessura dos corpos de prova foi feita em um laminador FENN modelo 051. O processo de refino de grão utilizado é uma patente registrada no INPI (Instituto Nacional de Propriedade Intelectual) com código de registro PI11072474 concedida em 25 de setembro de 2012 (Rodrigues et al., 2012). A composição química do material pode ser visualizada na Tabela 3.3.

Tabela 3.3 - Composição química do material utilizado nos ensaios de usinagem (\% em peso).

\begin{tabular}{ccccccccccccc}
\hline $\mathbf{C}$ & $\mathbf{M n}$ & $\mathbf{P}$ & $\mathbf{S}$ & $\mathbf{S i}$ & $\mathbf{A l}$ & $\mathbf{C u}$ & $\mathbf{C r}$ & $\mathbf{N i}$ & $\mathbf{N b}$ & $\mathbf{V}$ & $\mathrm{Ti}$ & $\mathbf{C e q}$ \\
0,15 & 1,49 & 0,027 & 0,009 & 0,27 & 0,046 & 0,005 & 0,276 & 0,008 & 0,048 & 0,044 & 0,016 & 0,40 \\
\hline
\end{tabular}

A presença dos elementos de liga cobre, vanádio, níquel e molibdênio, em concentrações combinadas, confere ao material maiores resistências do que os açoscarbono comuns com baixo teor de carbono, podendo ser classificado como pertencente ao grupo de ligas com baixo teor de carbono chamado aços de alta resistência e baixa liga (ARBL ou HSLA - High-Strength, Low-Alloy) (Callister, 2008). Além disso, o material como recebido (CR) foi fornecido laminado a frio, processo no qual prevalece o efeito do encruamento da matéria-prima, com coeficientes de encruamento " $n$ " entre 0,2 e 0,25 (Rodrigues \& Martins, 2005). A Tabela 3.4 apresenta as principais informações referentes à condição metalúrgica do material e propriedades mecânicas dos corpos de prova utilizados nos ensaios de usinagem.

Tabela 3.4 - Características metalúrgicas e mecânicas dos corpos de prova.

\begin{tabular}{|c|c|c|c|c|}
\hline CONDIÇÃO METALÚRGICA & $\mathrm{TG}^{1}[\mu \mathrm{m}]$ & Dureza $\left[\mathrm{HV}_{100 \mathrm{gf}}\right]$ & $\sigma_{o}{ }^{2}[\mathrm{GPa}]$ & Energia Charpy [J] \\
\hline Como recebido [CR] & 11 & 240 & 474 & 176 \\
\hline Grãos ultrafinos [GUF] & 0,7 & 274 & 510 & 285 \\
\hline
\end{tabular}

A Figura 3.2 apresenta a microestrutura dos materiais dos corpos de prova. A microestrutura da Figura 3.2a corresponde ao material bifásico (CR) contendo grãos de ferrita (cinza) e colonias de perlita (preto) geradas pelo bandeamento do carbono decorrente do processo de laminação do material. Em contraste, o material de fase única 
(GUF) na Figura 3.2b é constituído predominantemente por ferrita, e devido ao tamanho ultrafino dos grãos, microscopia eletrônica de transmissão (MET) foi utilizada para melhor definição dos grãos (Figura 3.2c). Além disso, houve formação de cementita globular nos contornos de grão, identificadas como pequenas estrutrutras negras globulares de tamanho namométrico.

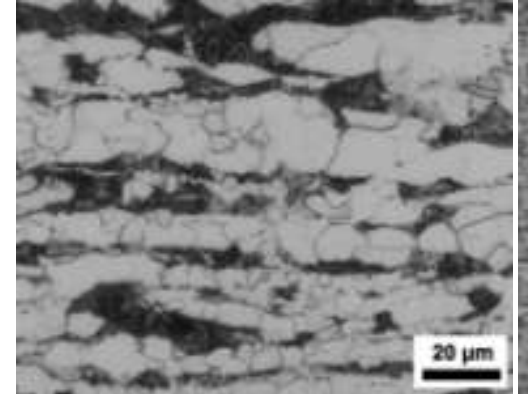

(a) Como Recebido (CR)

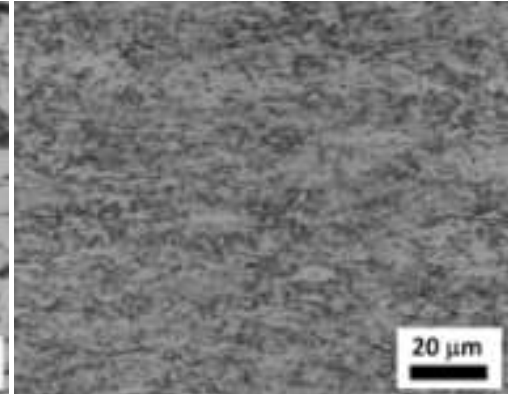

(b) Grãos Ultrafinos (GUF)

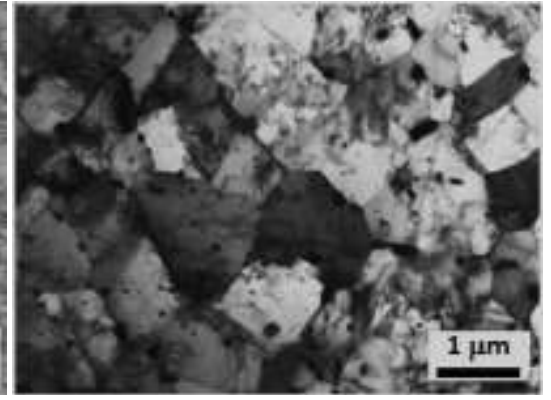

(c) MET do material GUF Figura 3.2 - Microestruturas dos materiais das peças.

Três configurações de corpos de prova foram preparadas para os ensaios de usinagem, conforme apresentado pela Figura 3.3. Nos ensaios sobre defeitos de superfície e subsuperfície, e formação de cavaco, os corpos de prova prismáticos tiveram por objetivo gerar uma maior área usinada, facilitando estudos de microestrutura da borda usinada, microdureza superficial e volume de cavaco para coleta.

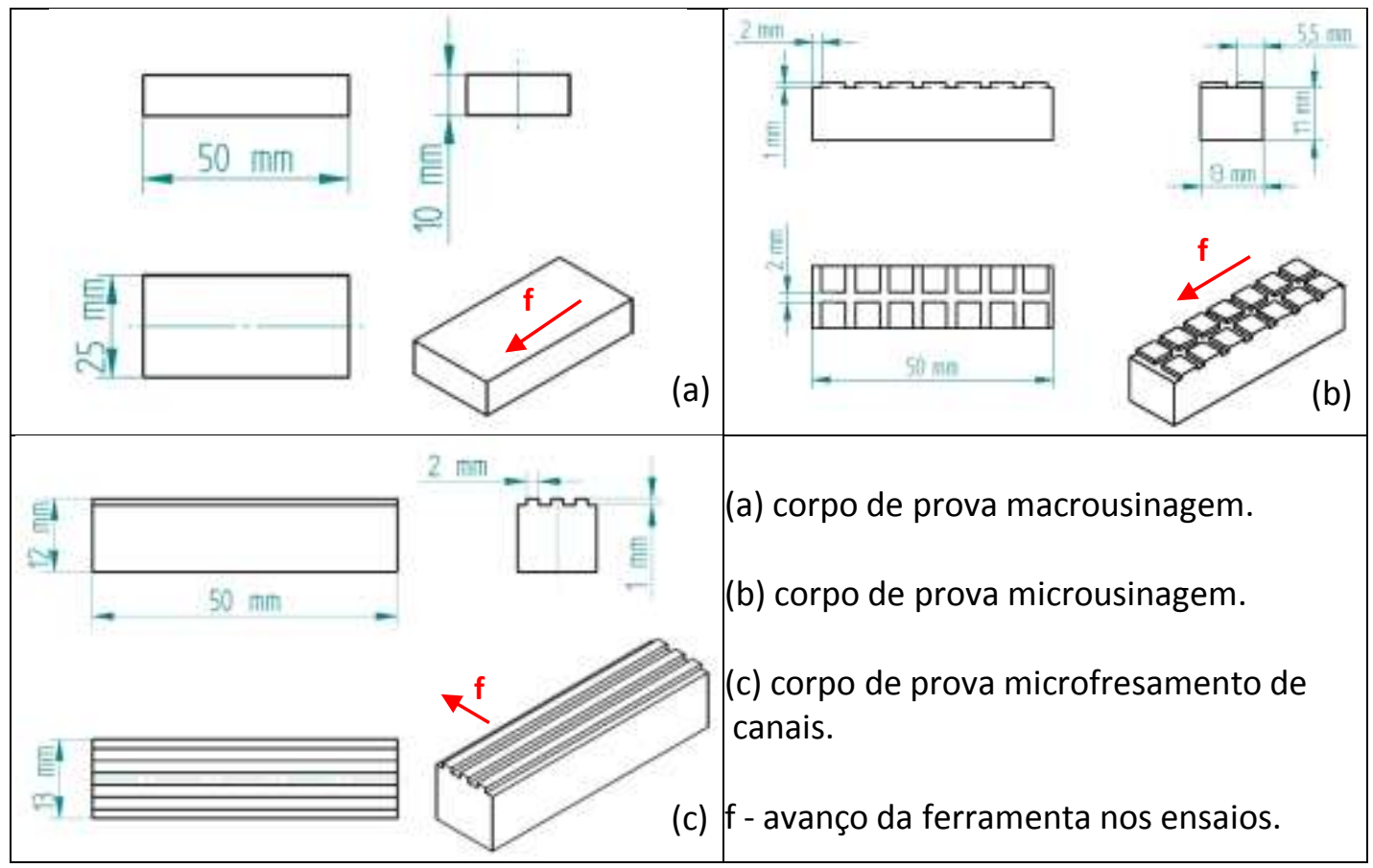

Figura 3.3 - Geometria dos corpos de prova. 


\subsection{Ferramentas de corte}

Os insertos de metal duro e o suporte para mandril porta-fresa empregados nos ensaios de macrofresamento foram especificados com auxílio da Sandvik Coromant, fabricante de ferramentas. Para os ensaios de microfresamento, as microfresas de metal duro foram especificados com auxílio da OSG Sulamericana. E nos ensaios de microfresamento de canais foram utilizadas microfesas da Mitsubishi Materials. Para determinação dos valores de avanço por dente da matriz experimental, fez-se necessário o conhecimento do raio de aresta dos insertos e das microfresas, e para tanto o revestimento das ferrmamentas foi fator a se considerar, visando a qualidade da aresta de corte.

Pastilhas e microfresas revestidas pela técnica de PVD (Physical vapor deposition) apresentaram valores médios de raio de aresta de 24,3 $\pm 2 \mu \mathrm{m}$ e 5,1 $\pm 1 \mu \mathrm{m}$, respectivamente, conforme ilustrado na Figura 3.4, medidos com auxílio de um Microscópio Laser 3D na marca Olympus, modelo OLS4000. As imagens da Figura 3.4a e Figura 3.4c apresentam imagens de MEV e perfilometria laser, respetivamente, das arestas das ferramentas, enquanto as imagens da Figura 3.4b e Figura 3.4c são referentes a técnica de medição aplicada.

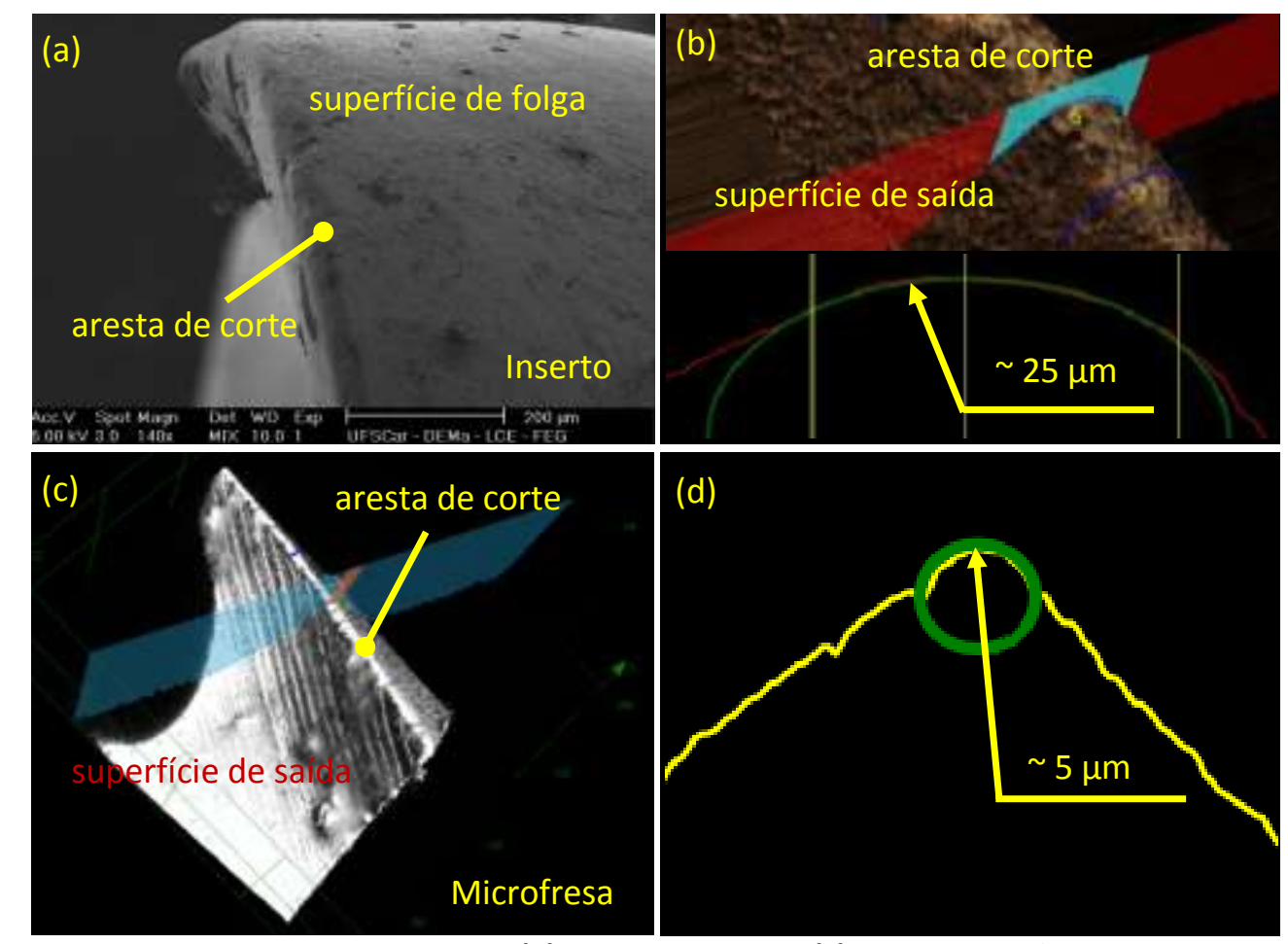

Figura 3.4 - Imagens das arestas obtidas por (a) MEV do inserto e (c) microscopia ótica laser da microfresa, e medições do raio de aresta do (b) inserto e (d) microfresa. 
Os insertos retangulares revestidos com PVD-TiN (código R390-11 T3 08M-PL 1025) apresentam espessura de 3,59 mm, comprimento de $11 \mathrm{~mm}$, largura de 6,8 $\mathrm{mm}$, raio de ponta de $0,8 \mathrm{~mm}$, ângulo de folga de $21^{\circ}$ e ângulo de posição de $90^{\circ}$. O suporte dos insertos (código R390-016A16-11L), apresenta haste cilíndrica e sistema de fixação hidráulico, diâmetro 16 mm e passo largo com 2 insertos intercambiáveis. Porém, para cada ensaio, apenas um inserto (novo) foi utilizado no suporte dos insertos. Três medidas de raio de aresta foram feitas em cada aresta utilizada, conforme apresentado na Figura A.1 do Anexo A, com valor aproximadamente constante ao longo da aresta.

As microfresas cilíndricas revestidas com PVD-TiN (76808 EX-TIN-EDS) possuem duas arestas cortantes, diâmetro de trabalho para o corte de $800 \mu \mathrm{m}$, diâmetro de haste e $6 \mathrm{~mm}$ e raio de ponta de $0,05 \mathrm{~mm}$. Dez medidas de raio de aresta foram feitas em cada aresta utilizada, conforme apresentado na Figura A.2 do Anexo A. As microfresas aplicadas nos ensaios de microfresamento de canais possuem duas arestas cortantes, diâmetro de haste de $4 \mathrm{~mm}$, diâmetros de trabalho para o corte de 200 e $800 \mu \mathrm{m}$, e raio de aresta de 3,7 e 5 $\mu \mathrm{m}$, respectivamente, medidos por microscopia eletrônica de varredura. Todas as microfresas possuem ângulo de hélice de $30^{\circ}$. Para fixação das ferramentas no eixo-árvore foram utilizados cones de fixação modelo ATC 2.10 .6 e pinças modelo SRP de 4 e $6 \mathrm{~mm}$, fornecidos pelo fabricante da máquina-ferramenta. Uma microfresa nova foi utilizada para cada ensaio.

\subsection{Procedimento experimental}

A seguir são apresentados os procedimentos experimentais relativos aos ensaios de fresamento e referentes às análises de acabamento da peça e rebarbas, microdureza superficial e mecanismo de formação de cavaco.

\subsubsection{Ensaios de usinagem}

Rotinas CNC foram elaboradas de modo a usinar os corpos de prova em suas respectivas configurações geométricas. A usinagem sem emprego de fluido de corte foi escolhida para facilitar a coleta dos cavacos após os experimentos de usinagem, em especial os cavacos gerados no microfresamento, devido ao seu tamanho extremamente pequeno. 
Para os ensaios de microusinagem foi aplicada a velocidade máxima do eixo-arvore (54000 rpm), correspondendo a uma velocidade de corte de $135 \mathrm{~m} / \mathrm{min}$ para as microfresas de $800 \mu \mathrm{m}$ de diâmetro. Estes experimentos de microfresamento foram realizados no laboratório de metrologia do Departamento de Engenharia Mecânica da University of British Columbia, em Vancouver, Canadá.

Nos ensaios de macrousinagem, a ferramenta usinou uma superfície plana, gerando um total de 10 passes ao longo de toda a área retangular das amostras de comprimento 50 $\mathrm{mm}$. Houve a usinagem de dois passes extras, um na entrada da ferramenta e outro na saída, desprezados nas análises seguintes para evitar larguras de usinagem menores que a estabelecida. O mesmo procedimento foi adotado nos ensaios de microusinagem, porém o comprimento de corte foi de $5 \mathrm{~mm}$, devido a redução da escala de usinagem.

Para este grupo de ensaios foi visada a coleta de cavacos, caracterização da borda usinada e medidas de microdureza, sendo por isso necessário a realização de vários passes da ferramenta. Durante todos os ensaios, cuidados quanto à fixação da ferramenta (estabilidade), comportamento da peça e ferramenta (vibrações), e formação de cavaco (faiscamento) foram tomados.

O ensaios de macro e microusinagem foram realizados em corte concordante por favorecer a preservação da ferramenta, na medida em que as direções dos vetores velocidade de corte e de avanço coincidem na tangente à penetração de trabalho. Dessa forma, a espessura do cacaco é máxima na entrada na ferramenta e mínima na saída. Este movimento da ferramenta garante menor força de corte, pois no caso do corte discordante a aresta principal de corte pode ser danificada devido a ferramenta ser tracionada na saída da peça devido à espessura do cavaco ser máxima nesta posição (Machado et al., 2009).

Nos ensaios de microfresamento de canais, a ferramenta penetrou a peça com largura de corte correspondente ao diâmetro das microfresas por um comprimento de corte de $2 \mathrm{~mm}$. Este ensaio visou a análise da superfície da base do canal e formação de rebarbas no topo dos microcanais. Os mesmos procedimentos quanto à fixação e monitoramento dos ensaios anteriores foram tomados. Neste tipo de usinagem, a aresta de corte realiza a entrada na peça em corte discordante e na saída o corte é concordante, afetando principalmente a formação de rebarbas entre os dois lados do microcanal. O corpo de prova do material CR foi posicionado de forma que a microfresa passasse por camadas distintas e justapostas de ferrita e perlita, enquanto no material GUF de microestrurua homogênea, a 
ferramenta cortou apenas grãos de ferrita. A Figura 3.5 apresenta a trajetória das microfresas pela microestrura dos materiais.

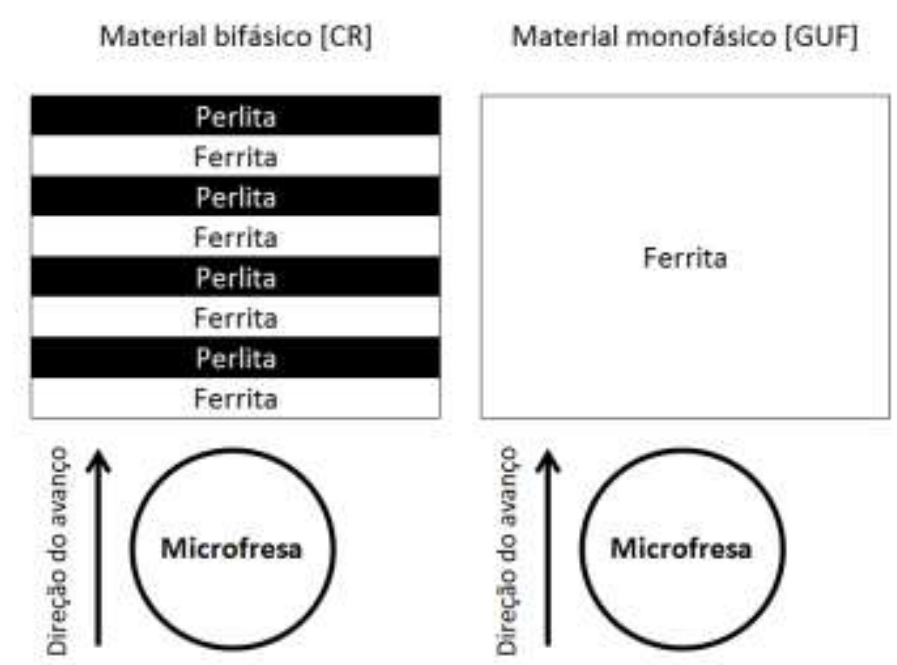

Figura 3.5 - Vista superior da trajetória das microfresas pela microestrutura dos materiais das peças.

Para cada condição de usinagem uma ferramenta nova foi utilizada. As microfresas inteiriças possuem duas arestas de corte e no macrofresamento uma aresta foi utilizada, e para assegurar o balanceamento do sistema, um inserto com a aresta manualmente desgastada foi colocado no porta inserto na posição oposta ao do inserto do ensaio. Vale citar que o porta insertos utilizado é projetado para usinar com dois insertos. 0 procedimento adotado na macrousinagem, utilizando uma única aresta de corte, visou garantir que os efeitos de uma aresta sobre a superfície usinada não fosse prejudicada pela aresta do outro inserto, devido problemas de desbalanceamento e tênues diferenças de posicionamento das pastilhas no porta inserto.

\subsubsection{Rugosidade, ferramentas, borda usinada e rebarbas}

Para análise da rugosidade foi empregado um perfilômetro ótico 3D da marca Veeco, modelo Wyko NT1100, cujos passos de medição seguiram a recomendação do fabricante do equipamento. As amostras foram posicionadas e alinhadas para manter as superfícies usinadas perpendiculares ao feixe de luz. Imagens planas e tridimensionais com escala de cores foram geradas em diversas regiões representativas de cada condição de usinagem. A avaliação da rugosidade superficial foi realizada com auxílio do software Vision 2.0 
Copyright $\left(02002-2008\right.$ da empresa Veeco Instruments. Os parâmetros medidos foram $\mathrm{S}_{\mathrm{a}}, \mathrm{S}_{\mathrm{sk}}$, $S_{\text {ku }}$ e $S_{z}$. O parâmetro de amplitude "S", diferentemente do parâmetro de amplitude "R", considera o relevo de toda a área registrada pelo perfilômetro. O parâmetro de amplitude "S" indica desvios significativos nas características de textura, sendo aplicado na análise de superfícies usinadas.

$\mathrm{O}$ parâmetro $\mathrm{S}_{\mathrm{a}}$ corresponde à rugosidade média e $\mathrm{S}_{\mathrm{q}}$ ao desvio médio quadrático da rugosidade. $\mathrm{O}$ parâmetro $\mathrm{S}_{\mathrm{z}}$ é a diferença média entre os cincos picos mais altos e os cinco vales mais profundos. $\mathrm{O}$ parâmetro $\mathrm{S}_{\mathrm{sk}}$ (skewness) representa o grau de simetria das elevações da superfície sobre o plano médio. Indica a preponderância de picos $\left(S_{s k}>0\right)$ ou estruturas de vales $\left(S_{s k}<0\right)$ na superfície. O parâmetro $S_{\mathrm{ku}}$ (kurtosis) indica a natureza da distribuição das elevações. Se as elevações na superfície seguem uma distribuição normal (curva de sino), então $S_{\mathrm{ku}}$ é igual a 3. Para superfícies compostas por picos excessivamente altos ou vales profundos $S_{k u}$ é maior que 3. Quando $S_{k u}$ é menor que 3 , significa que a superfície varia gradualmente. A Figura 3.6 apresenta exemplos de aplicação dos parâmetros $\mathrm{S}_{\mathrm{sk}}$ e $\mathrm{S}_{\mathrm{ku}}$ para melhor compreensão.

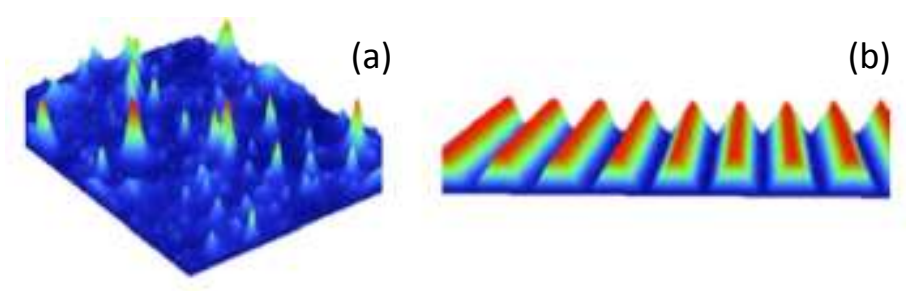

Figura 3.6 - (a) superfície de picos com $S_{\mathrm{sk}}=3,20$ e $S_{\mathrm{ku}}=18,71$, e (b) textura periódica com $\mathrm{S}_{\mathrm{sk}}=\mathbf{0 , 1 6}$ e $\mathrm{S}_{\mathrm{ku}}=\mathbf{1 , 6 3}$.

A caracterização das superfícies, ferramentas e bordas usinadas, além das rebarbas foi feita pela técnica de microscopia eletrônica de varredura (MEV), utilizando tanto elétrons espalhados, quando elétrons retroespalhados. A análise por elétrons espalhados possibilita a identificação de relevos na superfície, enquanto elétrons retroespalhados permite a distinção entre as diferentes fases presentes na microestrutura do material. Ambas as técnicas podem ser usadas individualmente ou associadas uma com a outra. Para visualização dos defeitos e demais características da microestrutura, diferentes ampliações e tensões de feixe foram aplicadas. Imagens foram geradas em diferentes regiões da superfície da peça, em especial nas regiões de entrada e saída da ferramenta e no meio da peça. 
Para análise da borda usinada, as peças foram seccionadas na direção do avanço da ferramenta e perpendicular ao plano da superfície usinada. As amostras foram embutidas com resina epóx e lixadas com granas 120, 220, 320, 400, 500, 600 e 1200 respectivamente, e finalizado com polimento em alumina $0,3 \mu \mathrm{m}$ e pasta de diamante $0,25 \mu \mathrm{m}$. Todas as amostras foram atacadas com reagente Nital $2 \%$ para revelação da microestrutura. As imagens da borda usinada foram obtidas por microscopia ótica (MO) e eletrônica de varredura (MEV), com diferentes aumentos, para melhor visualização dos defeitos e deformações na subsuperfície da peça.

\subsubsection{Microdureza superficial}

As medidas de microdureza na superfície das peças usinadas foram realizadas em um microdurômetro Vickers da marca Leica, modelo VMHT MOT, de acordo com especificações técnicas do fabricante do equipamento. Em todos os corpos de prova usinados nos ensaios de macro e microusinagem, foram realizadas 10 medidas em locais aleatórios da superfície da peça. Amostras não usinadas, com superfície adequadamente preparada para caracterizar a microdureza intrínseca dos materiais, serviram de referência para as comparações entre os resultados. Todas as médias foram calculadas considerando uma confiabilidade estatística de $95 \%$.

Para ambos os materiais alvo deste estudo, foi determinado uma carga de 100 gf, pois foi o menor valor de carga a apresentar endentações definidas. Além disso, a redução da carga causava maiores diferenças de recuperação elástica nas endentações. A Figura 3.7 apresenta o gráfico, elaborado para esta pesquisa, da variação na recuperação elástica entre os materiais para diferentes cargas do microdurômetro. De acordo com o gráfico, ambos os materiais apresentaram comportamento similar da recuperação elástica após aplicação de uma carga mínima aproximada de 100 gf, assegurando a confiabilidade das medições de microdureza nas superfícies macro e microfresadas e respectivas comparações dos resultados. Uma terceira razão para a escolha desta carga foi determinar a menor carga possível para garantir que a endentação tivesse a menor profundidade de penetração, na tentativa de caracterizar apenas a espessura de material sujeita a modificações derivadas do processo de macro e microfresamento aplicado aos corpos de prova. 


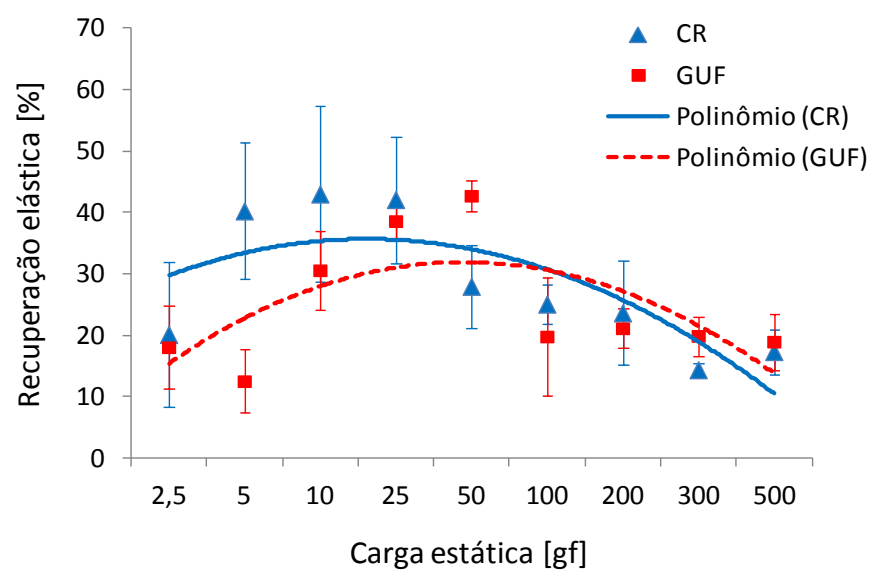

Figura 3.7 - Gráfico da recuperação elástica das endentações com a variação da carga aplicada pelo microdurômetro.

\subsubsection{Cavaco}

A Figura 3.8 apresenta o sistema montado para coleta dos cavacos durante os ensaios de usinagem. Após cada ensaio os cavacos foram coletados e armazenados em embalagens plásticas com lacre de fechamento e devidamente identificados.

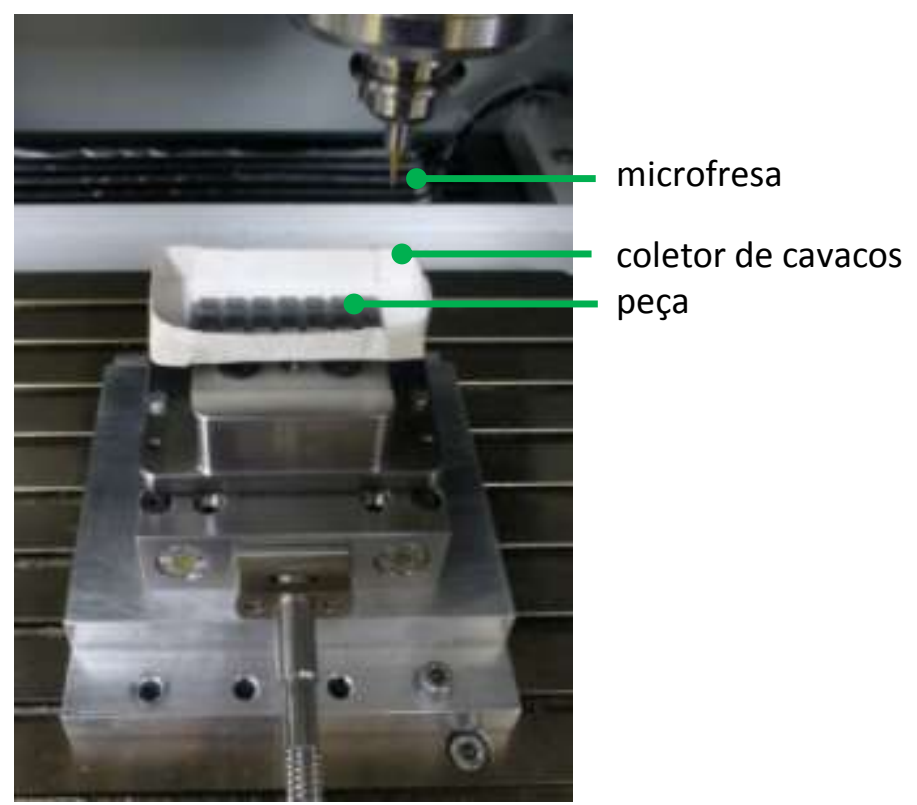

Figura 3.8 - Sistema para coleta dos cavacos na microusinagem.

A avaliação do mecanismo de formação dos cavacos foi realizada examinando-se exemplares de todas as combinações da matriz experimental em MO, MEV e a lupa. Para análise da microestrutura dos cavacos foi feito embutimento das amostras. Cada 
embutimento abrigou duas réplicas de cada ensaio. Foram selecionados em torno de 20 cavacos de cada condição. Para seleção, os cavacos foram espalhados em uma superfície plana revestida de cartolina branca, na qual foi possível identificar características comuns à maioria dos cavacos, a fim de encontrar um padrão (forma, cor e tamanho). Após o embutimento e secagem da resina epóx, as amostras foram lixadas com granas 120, 220, $320,400,500,600$ e 1200 respectivamente, e finalizado com polimento em alumina 0,3 $\mu \mathrm{m}$. Todas as amostras foram atacadas com reagente Nital $2 \%$ para revelação da microestrutura.

No microscópio ótico, imagens em ampliação de 500x foram obtidas, porém devido ao aumento, apenas pequenas regiões do cavaco eram fotografadas. A estratégia posterior foi unir todas as fotos (cerca de 50 imagens para cada cavaco) com auxílio de um software de imagens, formando um mosaico completo do cavaco. As imagens obtidas por microscópio eletrônico de varredura da marca Filips, modelo XL30-TMP, visaram evidenciar o cisalhamento da perlita e extrusão da ferrita entre os grãos de perlita.

A Figura 3.9 apresenta o procedimento aplicado para medição da espessura do cavaco ( $h$ ') e posterior cálculo do grau de recalque. Com auxílio de um software de CAD foram feitas medições de espessura em 10 pontos do cavaco, partindo do ponto de menor espessura para o de maior espessura. Utilizando o mesmo software de CAD foi projetada a espessura de material não removido (h) para determinação do grau de recalque. O cálculo foi feito com base na divisão entre a espessura do cavaco e a espessura do material não removido. Na imagem também são observadas medições de ângulo da microestrutura do cavaco ( $\eta)$, as quais não foram apresentadas nos resultados.

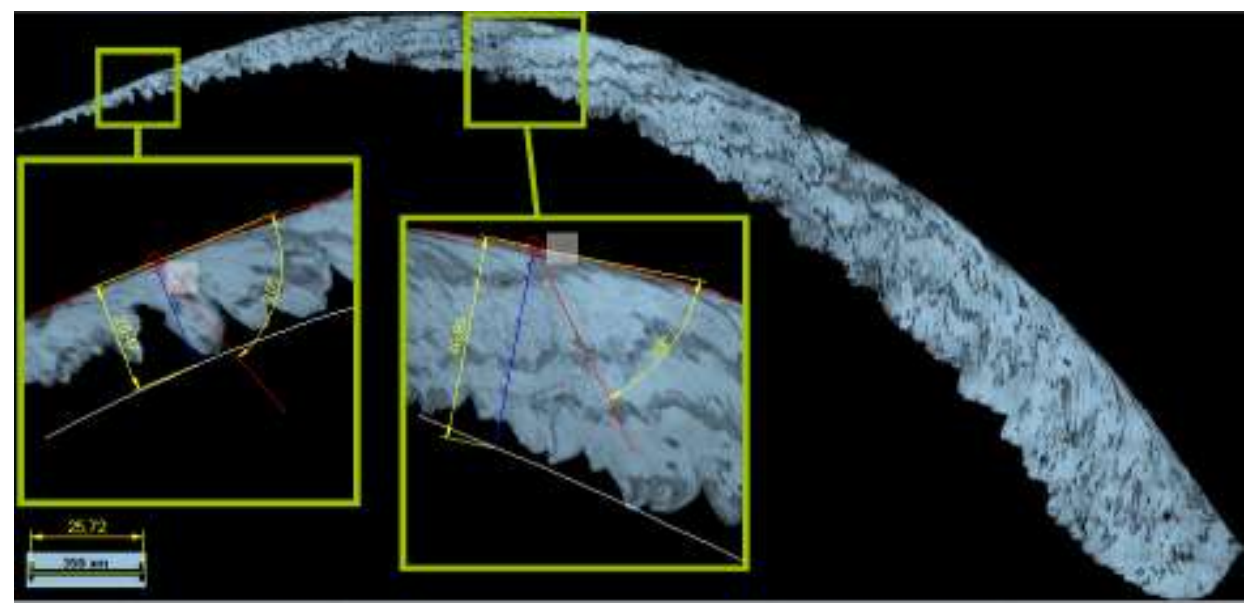

Figura 3.9 - Medição da espessura do cavaco para cálculo do grau de recalque. 


\section{Capítulo 4}

\section{RESULTADOS E DISCUSSÃO}

\subsection{Macro e microfresamento}

Nesta seção são apresentados os principais resultados obtidos em ensaios de fresamento em macro e microescala. Os resultados de ambas as escalas de usinagem serão explorados em conjunto para inferir nas principais semelhanças e diferenças na mudança da escala de usinagem. Para facilitar a identificação dos parâmetros, materiais e respectivas escalas de usinagem, uma nomenclatura foi adotada. A Tabela 4.1 apresenta a nomenclatura das condições de usinagem, com respectiva identificação da microestrutura do material da peça, tamanho de grão (TG), avanço por dente e escala de usinagem.

Tabela 4.1 - Nomenclatura aplicada à identificação dos resultados e discussão.

\begin{tabular}{l|c|c|c|c}
\hline Condição & Microestrutura & TG $^{\mathbf{1}}$ & $\mathbf{f}_{\mathbf{z}}[\boldsymbol{\mu \mathrm { m } / \mathbf { z } ]}$ & $\begin{array}{c}\text { Escala de } \\
\text { usinagem }\end{array}$ \\
\hline CR5 & Ferrita-Perlita & 11 & 5 & Micro \\
GUF5 & Ferrita & 0,7 & 5 & Micro \\
CR18 & Ferrita-Perlita & 11 & 18 & Micro \\
GUF18 & Ferrita & 0,7 & 18 & Micro \\
CR25 & Ferrita-Perlita & 11 & 25 & Macro \\
GUF25 & Ferrita & 0,7 & 25 & Macro \\
CR300 & Ferrita-Perlita & 11 & 300 & Macro \\
GUF300 & Ferrita & 0,7 & 300 & Macro \\
\hline \multicolumn{1}{l}{${ }^{1}$ Tamanho médio de grão ferrítico }
\end{tabular}

\subsubsection{Mecanismo de formação de cavaco}

A Figura 4.1 apresenta imagens em MO da morfologia dos cavacos formados com $\mathrm{f}_{\mathrm{z}} \approx \mathrm{r}_{\mathrm{e}}$ (micro e macrofresamento). As imagens mostram os grãos de ferrita alongados entre grãos de perlita para as condições CR5 e CR25. Na usinagem do material GUF o cavaco revelou justaposição das lamelas e tendência à formação de dentes de serra em GUF25. A mudança no mecanismo de formação do cavaco do material CR ocorreu devido à presença de uma fase mais dura (perlita) e outra mais dúctil (ferrita), e para uma espessura de corte 
maior que o tamanho médio de grão em CR25 $\left(f_{z}>T G\right)$ e menor em CR5 $\left(f_{z}<T G\right)$ conforme análise das imagens.

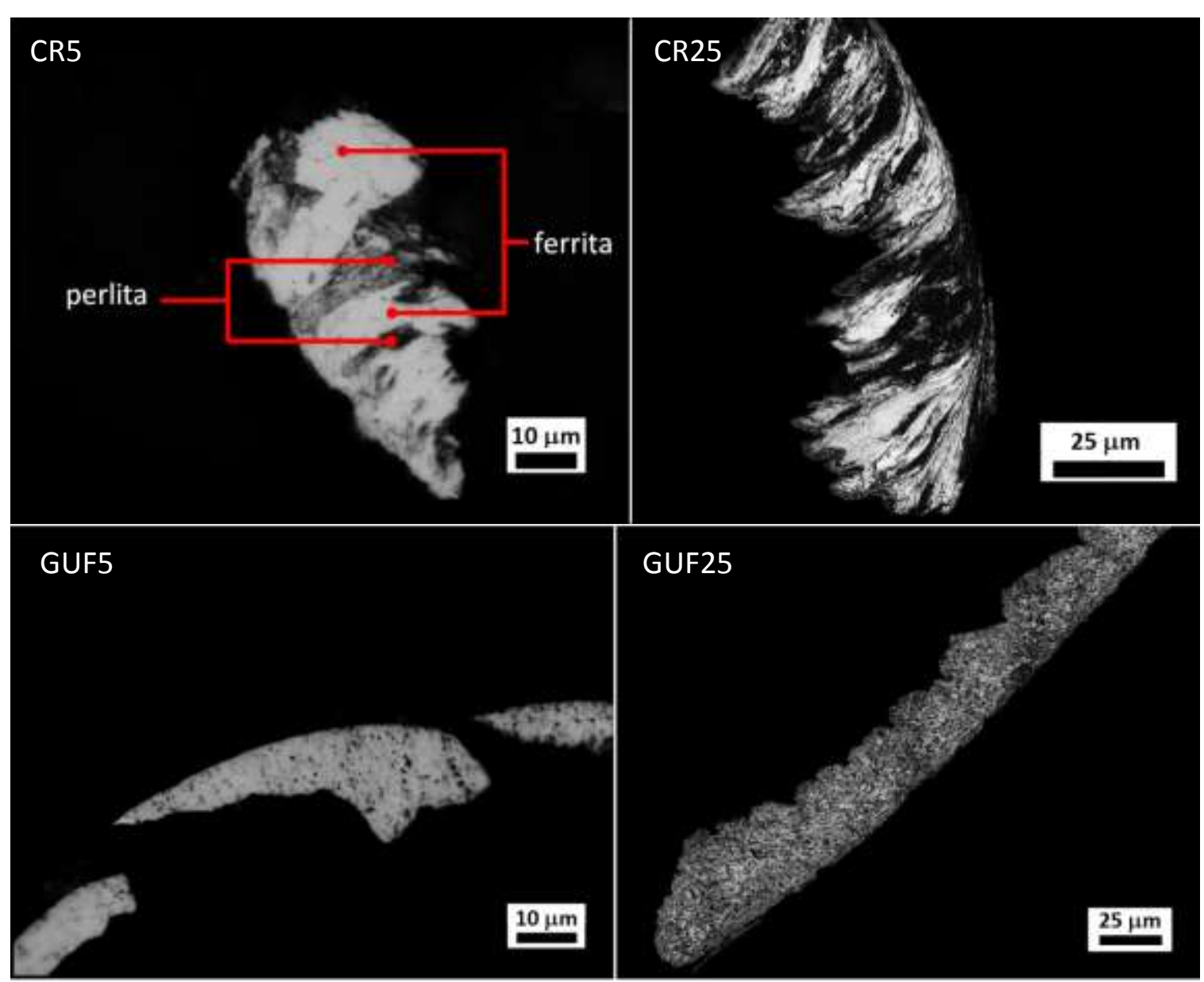

Figura 4.1 - Micrografias de MO do cavaco formado com $\mathrm{f}_{2} \approx \mathrm{r}_{\mathrm{e}}$ (ataque Nital $2 \%$ ).

A Figura 4.2 revela a morfologia dos cavacos gerados no fresamento com $f_{z}>r_{e}$ (micro e macrofresamento). Para as condições de usinagem e materiais, o cavaco revelou justaposição das lamelas ao longo de toda extensão da microestrutura, com a deformação dos grãos alinhada com as linhas de cisalhamento, sendo mais acentuada no material CR. Devido à diminuta dimensão e difícil manipulação dos cavacos gerados na microusinagem, as micrografias apresentam mais de um cavaco ou partes de cavacos, conforme observado em GUF5, GUF18 e CR18 das Figura 4.1 e Figura 4.2. 

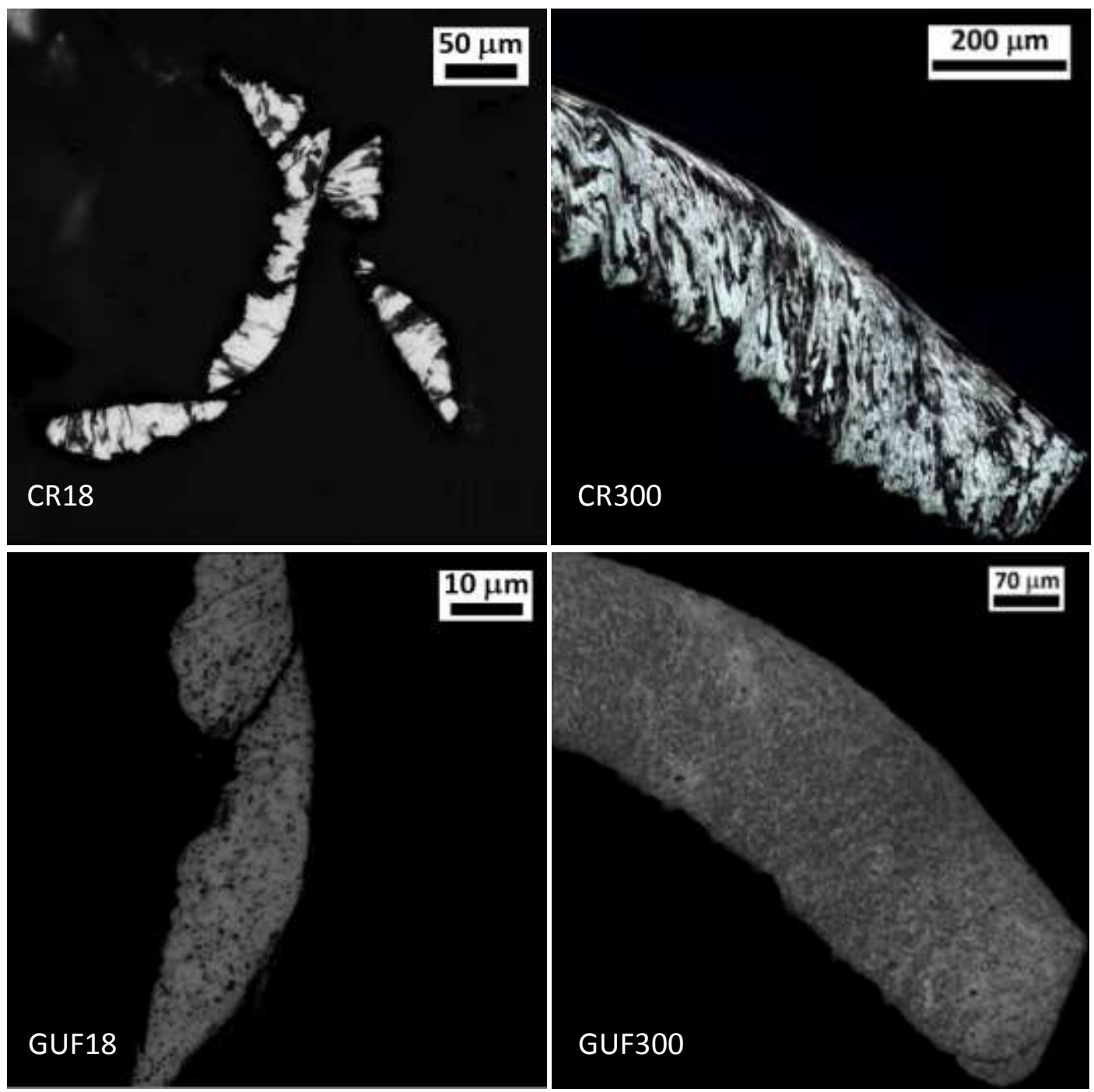

Figura 4.2 - Micrografias de MO do cavaco formado com $f_{z}>r_{e}$ (ataque Nital $2 \%$ ).

O cavaco formado nas escalas micro e macro de usinagem do material $\mathrm{CR}$, na relação 1:1 entre o avanço por dente e o raio de aresta da ferramenta $\left(f_{z}: r_{e}\right)$, é chamado quasicisalhamento-extrusão e foi observado no trabalho de Simoneau, Ng e Elbestawi (2006) para condições de velocidade de corte 11 vezes menor do que a aplicada nos ensaios de macrofresamento e 2 vezes menor do que a aplicada nos ensaios de microfresamento desta tese. Dessa observação e de acordo com as análises anteriores, o cavaco de quasicisalhamento-extrusão não depende da velocidade de corte, e sua formação ocorreu para raios de aresta da ferramenta maior (macrofresamento) e menor (microfresamento) que o tamanho médio de grão do material CR. Portanto, quanto aos parâmetros de corte e geometria da ferramenta, a formação deste tipo particular de cavaco depende apenas da 
relação entre o raio de aresta e o avanço por dente. A Figura 4.3 apresenta em detalhe o grão de ferrita extrudado por dois grãos de perlita (cisalhados por deformação).
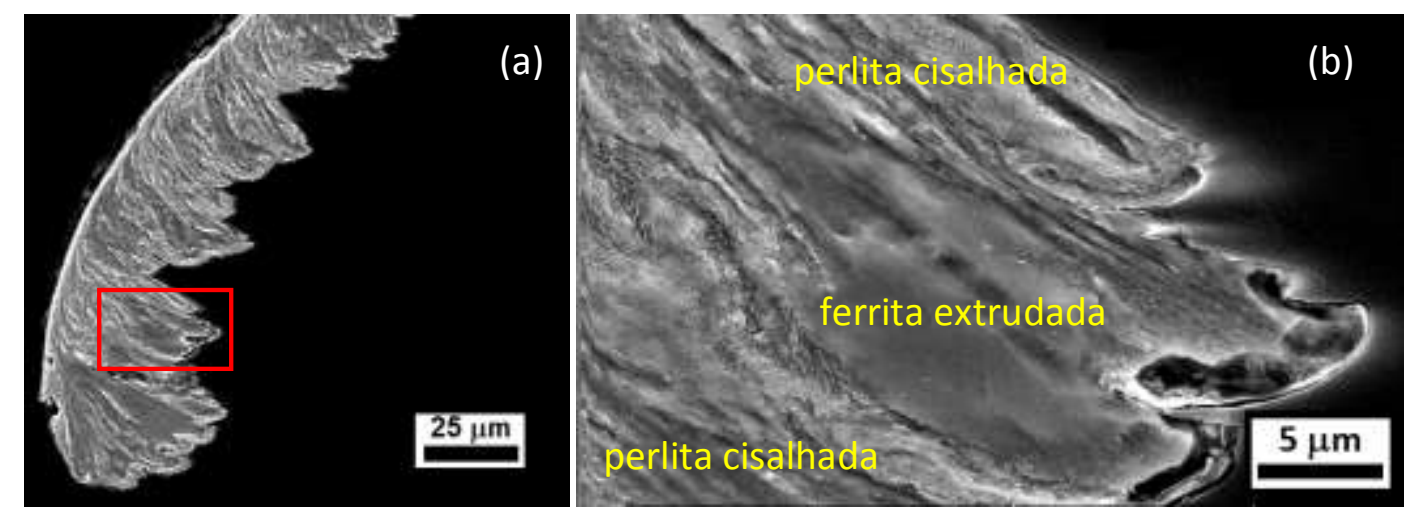

Figura 4.3 - Imagens de MEV do (a) cavaco de quasi-cisalhamento-extrusão na macrousinagem com $f_{z} \approx r_{e}$ do material CR e (b) detalhe das lamelas (ataque Nital 2\%).

A formação deste tipo de cavaco não ocorreu para o material GUF, pois a alteração metalúrgica proporcionou homogeneidade da microestrutura com a presença de uma única fase (ferrita). O fenômeno também não ocorreu na usinagem com $f_{z}>r_{e}$ do material $C R$. $A$ relação entre avanço por dente e raio de aresta de 12:1 na macrousinagem e aproximadamente 4:1 na microusinagem, demonstra que para esta condição a microestrutura comporta-se de forma homogênea perante o corte, independente da presença de uma segunda fase (com diferente grau de dureza). O comportamento homogêneo da microestrutura também pode ser relacionado à densidade planar de grãos de cada cavaco (quantidade de grãos de ferrita por área da seção de corte média). Considerando as condições de usinagem em que $f_{z} \approx r_{e}$, o cavaco gerado na usinagem do material CR possui 37 grãos de ferrita, enquanto o cavaco do material GUF possui 116 grãos. A densidade planar de grãos foi calculada com base na área da seção do cavaco (superfície livre da peça) e o tamanho de grão dos materiais dos corpos de prova.

A Figura 4.4 apresenta amostras visualizadas por MEV do material CR e na Figura 4.5 do material GUF. A estrutura de lamelas é observada ao longo da superfície livre do cavaco para $\mathrm{f}_{\mathrm{z}} \approx \mathrm{r}_{\mathrm{e}}$ com distinção das frentes de cisalhamento $(\mathrm{FC})$. A deformação foi periódica e com espaçamento médio ente 5 e $11 \mu \mathrm{m}$ para o material $C R$, enquanto no material GUF foi de 1 $\mu \mathrm{m}$ aproximadamente. Este aspecto revelou que o espaçamento das lamelas correspondeu ao tamanho de grão presente nos materiais, aproximadamente $5 \mu \mathrm{m}$ da perlita e $11 \mu \mathrm{m}$ da ferrita no material CR e $1 \mu \mathrm{m}$ da ferrita no material GUF. Complementando as observações, 
as imagens também revelaram formação de grooves (g) na interface cavaco-ferramenta em CR18 e CR300 (Figura 4.4).

As imagens da superfície livre e das lamelas do cavaco dos dois materiais mostram que houve separação das lamelas no macrofresamento, em particular para o avanço de 25 $\mu \mathrm{m} / \mathrm{z}$. A mesma distinção não foi observada para o avanço de $300 \mu \mathrm{m} / \mathrm{z}$. Marcas referentes a mudanças da taxa de deformação do cavaco (MTD) foram encontradas nas amostras de cavaco. Estes aspectos do cavaco serão mais bem discutidos adiante.

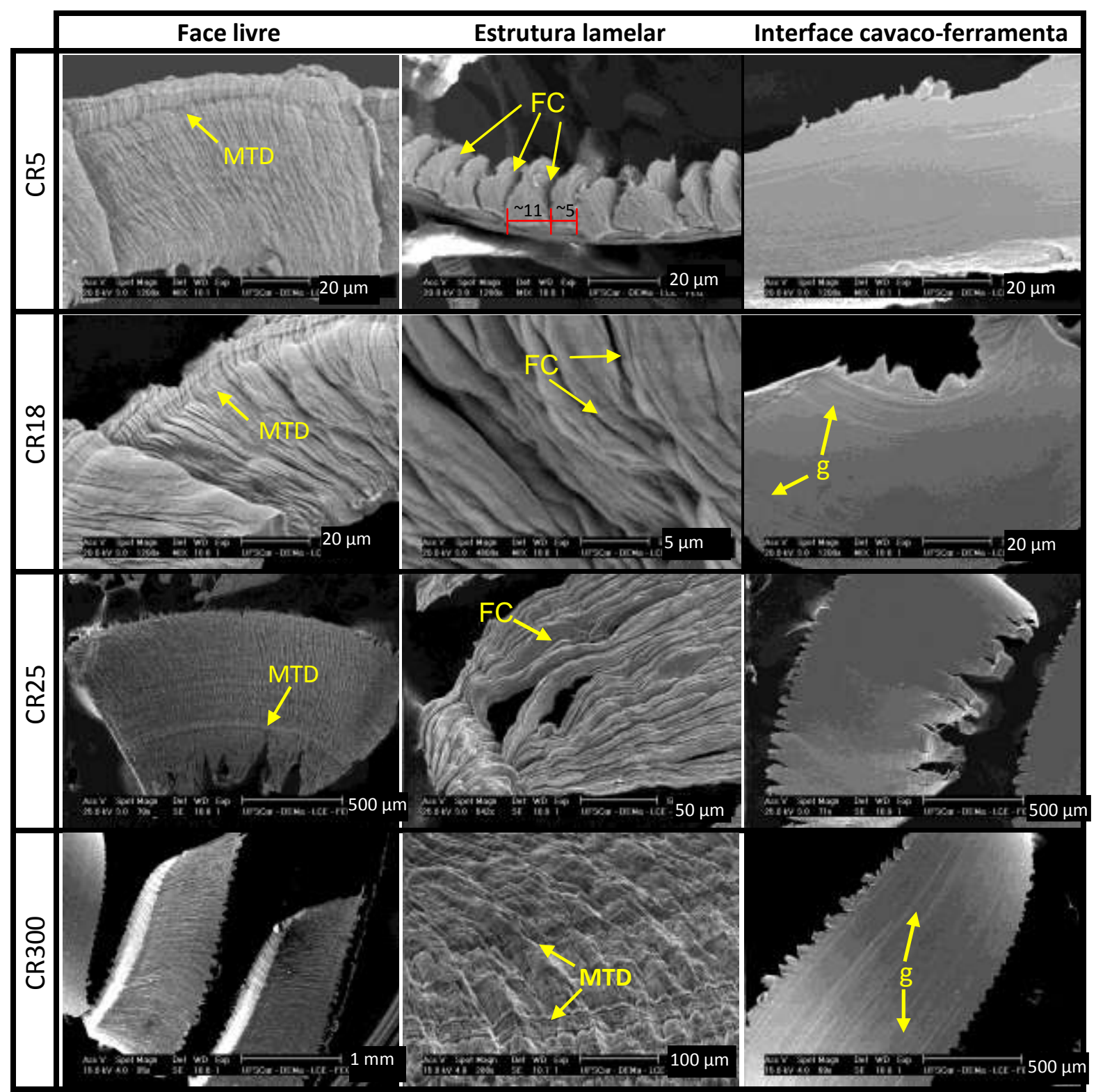

Figura 4.4 - Imagens de MEV do cavaco do material CR fresado em diferentes condições. FC = frente de cisalhamento e MTD = mudança da taxa de deformação. 


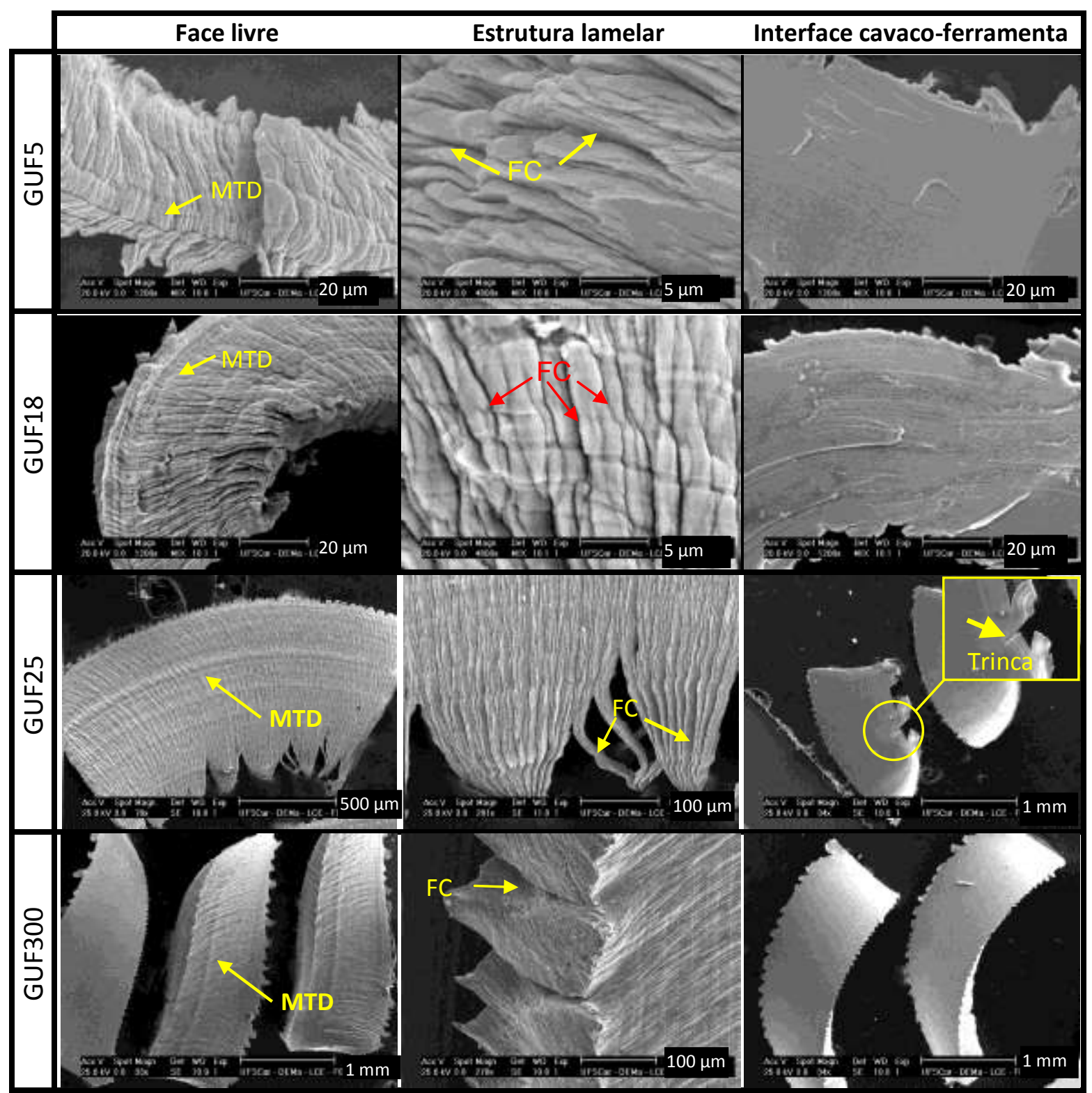

Figura 4.5 - Imagens de MEV do cavaco do material GUF fresado em diferentes condições. FC = frente de cisalhamento e MTD = mudança da taxa de deformação.

As análises das amostras de cavaco dos materiais CR e GUF revelaram que a separação das frentes de cisalhamento (FC) no material CR não dependeu da mudança no mecanismo de formação do cavaco, porém houve uma relação direta com a redução do avanço por dente e o tamanho médio de grão do material da peça. Na redução da espessura de corte até a ordem do raio de aresta da ferramenta, o ângulo de saída passa a ser negativo e elevado, aumentando a tensão de compressão do cavaco (Komanduri, 1971). O espaçamento das lamelas foi consistente com o tamanho médio de grãos dos materiais. Sendo assim, com a frente de cisalhamento sendo formada próxima a aresta da ferramenta, a deformação ocorre em camadas finas, com espaçamento limitado pela distância entre 
contornos de grão, com intensa deformação no interior do grão (Black, 1972). Esta proposição está coerente com o cisalhamento da perlita e extrusão da ferrita observados no cavaco formado para $f_{z} \approx r_{e}$ na usinagem do material $C R$.

No macrofresamento, o material GUF mostrou maior resistência às trincas na borda do cavaco correspondente à região mais fina do cavaco, enquanto para o material CR foi mais quebradiço. No fresamento o cavaco possui forma de vírgula, e para a geometria do corte adotada neste trabalho, a forma de vírgula também é vista entre a borda mais grossa (superfície livre da peça) e mais fina do cavaco (interface cavaco-peça), conforme observado nas imagens das Figura 4.4 e Figura 4.5. A porção mais fina foi submetida a maior deformação por compressão devido ao contato mais próximo com a aresta de corte, enquanto a porção mais espessa sofreu cisalhamento sem a forte influência da aresta de corte (Black, 1972). Este efeito tendeu a gerar um estado de tensão variável ao longo da espessura do cavaco, uma vez que o ângulo de cisalhamento deve mudar ao longo da espessura do cavaco. Esta variação no estado de tensão pode ser observada na variação no grau de recalque do cavaco apresentada a seguir.

A Figura 4.6 apresenta o grau de recalque medido ao longo da espessura do cavaco. Nos gráficos foi observado que para $\mathrm{f}_{\mathrm{z}} \approx \mathrm{r}_{\mathrm{e}} \mathrm{O}$ grau de recalque variou ao longo da espessura do cavaco, enquanto para $f_{z}>r_{e}$ foi mantido aproximadamente constante. A variação do ângulo de cisalhamento é inversamente proporcional à variação do grau de recalque (Shaw, 1997). Portanto, conforme a espessura do cavaco é reduzida, ocorre redução do grau de recalque e consequente aumento do ângulo de cisalhamento.

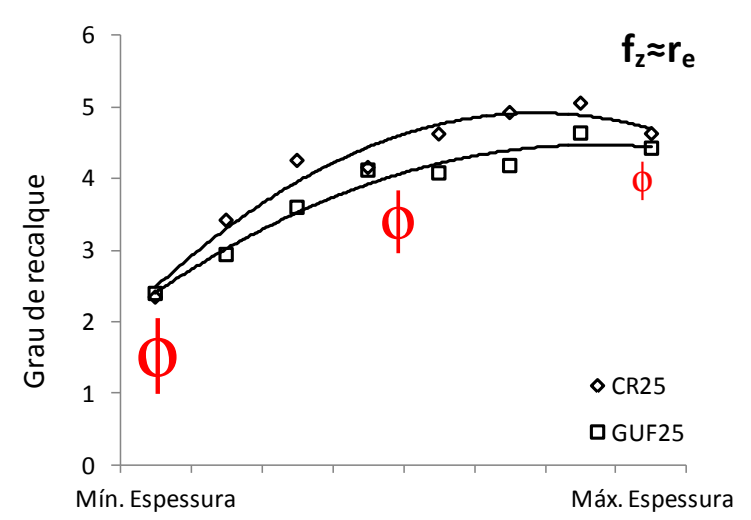

Espessura do cavaco

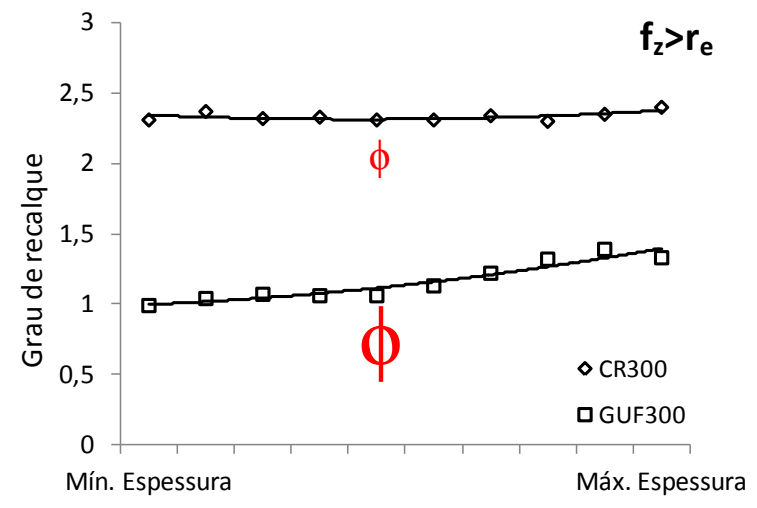

Espessura do cavaco

Figura 4.6 - Gráficos do grau de recalque medidos na macrousinagem. 
A tensão de compressão aumenta com a redução da espessura do cavaco, aumentando o deslocamento de discordâncias, favorecendo o aumento da plasticidade na porção mais fina do cavaco, gerando um ângulo de cisalhamento maior que na porção mais espessa (Black, 1972). Para a condição de maior avanço por dente $\left(f_{z}>r_{e}\right)$, a porção mais fina ainda é espessa o suficiente para manter o grau de recalque sem variação significativa, ou seja, sem mudança no comportamento plástico do material, ao contrário do observado para o menor avanço por dente. Dessa forma, o comprimento relativo de cada borda é diferente, causando o aspecto de rasgamento observado na borda mais fina do cavaco nas Figura 4.4 e Figura 4.5.

A Figura 4.7 ilustra o efeito do raio de aresta na formação do cavaco e no ângulo de cisalhamento. Com a variação do recalque é possível inferir a ocorrência da variação do ângulo de cisalhamento ao longo da espessura do cavaco para $f_{z} \leq r_{e}$. Dessa forma, a variação no estado de tensões devido à alta compressão na porção mais fina do cavaco e também mais próxima ao raio de aresta foi mais significativa para esta condição de usinagem. Além disso, o aumento da tensão de compressão tende a aumentar a deformação do material na zona de corte, sendo estendida para a subsuperfície da peça, afetando a integridade superficial da peça, conforme será visto na seção seguinte sobre acabamento da peça e defeitos na superfície usinada.
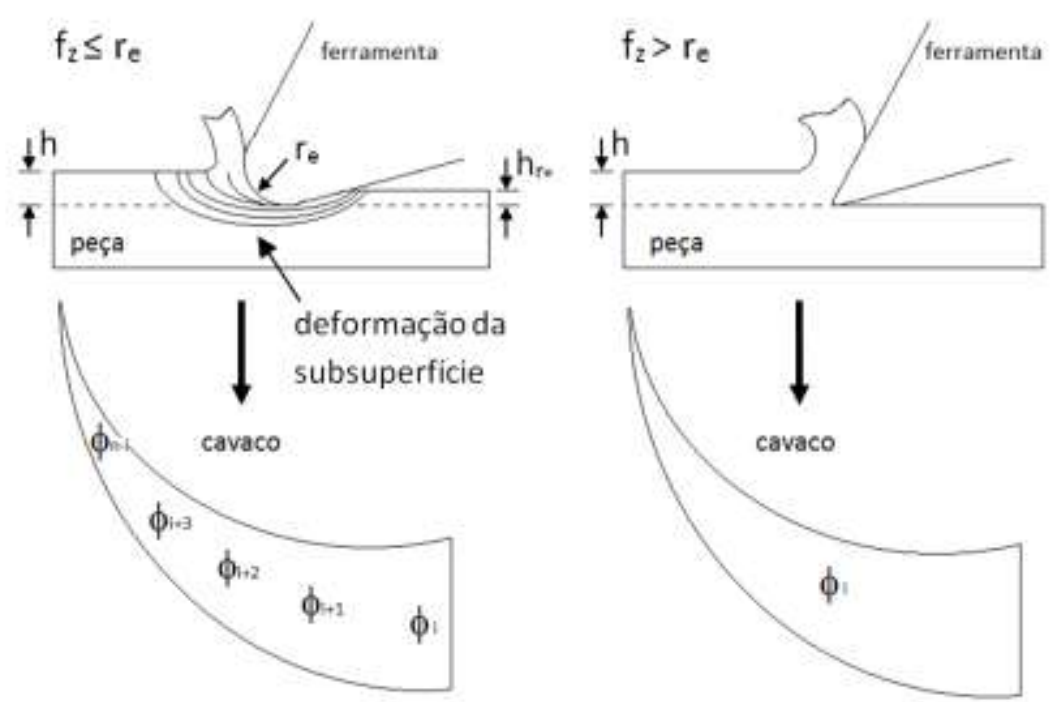

Figura 4.7 - Efeito do raio de aresta na formação do cavaco no fresamento para $f_{z} \leq r_{e}$ e $f_{z}>r_{e}$. 
A Figura 4.8 apresenta zonas de escorregamento e aderência do cavaco do material GUF na face de contato com a ferramenta. Análises de imagens de MEV revelaram a ocorrência de zonas de aderência na usinagem em GUF5 e GUF18. No macrofresamento houve apenas escorregamento para todas as condições de usinagem. Este fenômeno tem sido atribuído à redução da espessura de corte, ponto no qual há oscilações de atrito no contato do cavaco com a superfície de saída da ferramenta (Komanduri \& Turkovich, 1981). Esta mesma característica foi relatada por trabalhos realizados com aço ferrítico-perlítico, com ocorrência periódica de escorregamento e aderência na interface cavaco-ferramenta (Komanduri \& Turkovich, 1981; Barry, Byrne, \& Lennon, 2001; Mian, Driver, \& Mativenga, 2011).

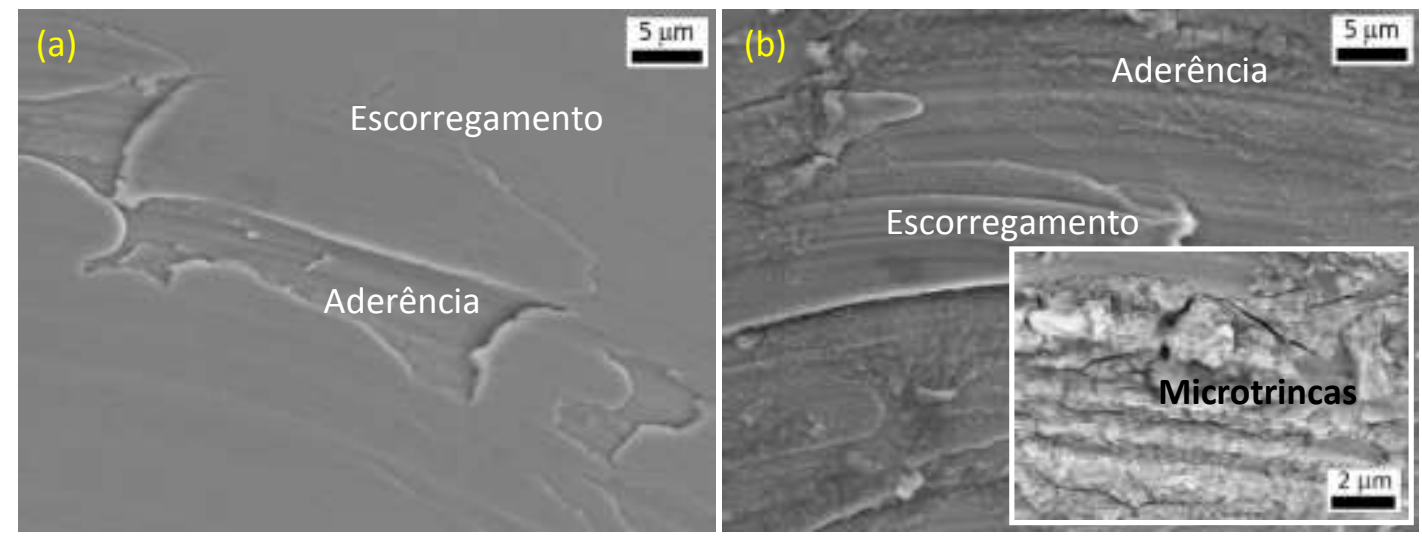

Figura 4.8 - Face de escorregamento do cavaco formado em (a) GUF5 e (b) GUF18.

De acordo com as análises dos cavacos, a formação de zonas de escorregamento e aderência foi aleatória, e além da espessura de corte, houve também influência da microestrutura do material da peça. Esta observação é um importante fator a se considerar em trabalhos futuros que envolvam simulação numérica. Em GUF18, a formação de zonas de aderência veio acompanhada de microtrincas, conforme observado na ampliação em destaque na Figura 4.8b, extraída de outra região do cavaco na interface cavaco-ferramenta. Estas microtrincas seriam um indicativo de maior atrito na região de aderência.

\subsubsection{Acabamento da peça e defeitos de superfície}

Os efeitos da microestrutura do material da peça e da microgeometria da aresta de corte foram também observados na superfície usinada, conforme mostrado na Figura 4.9. 
Para todas as condições foi observada a formação de regiões mais elevadas em relação a outras de acordo com a escala de cores ao lado da imagem em 3D da superfície. Em CR5 e CR25, a superfície apresentou irregularidades ou formação não periódica da superfície, tanto na direção do avanço quanto tangencial de giro da ferramenta. No entanto, para o material GUF a rugosidade cinemática foi regular em comparação ao material $C R$, em particular no microfresamento. Qualitativamente, o material GUF apresentou marcas de avanço mais bem definidas, enquanto o material CR apresentou efeitos de ploughing na geração das superfícies, em particular na condição de $\mathrm{f}_{\mathrm{z}} \approx \mathrm{r}_{\mathrm{e}}$.

Os dados quantitativos de rugosidade também contribuem para esta análise. O perfil em GUF5 foi mais uniforme, com clara definição dos picos e vales. Esta constatação pode ser feita pela análise dos parâmetros skewness $\left(\mathrm{S}_{\mathrm{sk}}\right)$ e kurtosis $\left(\mathrm{S}_{\mathrm{ku}}\right)$ na Tabela 4.2. A avaliação do parâmetro skewness $\left(S_{s k}\right)$ revelou que no microfresamento com $f_{z} \approx r_{e}$ (condição de maior interesse), houve simetria entre a formação de vales e picos $\left(S_{s k} \approx 0\right)$ no material GUF, enquanto no material $C R$ preponderou a formação de vales $\left(S_{s k}<0\right)$. Além disso, com relação à natureza da distribuição das elevações pela análise do parâmetro kurtosis, quando sob o efeito da microgeometria da aresta de corte, o material GUF apresentou uma distribuição normal (curva de sino) das elevações na superfície da peça $\left(S_{k u} \approx 3\right)$. Estas características na formação da superfície também podem ser visualizadas nas barras de cores das imagens em 3D das superfícies usinadas das condições CR5 e GUF5 na Figura 4.9.

Tabela 4.2 - Avaliação da formação de picos e vales nas peças micro e macrofresadas.

\begin{tabular}{|c|c|c|c|c|}
\hline Escala & Condição & Parâmetro & CR & GUF \\
\hline \multirow{4}{*}{ MICRO } & \multirow{2}{*}{$f_{z} \approx r_{e}$} & Skewness & $-1,80$ & $-0,34$ \\
\hline & & Kurtosis & 7,56 & 3,58 \\
\hline & \multirow{2}{*}{$f_{z}>r_{e}$} & Skewness & 0,33 & 0,13 \\
\hline & & Kurtosis & 2,81 & 2,87 \\
\hline \multirow{4}{*}{ MACRO } & \multirow{2}{*}{$f_{z} \approx r_{e}$} & Skewness & 0,06 & 0,30 \\
\hline & & Kurtosis & 2,87 & 3,10 \\
\hline & \multirow{2}{*}{$f_{z}>r_{e}$} & Skewness & $-0,09$ & 0,21 \\
\hline & & Kurtosis & 2,60 & 2,82 \\
\hline
\end{tabular}




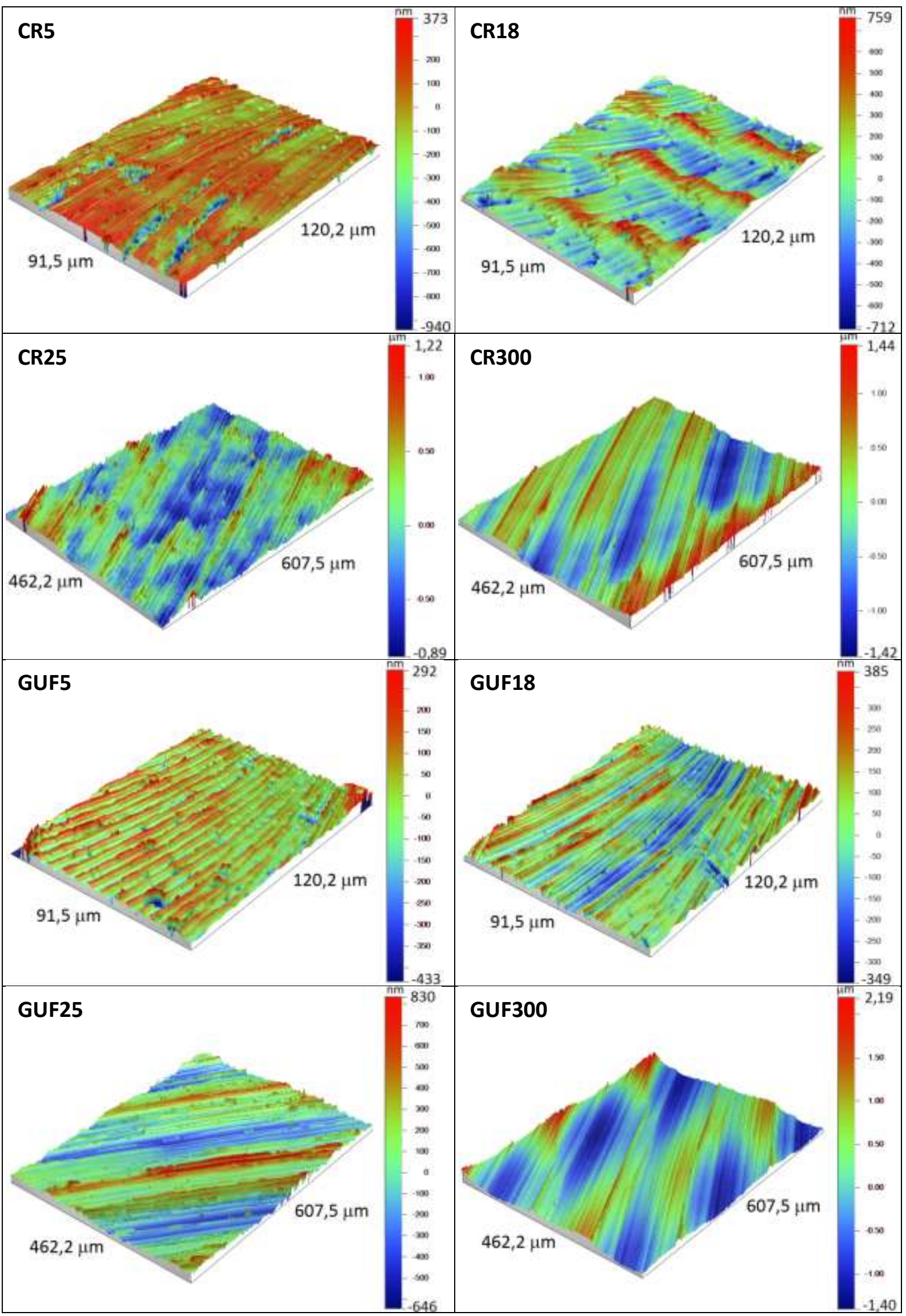

Figura 4.9 - Imagens 3D das superfícies micro e macrofresadas. 
Com base nas análises qualitativas e quantitativas das superfícies usinadas, aplicando avanços por dente equivalentes ao raio de aresta de corte $\left(f_{z} \approx r_{e}\right)$, o material GUF apresentou melhor comportamento perante a passagem da ferramenta, com preponderância de cisalhamento, formando uma superfície com variação gradual (picos e vales) e com textura periódica ao longo do caminho traçado pela ferramenta. Por outro lado, é possível afirmar que no material CR apresentou maior efeito de ploughing em comparação ao material homogêneo de grãos ultrafinos (mais resistente à deformação).

A Figura 4.10 apresenta a microestrutura da subsuperfície das peças usinadas. No geral, as superfícies usinadas do material GUF apresentam menos alterações da microestrutura em comparação ao material CR. Apenas em $5 \mu \mathrm{m} / z\left(f_{z} \approx r_{e}\right)$ houve alguma irregularidade no perfil da linha da superfície e algumas microrrebarbas em $18 \mu \mathrm{m} / z\left(f_{z}>r_{e}\right)$, porém sem deformação plástica severa aparente. O material CR apresentou vazios e cavidades, assim como deformações plásticas severas nos grãos próximos a superfície. Estes aspectos são muito importantes para aplicações nas quais o desempenho sob fadiga é necessário.

Trincas podem se formar nas regiões de contornos de grão de aços bifásicos devido à fragilidade causada pela precipitação de carbetos durante o processo de crescimento de grão e formação da microestrutura original (Bailey, 1977). Além disso, há um comportamento distinto do corte quando a ferramenta corta um grão de ferrita (dúctil) e em outro momento um grão de perlita (mais duro) durante a usinagem, conforme visto no mecanismo de formação de cavaco da Figura 4.3 para a condição de $\mathrm{f}_{\mathrm{z}} \approx \mathrm{r}_{\mathrm{e}}$. Estes fatores tendem a promover a formação de defeitos, como deformações e desprendimento de material próximo a aresta de corte (Simoneau \& Elbestawi, 2006). 


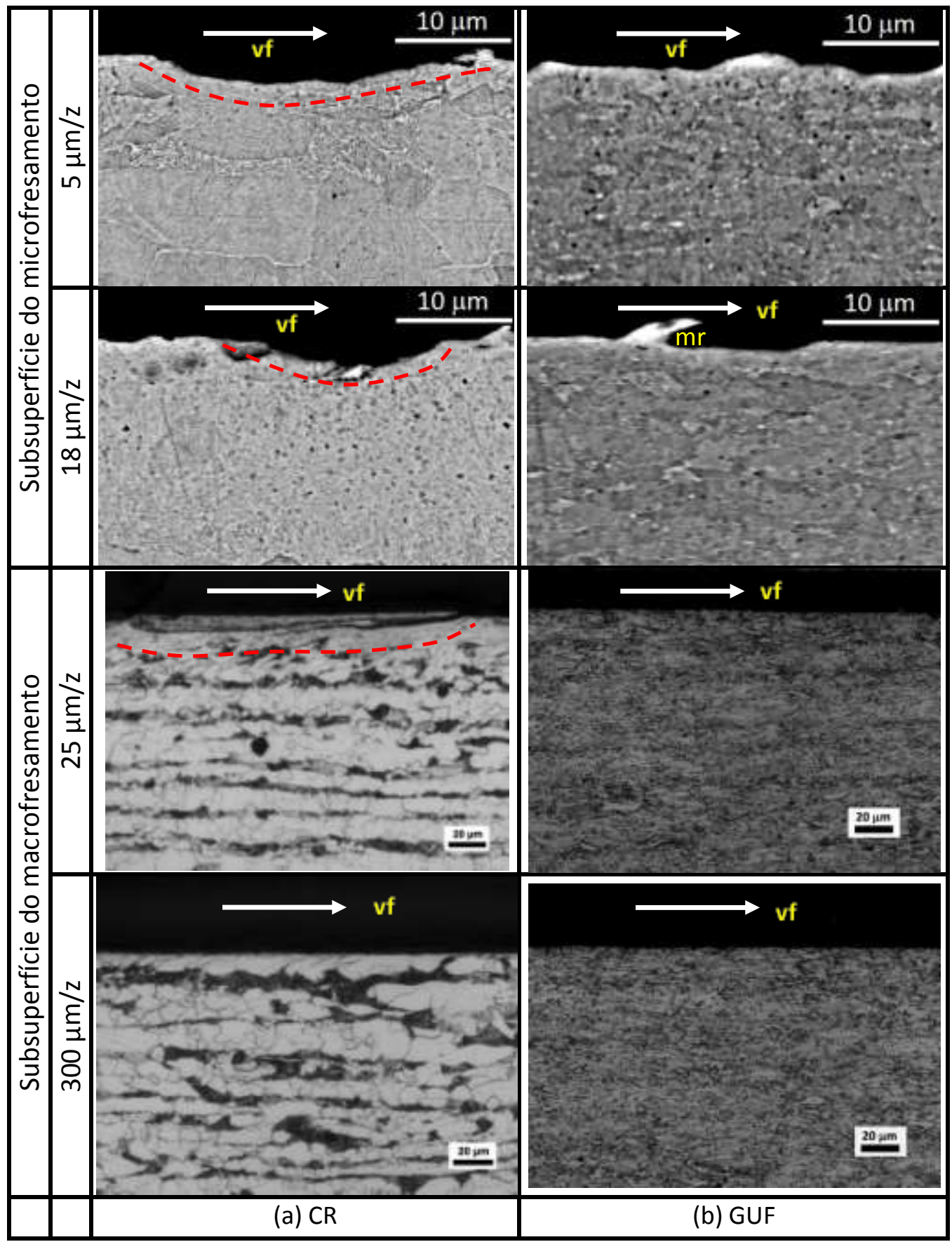

Figura 4.10 - Microestrutura da subsuperfície das peças micro e macrofresadas (ataque Nital 2\%). As setas indicam a direção da velocidade de avanço (vf) da ferramenta.

Analisando a Figura 4.11, houve formação periódica de fluxos de deformação ao longo da superfície da peça na microusinagem do material CR com $5 \mu \mathrm{m} / z \quad\left(f_{z} \approx r_{e}\right)$, estendendo pela subsuperfície. Estes fluxos de deformação compreenderam vários grãos, tanto de ferrita quanto de perlita. Em alguns desses fluxos de deformação ocorreu nucleação de uma trinca, o qual penetrou pela superfície usinada, propagando-se preferencialmente pelo entorno do fluxo de deformação. 


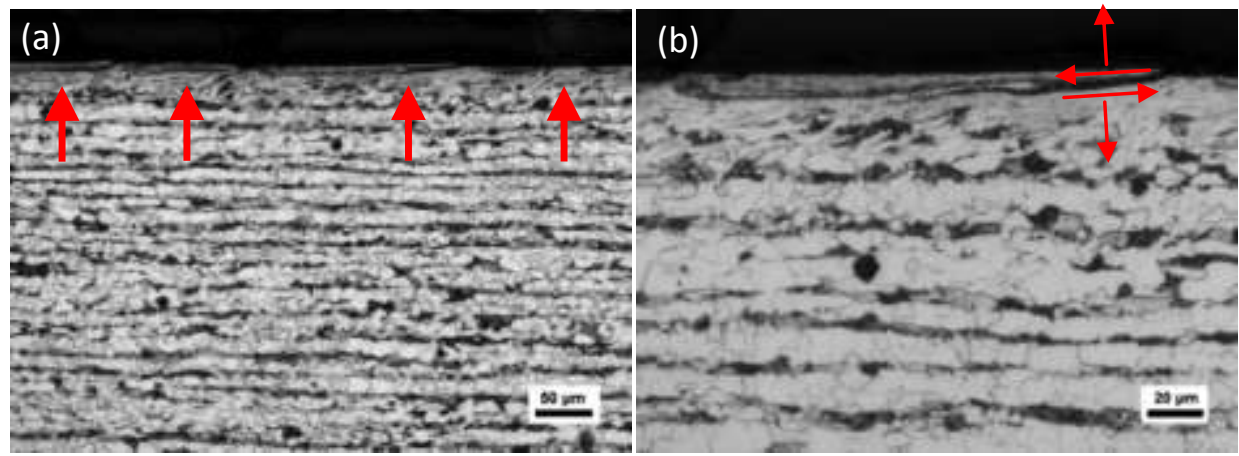

Figura 4.11 - Subsuperfície no microfresamento do material CR com $5 \mu \mathrm{m} / \mathrm{z}\left(\mathrm{f}_{\mathrm{z}} \approx \mathrm{r}_{\mathrm{e}}\right)$. Em (a) a distribuição periódica dos fluxos de deformação e em (b) a ampliação de um dos fluxos de deformação.

Quando a espessura de material não removido é menor que o raio de aresta da ferramenta, a deformação plástica na zona primária de deformação é estendida abaixo da superfície da peça, conforme ilustrado na Figura 4.7, apresentada anteriormente na subsecção sobre análise do cavaco. A periodicidade da deformação neste caso é devida a variação periódica da alta dissipação de energia durante a deformação plástica durante a formação do cavaco de quasi-cisalhamento-extrusão (Simoneau, Ng, \& Elbestawi, 2006). Conforme observado na Figura 4.11, a maioria dos fluxos de deformação manteve-se estável, sem desprendimento da superfície da peça por fratura. Uma possível explicação atribui à temperatura ser suficientemente alta na região do corte, ao ponto de a deformação plástica ocorrer sem fratura, ou seja, com deformação adiabática (Bailey, 1977).

A Figura 4.12 apresenta os principais defeitos encontrados na superfície usinada do material CR. Diferentes ampliações foram utilizadas para melhor identificação dos defeitos. Em CR5 houve formação de grooves (g), smeared material (s) e fluxo plástico (ps) acompanhado de steps (st). Em CR18 foram encontrados principalmente gooves (g), smeared material (s), cavidades, fluxo plástico (ps) seguido por steps (st) e marcas características de smeared material em forma de ondas (achatamento de grãos de ferrita), encontradas na parte final da peça por onde a ferramenta passou.

Para CR25 houve a formação de smeared material (s) na maior parte da superfície usinada, enquanto outras regiões da superfície da peça apresentaram formação incompleta do cavaco (i), deformado plasticamente ao longo da direção de corte. Nestas mesmas regiões foram também encontrados restos de material $(r)$ depositados na superfície da peça. Em CR300 foi verificada intensa formação de grooves (g) e grooves de microcavacos (gi) na direção do corte, fluxo plástico (ps) com característica fribosa (Bailey, 1977), inclinada em 
relação à direção de avanço da ferramenta e, em menor proporção de quantidade, microcavidades (c) com comprimento preferencial na direção do corte.

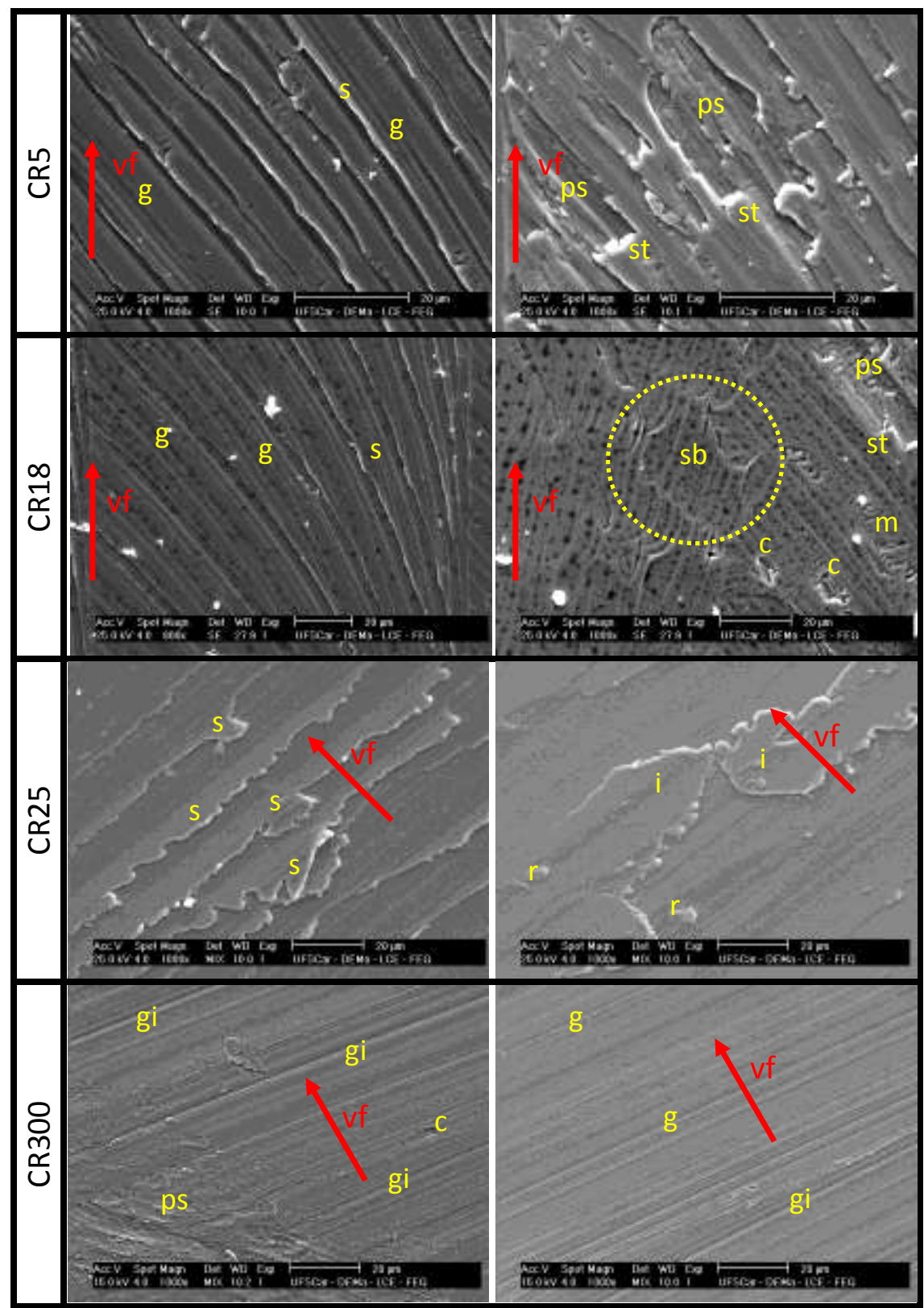

Figura 4.12 - Imagens de MEV da superfície usinada do material CR. vf = direção do avanço da ferramenta.

As imagens da Figura 4.13 para o material GUF apresentam os principais defeitos encontrados na superfície usinada para cada condição de usinagem. Diferentes ampliações foram utilizadas para melhor identificação dos defeitos. Em GUF5 a superfície mostrou bom acabamento, sem variedade e quantidade de defeitos, apenas gooves (g) e microcavidades (c) em algumas regiões da superfície da peça. Da mesma forma, em GUF18 foram 
encontrados apenas gooves de microcavacos (gi), microrebarbas $(\mathrm{mr})$ e repasse da ferramenta (re), distribuídos uniformemente ao longo da superfície da peça.

No macrofresamento, em GUF25 com $\mathrm{f}_{\mathrm{z}} \approx \mathrm{r}_{\mathrm{e}}$, houve escoamento lateral de material (e) em algumas regiões da superfície da peça. Para GUF300 a superfície foi uniforme e com menos variedade de defeitos em relação ao material $\mathrm{CR}$, apenas com formação de grooves (g) e grooves de microcavacos (gi) na direção do corte. Microcavidades (c) orientadas na direção do corte foram encontradas em algumas regiões da superfície da peça.

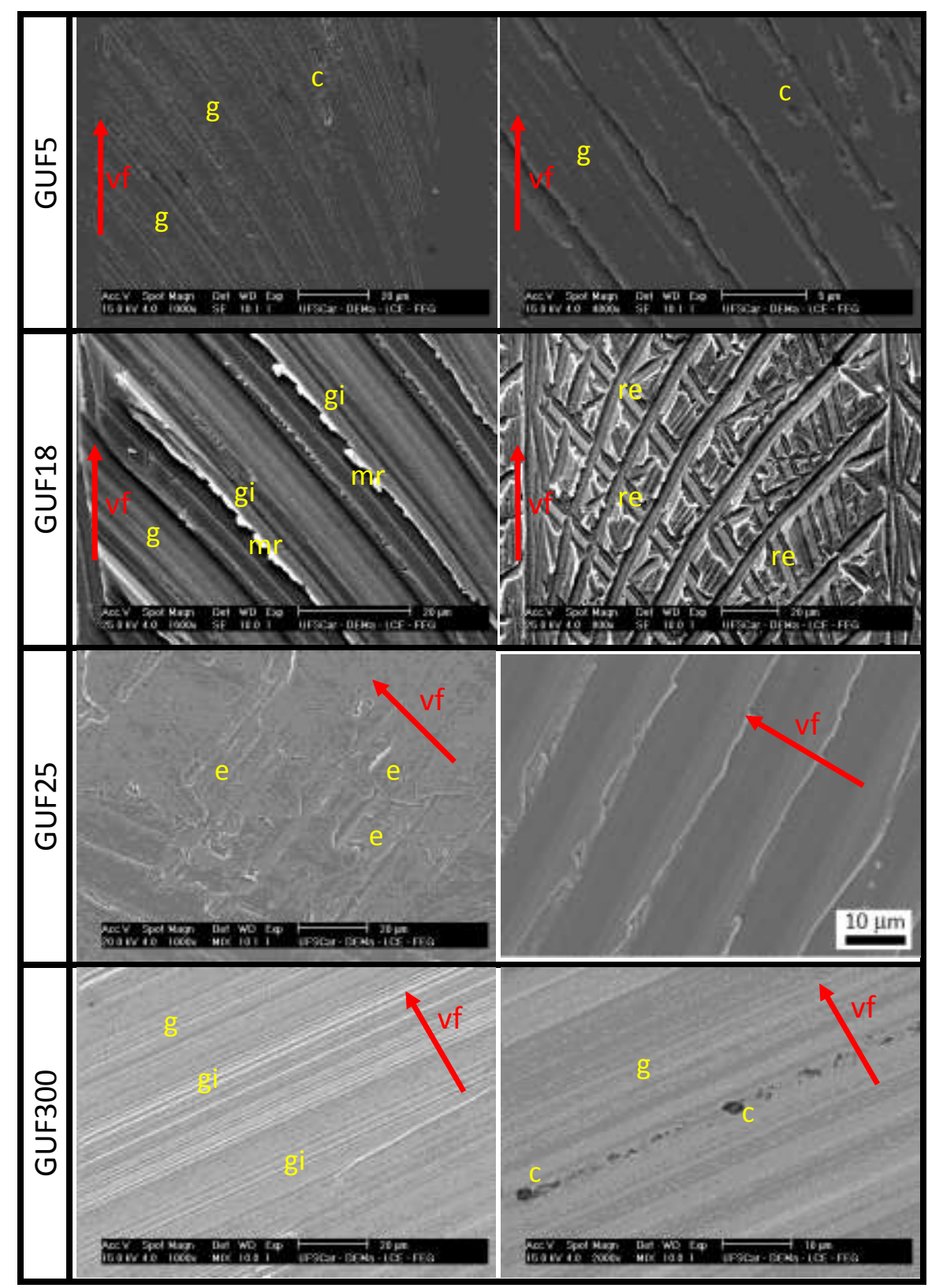

Figura 4.13 - Imagens de MEV da superfície usinada do material GUF. vf = direção do avanço da ferramenta. 
Os resultados de borda e superfície usinada mostraram considerável variação da aparência da superfície da peça quando a espessura de corte é da ordem do raio de aresta de corte $\left(f_{z} \approx r_{e}\right)$. Esta variação dos tipos de defeitos encontrados em diferentes áreas da superfície da peça é uma evidencia da transição entre cisalhamento e ploughing para ambos os materiais, tendo sido mais proeminente no material CR. Além disso, a mudança no mecanismo de formação do cavaco na usinagem do material CR revelou ter causado mais danos à superfície e subsuperfície da peça. A relação entre a mudança do mecanismo de formação do cavaco e aumento dos defeitos de superfície foi relatado na literatura (Bailey, 1977; Simoneau \& Elbestawi, 2006).

A formação de smeared material (s) foi observada como sendo predominante na maior parte da superfície usinada do material $C R$ para $\mathrm{f}_{\mathrm{z}} \approx \mathrm{r}_{\mathrm{e}}$. Este tipo de defeito também foi identificado na microusinagem com microfresas entre $200 \mu \mathrm{m}$ e $600 \mu \mathrm{m}$ de diâmetro, menores que as utilizadas neste trabalho (Bissacco, Hansen, \& De Chiffre, 2006). Trata-se de ondas de material plasticamente deformado, pertencente à última parte do cavaco. $\mathrm{Na}$ menor espessura do cavaco no fresamento, o ângulo de saída da ferramenta torna-se altamente negativo devido a microgeometria da aresta de corte, o cavaco então é rompido e o material remanescente é deformado pela aresta de corte (Bissacco, Hansen, \& De Chiffre, 2006).

Na macrousinagem, os grooves $(\mathrm{g})$ apareceram em ambos os materiais e condições de avanço por dente, exceto em GUF25, indicando maior resistência à tensão normal gerada no contato peça-ferramenta nesta condição. Houve geração de grooves de microcavacos (gi) para $f_{z}>r_{e}$ em ambos os materiais. Na microusinagem gooves (g) apareceram em todas as condições de usinagem e gooves de microcavacos (gi) foram identificados apenas no material GUF usinado com $f_{z}>r_{e}$.

A formação de grooves, verificada somente na face de escorregamento dos cavacos em CR18 e CR300 (Figura 4.8), indica que para $\mathrm{f}_{\mathrm{z}} \approx \mathrm{r}_{\mathrm{e}} \mathrm{O}$ atrito é maior na interface peçaferramenta em comparação a interface cavaco-ferramenta, revelando aumento da dureza e consequente aumento da resistência à tensão normal para esta condição de usinagem. Por outro lado, na usinagem do material GUF (mais duro) o atrito teria sido mais intenso na interface peça-ferramenta, independente da condição de avanço por dente.

Esta hipótese pode ser verificada na análise da aresta de corte. A Figura 4.14 apresenta imagens de MEV da aresta de corte, revelando que o atrito na interface peça- 
ferramenta é intenso na usinagem com $\mathrm{f}_{2} \approx \mathrm{r}_{\mathrm{e}}$. A zona $A$ corresponde a regiões de remoção da cobertura da pastilha e a zona B regiões de adesão de material da peça na ferramenta, conforme análise de composição química realizada por EDX. Quando a espessura do cavaco atinge um valor mínimo, o material passa a escorregar pela superfície de folga da ferramenta, gerando desgaste (Kishawy \& Elbestwi, 1999). Apesar do desgaste encontrado na usinagem com $\mathrm{f}_{\mathrm{z}} \approx \mathrm{r}_{\mathrm{e}}$ dos dois materiais, houve maior adesão de material da peça na ferramenta na usinagem do material CR. O material da peça aderido à ferramenta possui dureza de 3 a 5 vezes a dureza intrínseca do material, e tende a contribuir para a formação de defeitos na superfície da peça ao modificar a microgeometria da aresta de corte, além de possível desprendimento do material aderido e posterior deposição na superfície da peça (Simoneau \& Elbestawi, 2006). Estudos relativos à medição de desgaste das ferramentas não foram realizadas nesta pesquisa.

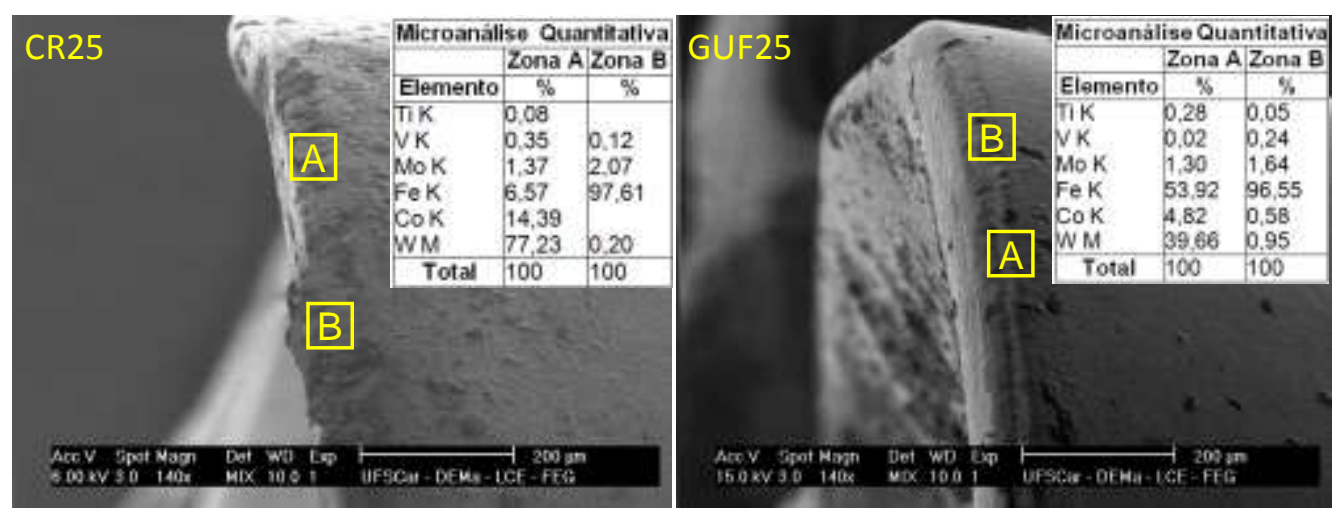

Figura 4.14 - Imagens de MEV e análise química por EDX da superfície de folga das ferramentas para $\mathrm{f}_{\mathrm{z}} \approx \mathrm{r}_{\mathrm{e}}$ na macrousinagem.

Microcavidades (c) surgiram no microfresamento com $f_{z}>r_{e}$ do material CR e com $f_{z} \approx r_{e}$ no material GUF em menor proporção quando comparados os materiais. No macrofresamento as microcavidades aparecem para $f_{z}>r_{e}$ na usinagem do material GUF. A redução do tamanho das cavidades tem sido associada à redução do tamanho de grão do material (Simoneau, Ng, \& Elbestawi, 2006). É associado às diferenças nos limites de escoamento dos materiais e ausência de estruturas duras de uma segunda fase, reduzindo o tamanho das cavidades (Bailey, 1977). O mecanismo de fratura opera em uma escala maior que o tamanho de grão e eventualmente envolve mais de um grão (Hasnaoui et al., 2003).

O material CR apresentou fluxo plástico (ps) na direção do corte para ambas as condições de avanço por dente no microfresamento. A formação incompleta do cavaco (i) 
surgiu no macrofresamento com $\mathrm{f}_{\mathrm{z}} \approx \mathrm{r}_{\mathrm{e}}$. Este tipo de defeito indica que a mínima espessura de corte do material CR foi maior quando comparado ao material GUF, na última porção do cavaco, região na qual este tipo de falha na superfície geralmente ocorre (Bissacco, Hansen, \& De Chiffre, 2006). Desse modo, houve escoamento de material pela superfície de folga da ferramenta na usinagem do material $C R$ e as condições de atrito causaram o desprendimento de material da superfície da peça.

Nas peças microfresadas, steps (st) inclinados na direção do corte surgiram para o material $C R$ na condição de $\mathrm{f}_{\mathrm{z}} \approx \mathrm{r}_{\mathrm{e}}$. Geralmente estão associados à existência de fluxo plástico (ps), e foram mais evidentes na superfície microfresada do que na macrofresada. As microtrincas $(m)$ apareceram somente na superfície microusinada do material CR, da mesma forma que as microrrebarbas ( $\mathrm{mr}$ ) para o material GUF na mesma escala de usinagem e avanço de $18 \mu \mathrm{m} / \mathrm{z}\left(\mathrm{f}_{\mathrm{z}}>\mathrm{r}_{\mathrm{e}}\right)$.

Diferentemente do smeared material $(\mathrm{s})$, as microrebarbas $(\mathrm{mr})$ surgem quando ocorre separação entre a porção mais fina do cavaco, na região da aresta em que o ângulo de saída é fortemente negativo, devido a efeitos de escoamento lateral (Bissacco, Hansen, \& De Chiffre, 2005). Microrebarbas têm sido relatadas na microusinagem de materiais endurecidos, usinados com fresas de topo de cabeça semiesférica, devido ao seu raio de arredondamento (Bissacco, Hansen, \& De Chiffre, 2005). Ainda segundo os autores, uma porção significativa do material, correspondente a uma parcela do volume do material não removido, é deitada para o lado e à frente da aresta de corte, permanecendo ligada a superfície fresada e com aparência de rebarbas. A incidência de repasse da ferramenta (re) pode ser decorrente de desbalanceamento da microfresa, devido à aplicação de avanço por dente superior ao recomendado pelo fabricante da ferramenta. Estes defeitos foram exclusivos do material GUF no microfresamento com $\mathrm{f}_{\mathrm{z}}>\mathrm{r}_{\mathrm{e}}$.

O efeito da formação e distribuição de defeitos na superfície usinada pode ser visto no comportamento da rugosidade, através do parâmetro de superfície $S_{z}$, medido em diferentes regiões da superfície das peças usinadas. Quando a superfície é modificada por diferentes processos de fabricação, $S_{z}$ demonstra uma mudança da característica da superfície mais rápido do que $\mathrm{S}_{\mathrm{a}}$ ou $\mathrm{S}_{\mathrm{q}}$. A Figura 4.15 mostra que melhores resultados foram obtidos no micro e macrofresamento do material GUF, de acordo com a análise da distribuição estatística da barra de erros. A maior variação do parâmetro $S_{z}$ na usinagem do material CR é um indicativo da variação na formação da superfície ao longo de toda a sua 
extensão. Em comparação, o material GUF apresentou menos variação da rugosidade ao longo da superfície da peça, revelando que a formação da superfície foi mais homogênea, mesmo quando em condições de $f_{z} \approx r_{e}$.

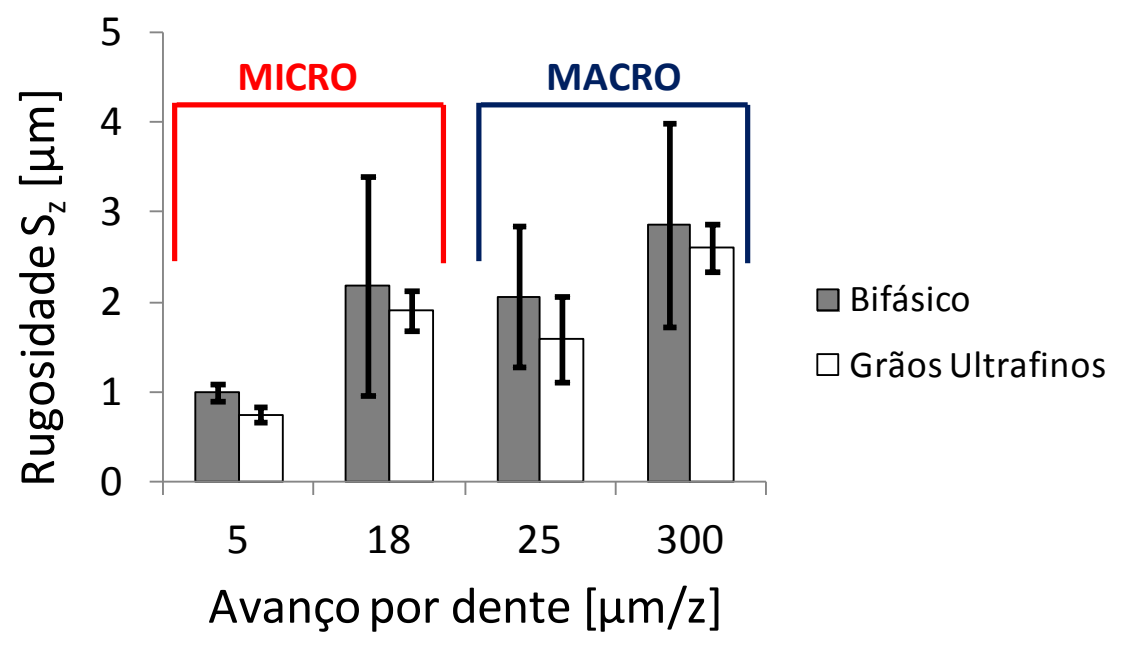

Figura 4.15 - Avaliação da formação de superfície pelo parâmetro de rugosidade $S_{z}$.

Estes resultados de rugosidade indicam que a formação da superfície não foi contínua para diferentes regiões da superfície da peça, principalmente na usinagem do material CR. No geral, o material GUF apresentou menos defeitos de superfície e subsuperfície em comparação ao material $C R$, especialmente quando usinado com avanço por dente da ordem do raio de aresta de corte. Nesta condição os efeitos de ploughing foram menos agressivos e a superfície apresentou melhor acabamento. A presença de diferentes fases na microestrutura, em particular uma fase mais dúctil e outra mais dura, apresentam um comportamento diferente durante o corte em microescala quando comparado a uma microestrutura homogênea (Popov et al., 2006).

Diferentes ângulos de cisalhamento ocorrem durante a formação de cavaco de quasicisalhamento-extrusão devido ao processo de cisalhamento da perlita e extrusão da ferrita (Simoneau, Ng, \& Elbestawi, 2006). Seguindo a constatação feita pelos autores citados, na usinagem em micro e mesoescala de um aço AISI 1045 ferrítico-perlítico, as variações no ângulo de cisalhamento durante a formação do cavaco na usinagem do material CR seriam maiores que as variações no material GUF, cujas lamelas foram justapostas. Isto de acordo com as análises da morfologia do cavaco e da superfície usinada, realizadas anteriormente 
para a condição de $f_{2} \approx r_{e}$. Um ângulo de cisalhamento constante durante o corte proporciona melhor acabamento da peça e a usinagem de materiais de fase única minimiza a recuperação elástica, favorecendo a qualidade superficial da peça (Mian, Driver, \& Mativenga, 2010).

Os valores de rugosidade $S_{z}$ quase na mesma grandeza em CR5 e GUF5, juntamente com as análises da formação de picos e vales apresentados na Figura 4.9 e Tabela 4.2, são indicativo de que há a necessidade da aplicação de outros parâmetros de rugosidade para a avaliação do acabamento na peça quando a microgeometria da aresta de corte passa a influenciar o processo de formação da superfície. Juntamente com os parâmetros aplicados neste trabalho poderiam ser associadas às análises parâmetros de rugosidade que realizassem contagem dos picos verticais e/ou ondas na horizontal do perfil. Estes parâmetros poderiam ser o $R_{s m}$ (largura média dos elementos do perfil), para medir o espaçamento médio das irregularidades do perfil, $\mathrm{R}_{\mathrm{HSC}}$ (High Spot Count), o qual determina o número de picos completos no perfil e $\mathrm{R}_{\mathrm{pc}}$ (Peak Count) para fazer a contagem de picos. Dessa forma, seria possível melhor avaliação da ocorrência de cisalhamento ou ploughing na superfície usinada da peça.

Estas mudanças na superfície e subsuperfície da peça tiveram reflexo na integridade superficial da peça. Considerando a dureza como parâmetro de avaliação indireta da resistência na superfície usinada, a Figura 4.16 apresenta o gráfico da microdureza pósusinagem comparada com a microdureza normal dos materiais. As linhas sobre as barras são para facilitar a visualização da variação da microdureza superficial. Na mesma figura também são apresentadas imagens de endentações realizadas na superfície dos materiais nas condições CR5 e GUF5 para mostrar que foram uniformes, sem deformações das bordas dos losangos, conferindo confiabilidade às medidas de dureza. 


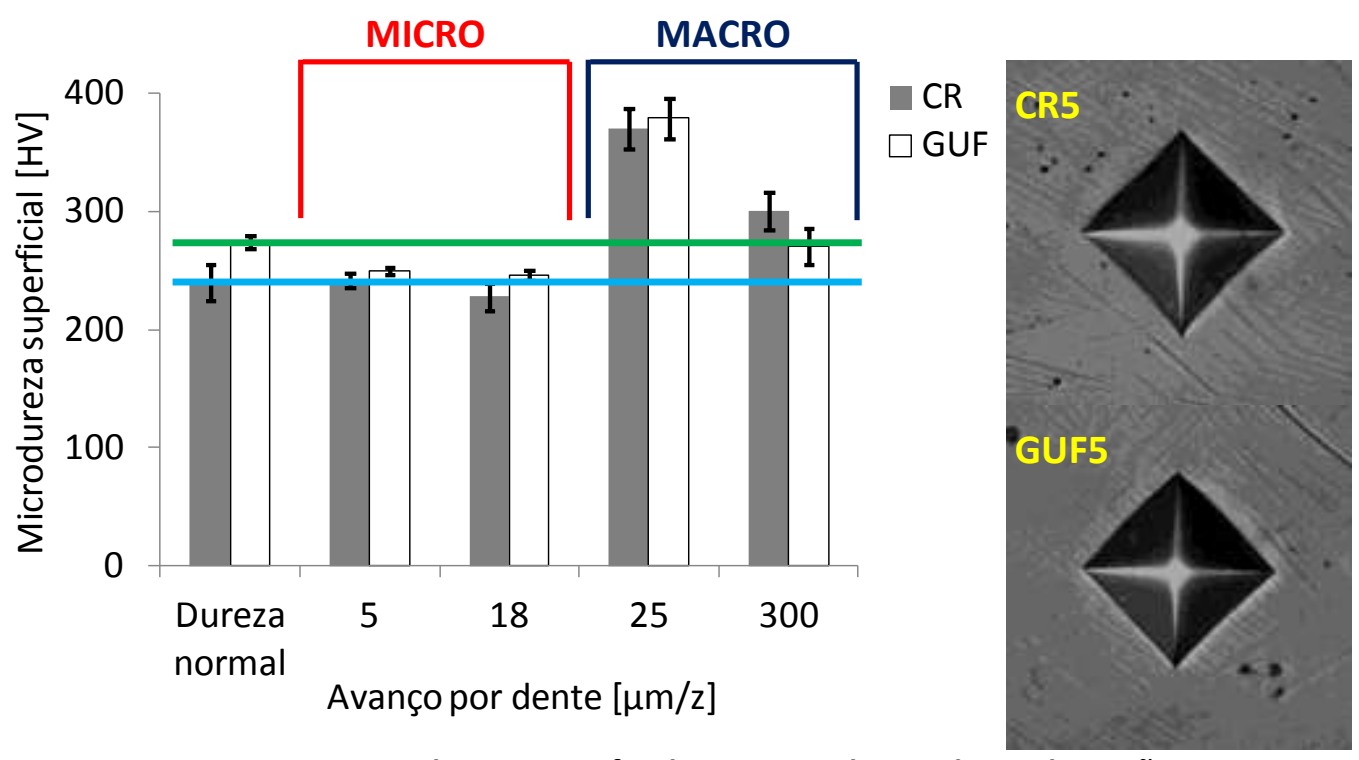

Figura 4.16 - Microdureza superficial e imagens de MO das endentações.

No microfresamento não houve variação da dureza superficial do material CR. Para o material GUF ocorreu queda na dureza superficial nas duas condições de usinagem, com redução média de $9 \%$ em relação à dureza normal do material. Entre os materiais não houve diferença estatística na dureza da superfície após a usinagem. Por outro lado, no macrofresamento, houve elevação da dureza na superfície usinada dos dois materiais para $\mathrm{f}_{\mathrm{z}} \approx \mathrm{r}_{\mathrm{e}}$, com incremento de $54 \%$ em CR25 e 38\% em GUF25. Para CR300 o aumento da dureza foi de $25 \%$, enquanto em GUF300 não ocorreu variação da dureza. Comparando os materiais, CR25 apresentou dureza equiparada à GUF25, e CR300 teve dureza ligeiramente maior que GUF300. Esta característica poderia estar associada ao fato da resistência mecânica do material GUF ser maior que a do material $C R$, dificultando o encruamento por deformação e favorecendo a integridade da peça.

Estes resultados revelaram diferentes aspectos entre as duas escalas de usinagem. Na macrousinagem, o material CR foi mais afetado pela redução da espessura de corte do que o material GUF. Isto devido à deformação dos grãos próximos à superfície do material $C R$, conforme análises da borda usinada (Figura 4.10). Na condição de $f_{z} \approx r_{e}$, a aresta gera escoamento lateral, atuando como um micro laminador na superfície da peça, aumentando o encruamento decorrente da deformação. Para CR25 a deformação foi mais acentuada, em parte pela contribuição dos fluxos de deformação distribuídos pela superfície da peça, enquanto para CR300 a deformação foi menor. Na condição de $f_{z}>r_{e} \circ$ cisalhamento foi o mecanismo predominante, gerando menor incremento de dureza. Condição semelhante foi 
relatada em outros trabalhos com materiais multifásicos e semelhantes aos utilizados nesta tese, variando-se tanto o avanço por dente quanto a velocidade de corte (Rodrigues et al., 2010; Rodrigues et al., 2012).

No microfresamento, a dureza superficial do material CR manteve-se constante com a variação do avanço por dente em relação à dureza normal do material, com amolecimento em CR18, porém o erro estatístico revela variação significativa da microdureza ao longo da superfície. A deformação da borda usinada foi diferenciada ao longo da superfície usinada da peça, contribuindo para a dispersão das medidas de microdureza. Em contrapartida, para o material GUF houve redução da dureza após o microfresamento, e para as duas condições de avanço por dente. A análise da borda usinada da Figura 4.10 não apresentou deformação aparente dos grãos, indicando que as condições de avanços por dente aplicados nos ensaios de microfresamento não afetaram a morfologia dos grãos na subsuperfície da peça.

\subsection{Microfresamento de canais}

A seguir são apresentados caracterizações feitas por MEV da base dos canais microusinados e formação de rebarbas utilizando microfresas com diâmetros de 200 e 800 $\mu \mathrm{m}$, sendo os ensaios com menor diâmetro de microfresa apenas com velocidade de rotação do eixo-árvore de 10000 rpm, e para o maior diâmetro velocidades de 10000 e 54000 rpm. Devido à fragilidade das microfresas de $200 \mu \mathrm{m}$, não foi possível realizar ensaios com 54000 rpm. Apenas para nota, na tentativa todas as microfresas quebraram ao tocar a peça, apesar de todo o controle e cuidado durante a realização dos experimentos. Todas as imagens foram obtidas no início do canal, região onde o desgaste da ferramenta ainda não influencia a formação da superfície e das rebarbas.

A análise qualitativa das imagens de superfície da Figura 4.17 revelou melhor acabamento na microusinagem com $f_{z} \geq r_{e}$ do material GUF, enquanto para $f_{z}<r_{e}$ o aspecto das superfícies foi similar, sem a presença aparente de defeitos. Para o material CR, conforme o avanço por dente aumentou, houve aumento da intensidade dos defeitos na superfície da base do canal. Os tipos de defeitos já foram identificados e explanados na secção anterior, e por essa razão não serão novamente explorados nesta secção. Os defeitos de superfície na usinagem com microfresa de $200 \mu \mathrm{m}$ tiveram origem na dificuldade de 
formação do cavaco, principalmente para o material bifásico (CR), o qual não se formou completamente pelo processo de cisalhamento, gerando rebarbas na lateral superior dos canais, conforme será visto adiante na análise sobre formação de rebarbas da Figura 4.18.

Na condição de $f_{z}>r_{e}$ da Figura 4.17 foi também observado a impressão da ferramenta na superfície da peça como sendo um cicloide alongado (Kaczmarek, 1976). Esse efeito ocorre devido à excentricidade da ferramenta, inclinação do eixo árvore, deterioração dos dentes da microfresa e flexões elásticas do sistema máquina-ferramenta-peça (Li, Liu, \& Li, 2001). Neste trabalho, esse efeito foi acentuado pelo aumento do avanço por dente, e verificado apenas no microfresamento com as microfresas de $200 \mu \mathrm{m}$ de diâmetro. 0 aumento do avanço por dente incorre no aumento da força de usinagem, favorecendo estes efeitos e consequente alteração do acabamento da peça (Li, Liu, \& Li, 2001).

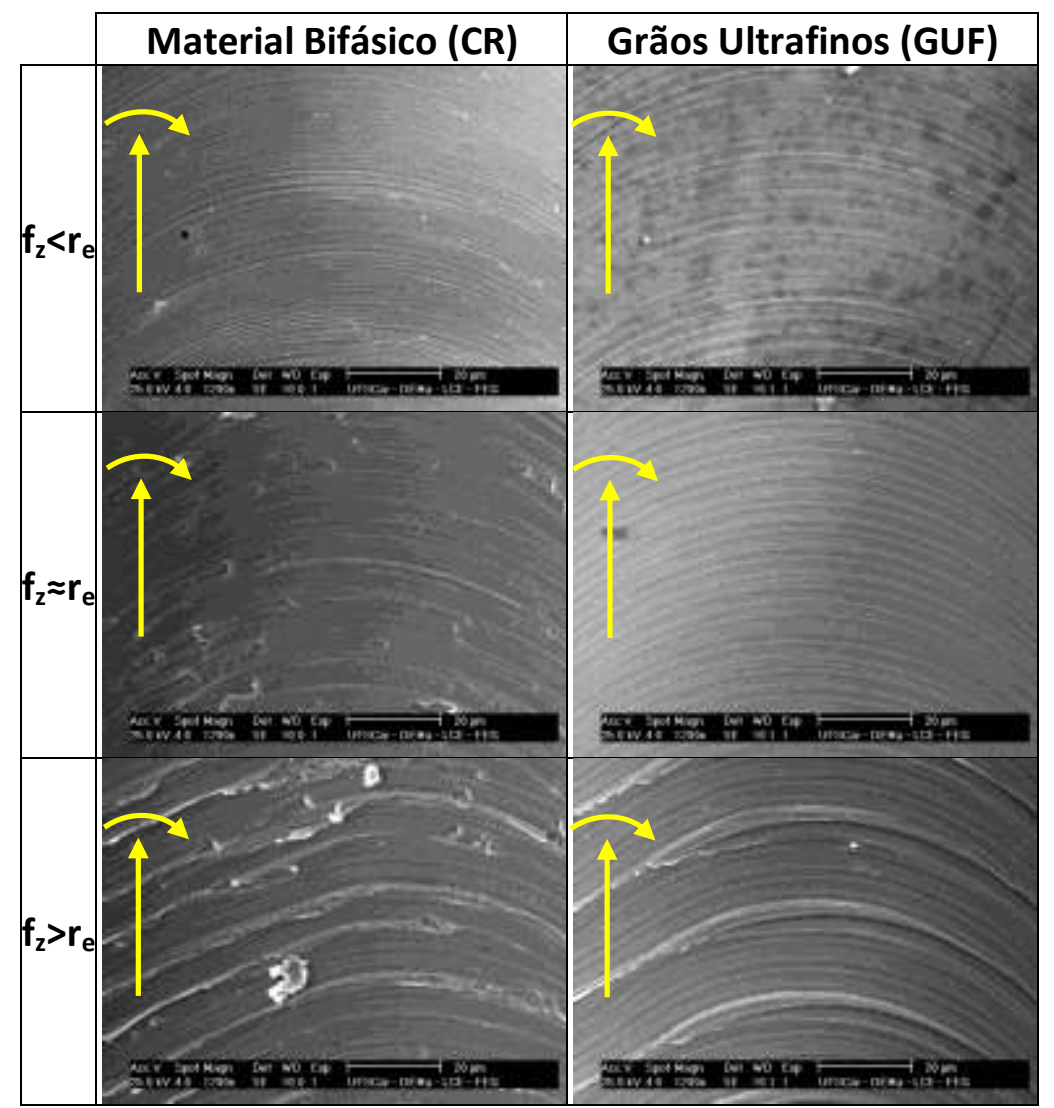

Figura 4.17 - Imagens de MEV da superfície da base dos canais para microfresa de $\mathbf{2 0 0}$ นm de diâmetro e $10000 \mathrm{rpm}$. As setas indicam a direção da velocidade de avanço e de rotação da ferramenta.

A Figura 4.18 apresenta imagens de MEV do topo da lateral dos canais microfresados. Numa análise qualitativa, a formação de rebarbas foi mais intensa no lado correspondente a 
saída da aresta de corte para ambos os materiais, mantendo-se uniforme independente do avanço por dente no material CR, enquanto para o material GUF o incremento de avanço por dente gerou rebarbas menores. Para todas as condições a formação de rebarbas foi constante ao longo do comprimento de corte. Comparativamente, o material GUF apresentou maiores rebarbas na condição de $\mathrm{f}_{\mathrm{z}}<\mathrm{r}_{\mathrm{e}}$. Para ambos os materiais o mecanismo de remoção de material observado foi ploughing do material da peça à frente da aresta da ferramenta, a qual empurrou material da peça para as laterais do canal.

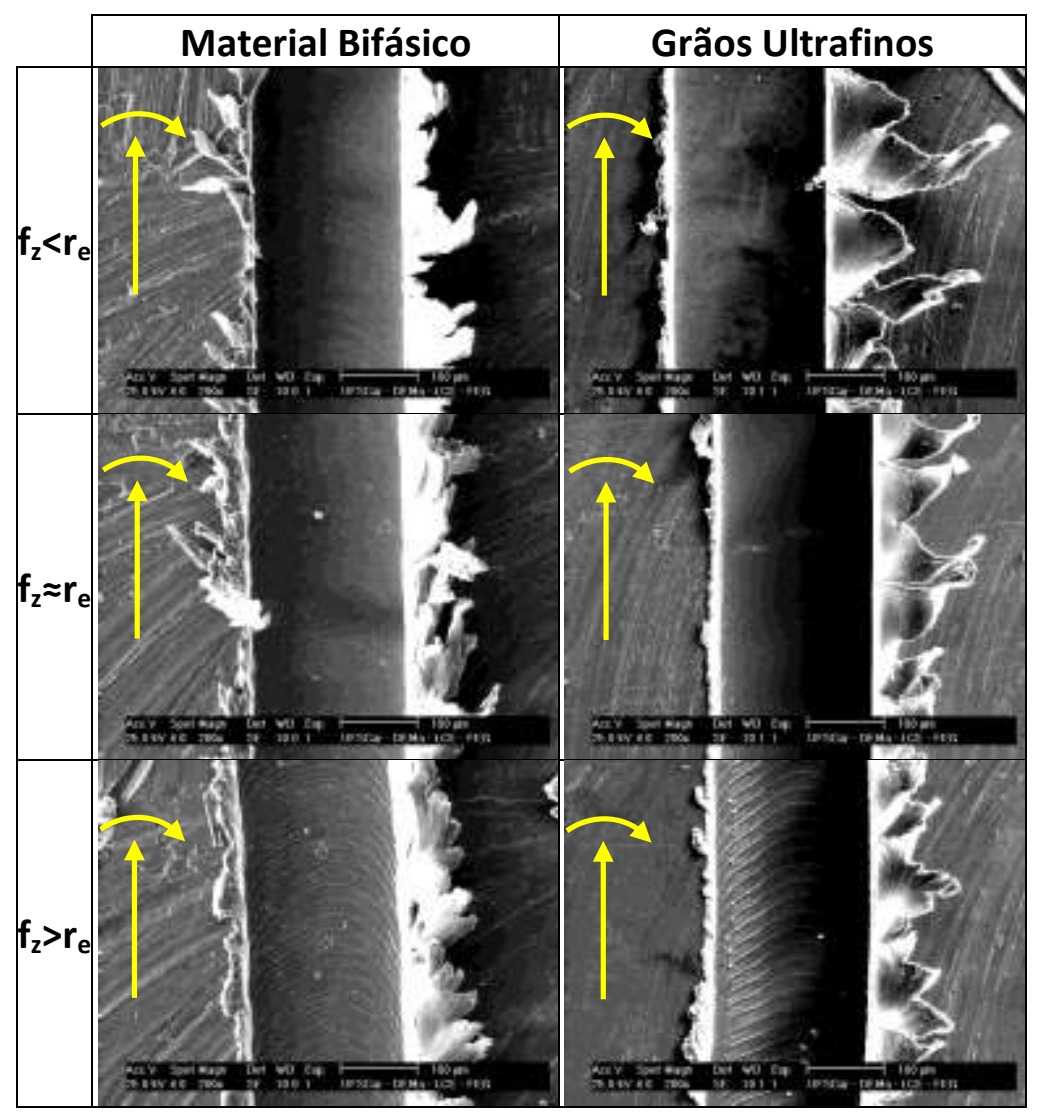

Figura 4.18 - Imagens de MEV das rebarbas para microfresa de $200 \mu \mathrm{m}$ de diâmetro e $10000 \mathrm{rpm}$. As setas indicam a direção da velocidade de avanço e de rotação da ferramenta.

A maior resistência à deformação apresentada pelo material GUF está refletida no tamanho das rebarbas observado na Figura 4.18. Sendo as rebarbas, no lado de entrada da aresta cortante, menores para o material GUF, é possível inferir que a espessura mínima de corte do material GUF é menor que a do material $C R$, gerando menor quantidade de material a ser empurrado para o topo da lateral do canal no lado de entrada da aresta cortante. Com o material GUF sendo rompido antecipadamente ao rompimento do material $\mathrm{CR}$, há maior porção de material sendo empurrada para o topo da lateral de saída da aresta 
cortante, formando rebarbas maiores. A presença de diferentes fases com diferentes durezas na microestrutura do material da peça contribuem para diferentes valores de mínima espessura de corte, alterando o mecanismo de formação de cavaco e causando danos à superfície usinada em comparação a um material homogêneo (Vogler, DeVor, \& Kapoor, 2004).

Com o aumento do diâmetro da ferramenta e mesma rotação do eixo árvore (10000 rpm), a Figura 4.19 apresenta o mesmo aspecto qualitativo observado na análise anterior. Da mesma forma, o material CR apresentou danos na superfície da base do canal, no entanto, diferentemente da Figura 4.18, na condição de $f_{z}<r_{e}$, o material CR apresentou defeitos na superfície da base do canal.

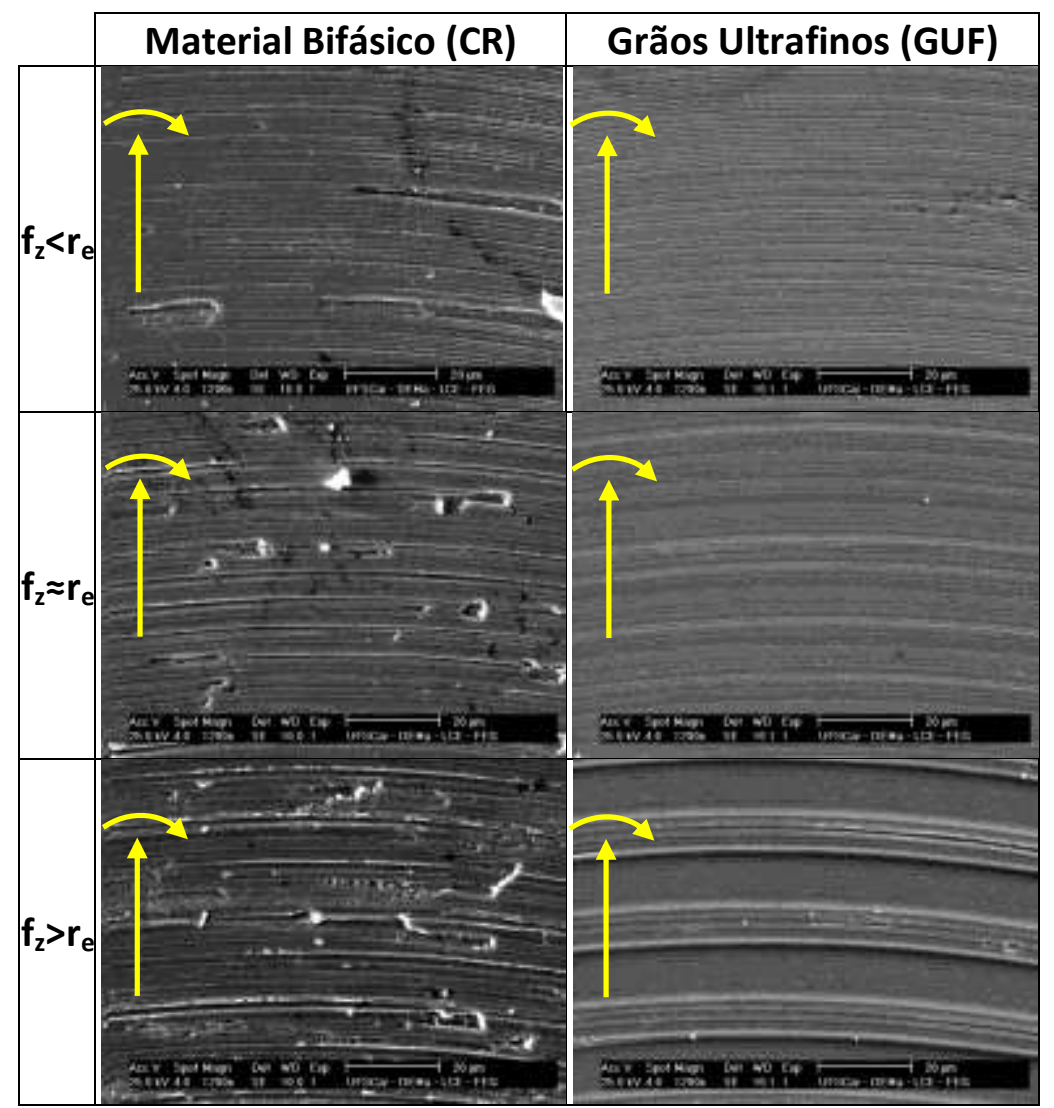

Figura 4.19 - Imagens de MEV da superfície da base dos canais para microfresa de 800 um de diâmetro e $10000 \mathrm{rpm}$. As setas indicam a direção da velocidade de avanço e de rotação da ferramenta.

A Figura 4.20 apresenta imagens de MEV do topo da lateral dos canais microfresados. Numa análise qualitativa, o incremento de avanço por dente favoreceu a redução das rebarbas em ambos os materiais, porém para o material $C R$ as rebarbas formaram-se em maior quantidade e tamanho no lado de entrada da aresta de corte. Por outro lado, para o 
material GUF, as rebarbas foram maiores e mais largas e em igual proporção para os dois lados do canal.

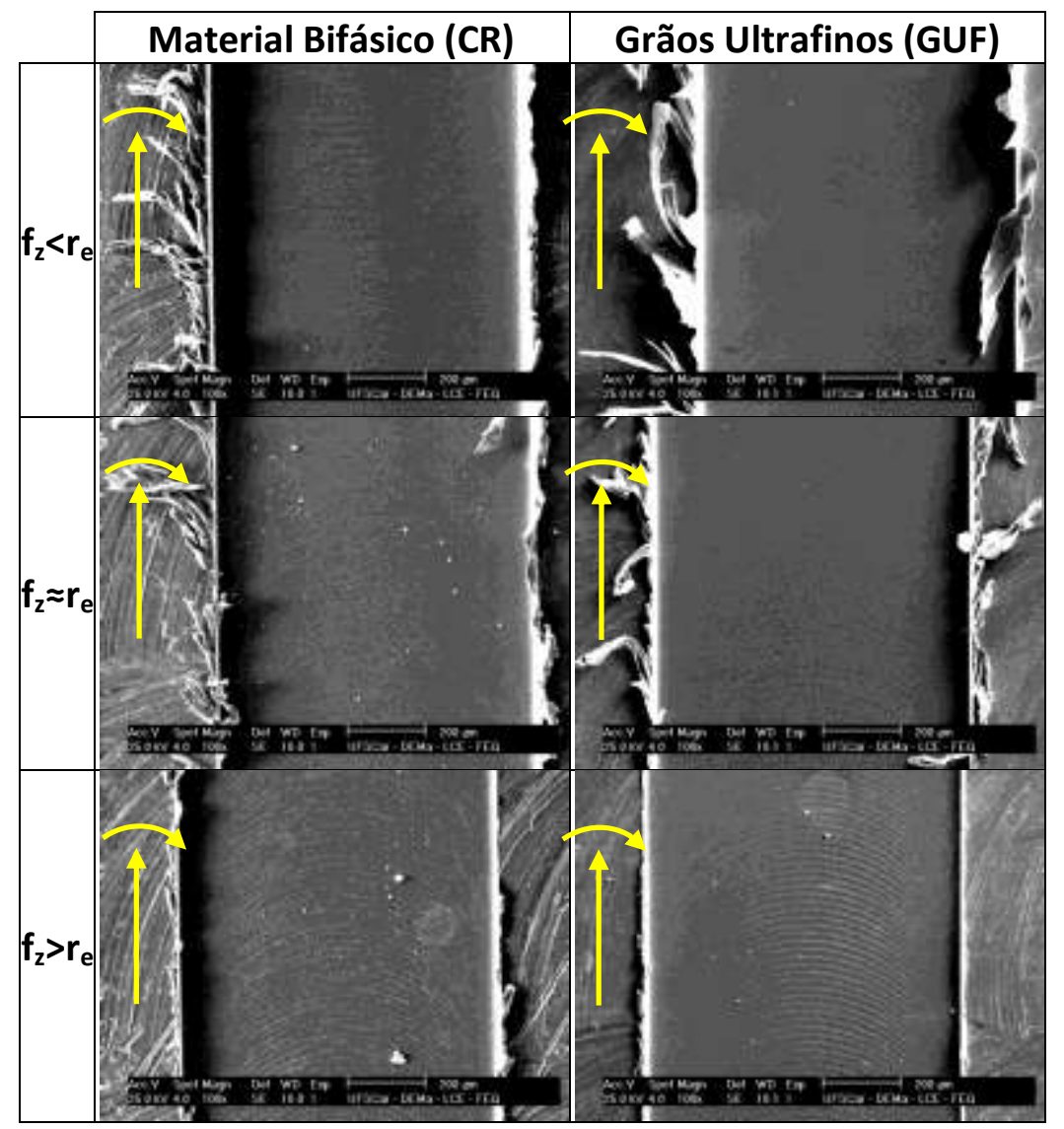

Figura 4.20 - Imagens de MEV das rebarbas para microfresa de $800 \mu \mathrm{m}$ de diâmetro e 10000 rpm. As setas indicam a direção da velocidade de avanço e de rotação da ferramenta.

É conhecido que o aumento da dureza do material da peça tende a direcionar a formação de rebarbas maiores no lado de saída da aresta de corte devido à redução da mínima espessura de corte (Li \& Chou, 2010). No entanto, as características apresentadas pelas rebarbas do material GUF na condição de $f_{z}<r_{e}$ da Figura 4.20 revelam que houve rompimento de material a frente da ferramenta, aproximadamente no meio do canal. Quando a microfresa não consegue produzir cavaco após a entrada da aresta de corte na peça, um amassamento de material ocorre.

O material a frente da ferramenta é empurrado e deformado plasticamente, e uma fratura ocorre aproximadamente no meio do canal, formando rebarbas com comprimento de cerca de metade do diâmetro da microfresa (Chern et al., 2007). No material CR, para a mesma condição de avanço por dente, o cisalhamento ocorreu após a aresta de corte atingir 
a mínima espessura de corte, convertendo uma parcela do material a frente da ferramenta em rebarbas na entrada da aresta de corte e a parcela restante em cavaco.

Esta característica da formação das rebarbas na condição de $f_{z}<r_{e}$ para ambos os materiais é condizente com a formação de superfície verificada na Figura 4.19. A presença de defeitos (desprendimento de material da peça) no material CR é relacionada à má formação do cavaco, sendo indicativo de efeitos mútuos de mínima espessura de corte e cisalhamento parcial do material na peça na passagem da ferramenta.

A Figura 4.21 apresenta imagens de MEV das superfícies da base dos canais para a velocidade de rotação de eixo-árvore de 54000 rpm e ferramenta com diâmetro de $800 \mu \mathrm{m}$. Para a condição de $f_{z} \geq r_{e}$, o material $C R$ apresentou danos na superfície microfresada, enquanto no material GUF foram observadas microrrebarbas direcionadas no sentido contrário ao do avanço da ferramenta. Na condição de $\mathrm{f}_{\mathrm{z}}<\mathrm{r}_{\mathrm{e}}$ as superfícies apresentam aspecto semelhante e sem defeitos aparentes.

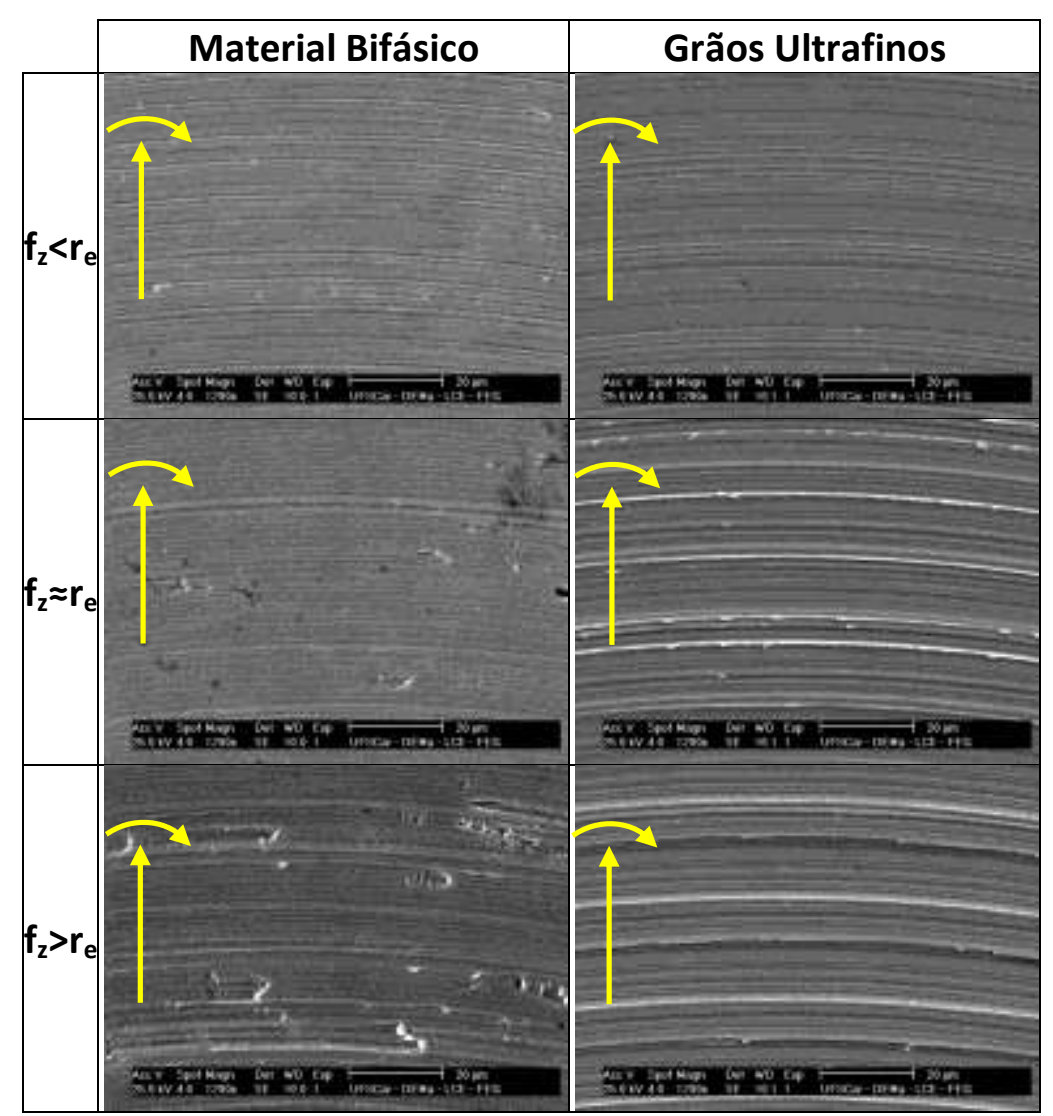

Figura 4.21 - Imagens de MEV da superfície da base dos canais para microfresa de 800 um de diâmetro e $54000 \mathrm{rpm}$. As setas indicam a direção da velocidade de avanço e de rotação da ferramenta. 
A Figura 4.22 apresenta imagens de MEV do topo da lateral dos canais microfresados com velocidade de rotação do eixo-árvore de 54000 rpm e diâmetro da ferramenta de 800 $\mu \mathrm{m}$. Comparando os materiais, o material GUF apresentou menor formação de rebarbas em ambos os lados do canal e para todas as condições de avanço por dente. Diferentemente do verificado no microfresamento com 10000 rpm da Figura 4.20, rebarbas com forma de pena foram produzidas no microfresamento com $54000 \mathrm{rpm}$. Geralmente esta forma de rebarba surge quando ocorre fratura na rebarba primária durante o processo de microfresamento e são geralmente encontradas no lado de entrada da aresta de corte (Chern et al., 2007). O aumento da resistência à deformação devido ao aumento da velocidade de corte antecipou a fratura do material à frente da ferramenta, favorecendo a formação desta forma de rebarba. No lado oposto as rebarbas tenderam a ser removidas devido à ocorrência de cisalhamento e consequente formação de cavaco.

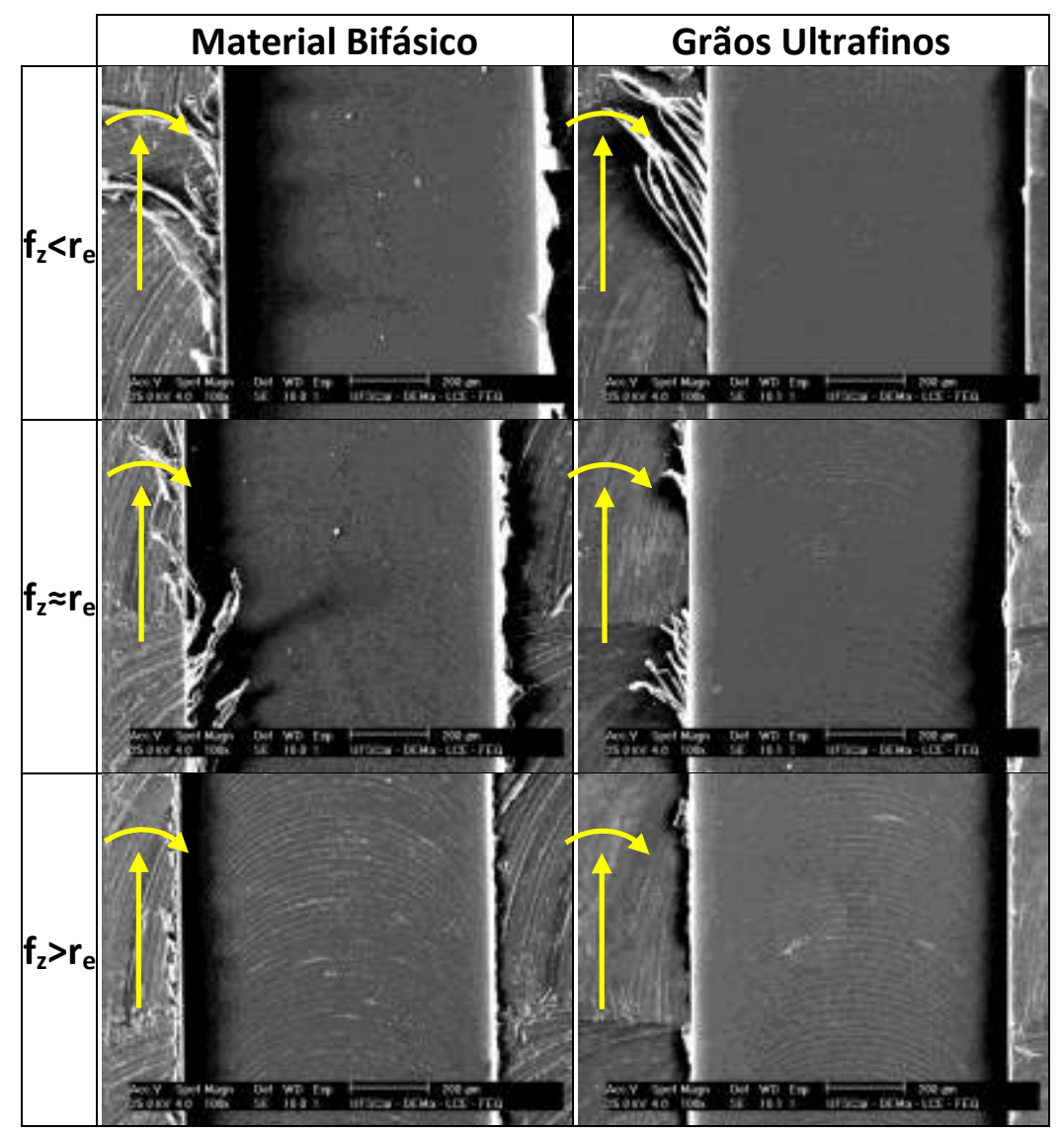

Figura 4.22 - Imagens de MEV das rebarbas para microfresa de $800 \mu \mathrm{m}$ de diâmetro e $54000 \mathrm{rpm}$. As setas indicam a direção da velocidade de avanço e de rotação da ferramenta. 
Para complemento destes resultados de acabamento, a Figura 4.23 apresenta o comportamento da rugosidade $S_{a}$ medida na superfície da base dos canais. A escolha do parâmetro $S_{a}$ para quantificar o acabamento das superfícies usinadas visou facilitar comparações com a literatura. O gráfico da Figura 4.23a revela o comportamento da rugosidade $S_{a}$ considerando microfresas de 200 e $800 \mu \mathrm{m}$ de diâmetro e velocidade de rotação do eixo-árvore de $10000 \mathrm{rpm}$. De acordo com a análise do gráfico, a rugosidade aumentou em ambos os materiais de acordo com o incremento de avanço por dente, sendo este aumento mais expressivo no material GUF para microfresa de $200 \mu \mathrm{m}$. O material GUF microusinado com microfresa de $800 \mu \mathrm{m}$, apresentou menor rugosidade dentre todas as condições. Para ambos os materiais, as microfresas de $800 \mu \mathrm{m}$ apresentaram menor rugosidade em comparação as microfresas de $200 \mu \mathrm{m}$.

Diferentemente do trabalho de Aramcharoen e Mativenga (2009) com aço endurecido e Vogler, DeVor e Kapoor (2004) na microusinagem de aço ferrítico-perlítico, a rugosidade foi crescente com o aumento de $f_{z}$ para as condições apresentadas pelos gráficos da Figura 4.23. A variação da rugosidade no microfresamento com microfresas de $200 \mu \mathrm{m}$, observada na Figura 4.23a, revelou comportamento distinto entre os dois materiais. Enquanto o material CR apresentou aumento quase linear e expressivo da rugosidade, no material GUF a elevação acentuada da rugosidade ocorreu apenas quando o avanço por dente passou a ser maior que o raio de aresta de corte. Para ambos os diâmetros de microfresa, o material GUF apresentou o mesmo comportamento da rugosidade com a variação do avanço por dente.

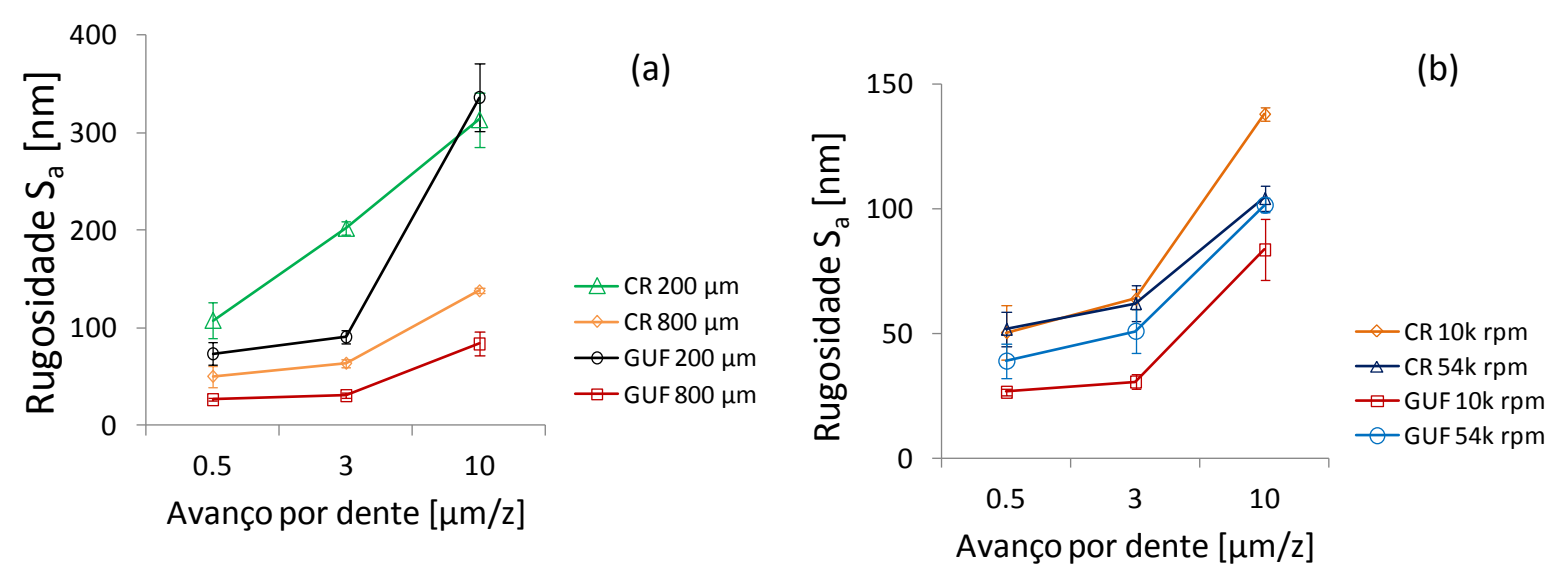

Figura 4.23 - Rugosidade média Sa para (a) microfresas de diferentes diâmetros e rotação do eixo árvore de 10000 rpm e (b) microfresas de diâmetro de $800 \mu \mathrm{m}$ e rotação do eixo-árvore de 54000 rpm. 
Os resultados apresentados na Figura 4.23a sustentam as hipóteses feitas nas análises das imagens de MEV das superfícies microfresadas e rebarbas para microfresas com diferentes diâmetros e mesma rotação do eixo-árvore. Com o aumento do diâmetro da ferramenta, o cisalhamento passa a ser o mecanismo de remoção de material preponderante, com formação de cavaco e respectiva redução da formação de rebarbas no lado de saída da aresta de corte, com melhora do acabamento da base do canal, enquanto para as microfresas de menor diâmetro o mecanismo preponderante é o de deformação plástica e fratura.

O gráfico da Figura 4.23b corresponde ao comportamento da rugosidade $\mathrm{S}_{\mathrm{a}}$ com a variação da velocidade de rotação do eixo-árvore e mesmo diâmetro das microfresas (800 $\mu \mathrm{m})$. Conforme observado, a rugosidade aumentou em ambos os materiais de acordo com o incremento de avanço por dente, sendo este aumento mais expressivo no material CR para a rotação de $10000 \mathrm{rpm}$. O material GUF, para a rotação de $10000 \mathrm{rpm}$, teve melhor acabamento em comparação a todas as outras condições. Por outro lado o aumento da velocidade de corte prejudicou o acabamento da base do canal. Para o material CR o aumento da velocidade de corte surtiu efeito significativo na rugosidade apenas no avanço de $10 \mu \mathrm{m} / \mathrm{z}$.

Em operações de microusinagem o mecanismo de corte é diferente do tradicional. Devido às baixas velocidades de corte empregadas, a aresta de corte falha em remover material por cisalhamento e o efeito de ploughing prevalece (Chern et al., 2007). No entanto, a microestrutura do material GUF não gerou defeitos aparentes na superfície da base dos canais e o amassamento do material da peça com a passagem da ferramenta resultou em uma superfície com menor rugosidade, enquanto no aumento da velocidade de corte o material passou a ser removido por cisalhamento. Fato este verificado pela redução das rebarbas no lado de saída da aresta de corte (Figura 4.22). Estas diferenças na formação da superfície da base dos canais resultaram no melhor acabamento do material GUF, verificado no microfresamento com menor velocidade de corte.

Esta hipótese pode ser avaliada com a análise da Figura 4.24, através das imagens em 3D das superfícies da base dos canais do material GUF e dos parâmetros de rugosidade skewness, kurtosis e $\mathrm{S}_{\mathrm{z}}$, no microfresamento com microfresa de $800 \mu \mathrm{m}$ de diâmetro na condição de $\mathrm{f}_{\mathrm{z}} \approx \mathrm{r}_{\mathrm{e}}$. $\mathrm{O}$ parâmetro de rugosidade skewness indica maior preponderância de 
vales $\left(S_{s k}<0\right)$ no microfresamento com $10000 \mathrm{rpm}$ e formação simétrica da superfície $\left(S_{s k} \approx 0\right)$ no microfresamento com 54000 rpm. Além disso, a natureza da distribuição das elevações (kurtosis), indica distribuição normal (curva de sino) no microfresamento com 54000 rpm $\left(S_{\mathrm{ku}} \approx 3\right)$, característica típica de superfícies usinadas geradas por cisalhamento. Esta diferença na formação da superfície causou menor rugosidade no microfresamento com 10000 rpm, conforme análise do parâmetro $S_{z}$, o qual foi de 431 nm com 10000 rpm e 732 nm com 54000 rpm de rotação do eixo-árvore.

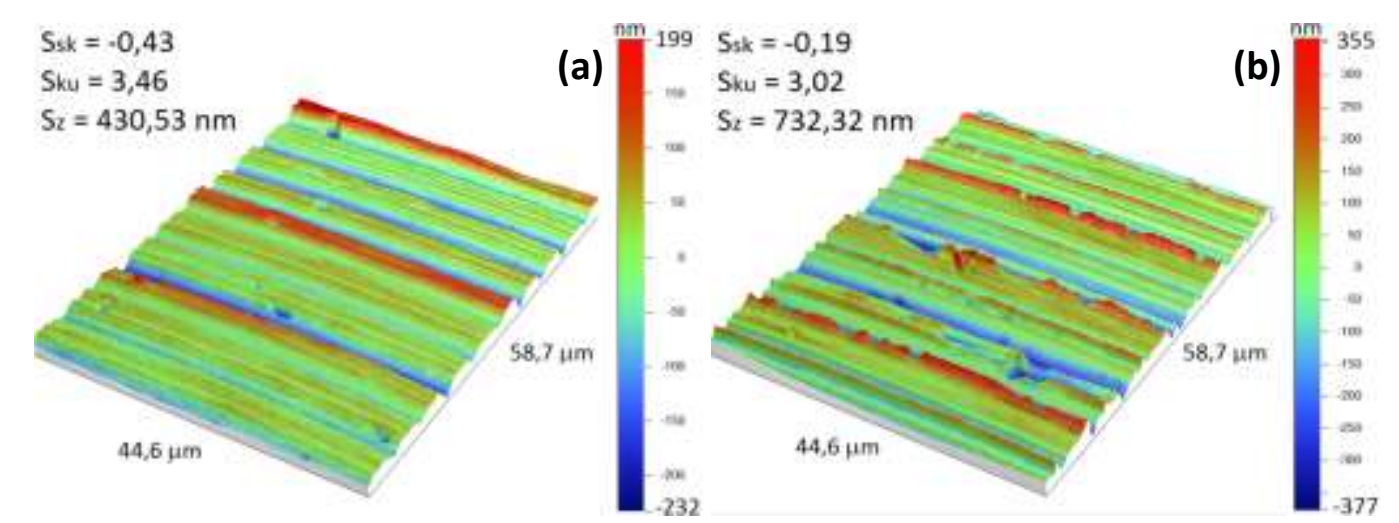

Figura 4.24 - Imagens em 3D das superfícies da base dos canais do material GUF microfresados com ferramentas de $800 \mu \mathrm{m}$ de diâmetro na condição de $f_{z} \approx r_{e}$, e velocidades de rotação do eixo-árvore de 10000 rpm em (a) e 54000 rpm em (b).

Com a redução do volume de material a ser removido, efeitos decorrentes da presença de uma segunda fase mais dura na microestrutura do material (perlita), além da influência de contornos de grão e precipitados, alteram o processo de corte, na medida em que a espessura de corte encontra-se na mesma dimensão do tamanho médio de grão do material. O material com grãos ultrafinos continuou a apresentar o mesmo comportamento da rugosidade, independe da redução do diâmetro das microfresas, ou seja, a homogeneidade da microestrutura e o tamanho reduzido dos grãos favoreceu a usinagem com a redução da escala de usinagem.

As análises realizadas até este ponto contribuem para a hipótese de que a homogeneização e refino de grão da microestrutura é um caminho viável para a adequação de materiais para a fabricação de componentes em microescala. A formação de defeitos foi substancialmente menor na microusinagem de canais no material GUF. Além disso, o aumento da velocidade de corte não se mostrou eficiente para melhora da qualidade no acabamento da peça no material GUF, apesar de ter favorecido o cisalhamento como 
mecanismo de remoção de material. Dessa forma, ao invés de viabilizar maiores velocidades de rotação do eixo árvore para sanar problemas de acabamento da peça na microusinagem, a intervenção metalúrgica na microestrutura do material seria uma alternativa para usinagens com baixas velocidades de corte.

Em microusinagem de canais, na entrada da aresta de corte (corte discordante), a espessura do cavaco é zero e cresce até atingir uma espessura mínima de corte. Até chegar neste ponto o material é comprimido, prensado e empurrado para o topo da lateral do canal (Lekkala et al., 2011). Após este estágio o cisalhamento acontece. De forma contrária, na saída da ferramenta, o material continua o cisalhamento até atingir novamente uma espessura mínima de corte, ponto do qual o material é empurrado para uma direção de menor resistência (Biermann \& Steiner, 2012). Para condições de $f_{z}>r_{e}$, a espessura mínima de corte diminui com o aumento do avanço por dente, reduzindo as rebarbas formadas na saída da aresta de corte (Jin et al., 2009). Este fenômeno ocorreu no microfresamento com microfresas de $800 \mu \mathrm{m}$, e foi beneficiado com o aumento da velocidade de corte na microusinagem do material GUF.

A formação de rebarbas diminui com o aumento do ângulo de saída da ferramenta no microfresamento (Aramcharoen et al., 2008; Saptaji, Subbiah, \& Dhupia, 2012). No entanto, com a redução do diâmetro da microfresa, este fenômeno não foi observado. Independente da condição de avanço por dente ser inferior, equivalente ou maior que o raio de aresta da ferramenta (diferentes ângulos de saída efetivos), as rebardas continuaram a se formar na mesma proporção para os dois materiais, em particular na saída da aresta de corte.

A espessura de corte foi muito pequena, mesmo no avanço de $10 \mu \mathrm{m} / \mathrm{z}$, levando a hipótese de aumento do atrito e alta deformação na porção de material próxima a aresta de corte. O aumento do atrito e da deformação plástica com a redução da espessura de corte tem sido estudado por outros pesquisadores e corroboram com esta análise (Madhavan, Chandrasekar, \& Farris, 2002; Saptaji, Subbiah, \& Dhupia, 2012).

Para melhor compreensão, a Figura 4.25 apresenta esquematicamente a formação de rebarbas na usinagem com microfresas de $200 \mu \mathrm{m}$ de diâmetro utilizadas neste trabalho. Nesta condição, a ferramenta penetra a peça aumentando o encruamento por deformação à frente da ferramenta em (a) e causando fratura, conforme visto em (b). Neste instante a ferramenta passa a remover material à frente da ferramenta por deformação plástica em (c), 
e empurra o material para o topo da lateral do canal em (d) (Chern et al., 2007). O material que deveria ser removido na forma de cavaco é na maior parte e/ou totalmente convertido em rebarbas. Esta característica das rebarbas pode ser claramente observada na Figura 4.18.

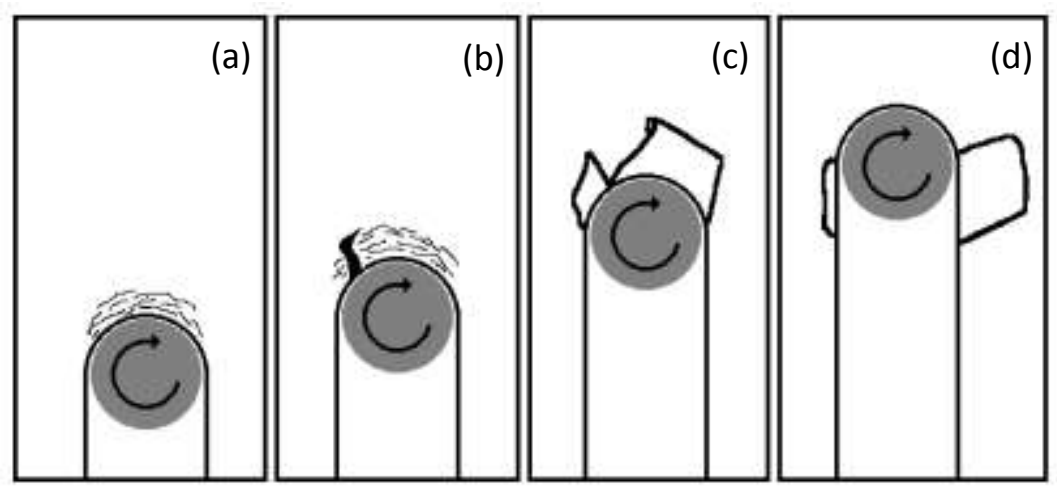

Figura 4.25 - Formação de rebarbas na usinagem com microfresa de $200 \mu \mathrm{m}$. (a) deformação, (b) fratura, (c) remoção do material e (d) rebarbas na lateral do canal. As setas circulares indicam o sentido de giro da microfresa. A direção do avanço da ferramenta é de baixo para cima.

Com a redução do diâmetro da microfresa, o material GUF apresentou melhores resultados em condição de avanço por dente da ordem ou inferior ao raio de aresta da ferramenta $\left(\mathrm{f}_{z} \leq \mathrm{r}_{\mathrm{e}}\right)$. O aumento da velocidade de corte favoreceu a redução da formação de rebarbas. Na redução do diâmetro da ferramenta, os efeitos do aumento do atrito e da alta deformação da porção de material à frente da aresta de corte poderiam ser minimizados aplicando maiores velocidades de corte. No aumento da velocidade de corte a resistência contra a deformação plástica é maior, favorecendo o cisalhamento (Biermann \& Steiner, 2012).

Contudo, velocidades de corte muito altas aumentariam substancialmente a resistência à deformação plástica. Nessa condição, o material é prensado por uma maior extensão durante o processo de corte, em seguida o material seria empurrado para o topo do canal, formando rebarbas mais altas. No endurecimento do material, a formação de rebarbas é maior que em materiais mais dúcteis, e o desgaste da ferramenta também é maior, podendo causar à quebra da ferramenta, devido ao aumento da força durante a usinagem (Schaller et al., 1999; Schmidt \& Tritschler, 2004). 


\section{Capítulo 5}

\section{CONCLUSÕES}

Um aço baixo-carbono bifásico (ferrita-perlita) passou por processamento termomecânico para homogeneização e refino dos grãos da microestrutura. Ensaios de macro e microfresamento foram realizados em ambas as condições metalúrgicas. $\mathrm{O}$ avanço por dente foi o parâmetro de controle nos ensaios, considerando raio de aresta constante da ferramenta. Superfície usinada, mecanismo de formação de cavaco e rebarbas foram avaliados visando verificar os efeitos da mudança de escala macro para micro de usinagem. No microfresamento de canais, a velocidade de corte, o avanço por dente e diâmetro das microfresas foram os parâmetros de controle. Com base na análise dos resultados e da literatura, as principais conclusões são apresentadas a seguir:

- Apesar dos parâmetros de usinagem não serem todos proporcionais, e a geometria do corte possuir diferenças entre as duas escalas de usinagem, ainda assim foi possível verificar efeitos semelhantes e as diferenças mais significativas na mudança de escala de macro para micro de usinagem;

- O material GUF apresentou melhor acabamento $\left(S_{s k} \approx 0\right.$ e $\left.S_{k u} \approx 3\right)$ e resistência à deformação. Os parâmetros e rugosidade skewness e kurtosis revelaram maior formação de vales no material $C R$, relacionada a cavidades e fluxos plásticos na superfície usinada;

- Na macrousinagem com $f_{z} \approx r_{e}$ a microdureza superficial aumentou em $54 \%$ no material CR e 38\% no GUF (esperado). Na microusinagem houve redução de $9 \%$ na dureza. Possível relação com efeitos térmicos que devem ser melhor estudados;

- Na redução da espessura de corte houve variação do grau de recalque ao longo da extensão do cavaco de ambos os materiais (cerca de 5 para 2,5);

- Para $f_{z} \approx r_{e}$ ocorreu mudança no mecanismo de formação de cavaco do material $C R$;

- O material GUF apresentou menor formação de rebarbas no lado de entrada da aresta de corte no microfresamento com menor diâmetro de ferramenta ( $200 \mu \mathrm{m})$ e 
também com o aumento da velocidade de corte no microfresamento com ferramentas de $800 \mu \mathrm{m}$ de diâmetro.

\section{Sugestões para pesquisas futuras}

Esta tese de doutorado revelou novos aspectos e interpretações relacionados ao efeito da microestrutura do material da peça na microusinagem, considerando parâmetros de usinagem, geometria e dimensão da ferramenta. Com base nas análises foi possível propor a seguir, sugestões para outros projetos, estreitamente relacionados a esta pesquisa:

- Realizar a análise dos sinais de força na redução da escala de usinagem e posterior cálculo da energia específica de corte como parâmetro de avaliação do processo de corte;

- Estudos dinâmicos na interação máquina-ferramenta-peça, com propósito de minimizar a interferência do centro de usinagem no acabamento da peça, e a relação destes efeitos dinâmicos com a microestrutura da peça;

- Determinar um ou mais parâmetros de rugosidade que sejam mais adequados para avaliação do acabamento de peças usinadas com espessuras de corte inferiores a dimensão do raio de aresta;

- Realizar a usinagem do material com grãos ultrafinos com microfresas de diâmetros ainda menores que as utilizadas neste trabalho. Determinar se com reduções ainda mais severas da escala de usinagem, o material passaria a apresentar características heterogêneas durante o corte;

- Avaliar o desgaste e gerar curvas de desgaste para microfresas, visando estimar o comprimento ideal de corte na usinagem de microcanais. 


\section{REFERÊNCIAS}

Aramcharoen et al., A. (2008). Evaluation and selection of hard coatings for micro milling of hardened tool steel. International Journal of Machine Tools \& Manufacture , 48, pp. 15781584.

Aramcharoen, A., \& Mativenga, P. T. (2009). Size effect and tool geometry in micromilling of tool steel. Precision Engineering , 33, pp. 402-407.

Bailey, J. A. (1977). Surface damage during machining of annealed $18 \%$ nickel maragine steel. Wear, 42, pp. 277-296.

Bernardos, P. G., \& Vosniakos, G. C. (2003). Predicting surface roughness in machining: a review. International Journal of Machine Tools \& Manufacture , 43, pp. 833-844.

Biermann, D., \& Steiner, M. (2012). Analysis of Micro Burr Formation in Austenitic Stainless Steel X5CrNi18-10. 45th CIRP Conference on Manufacturing Systems 2012, 3, pp. 97-102.

Bissacco, G., Hansen, H. N., \& De Chiffre, L. (2005). Micromilling of hardened tool steel for mould making applications. Journal of Materials Processing Technology , 167, pp. 201-207.

Bissacco, G., Hansen, H. N., \& De Chiffre, L. (2006). Size effects on surface generation in micro milling of hardened tool steel. Annals of the CIRP, 55, pp. 593-596.

Black, J. T. (1972). Shear front-lamella structure in large strain plastic deformation processes. Journal of Engineering for Industry, 94, pp. 307-313.

Brown, R. H., \& Armarego, E. J. (1964). Oblique machining with a single cutting edge. International Journal of Machine Tool Design and Research , 4, pp. 9-25.

Callister, W. D. (2008). Ciência e engenharia de materiais: uma introdução. Rio de Janeiro: LTC .

Câmara et al., M. A. (2012). State of the art on micromilling of materials, a review. Journal of Materials Science \& Technology , 28, pp. 673-685.

Chae, J., Park, S. S., \& Freiheit, T. (2006). Investigation of micro-cutting operations. International Journal of Machine Tools \& Manufacture , 46, pp. 313-332.

Chern et al., G. (2007). Study on burr formation in micro-machining using micro-tools fabricated by micro-EDM. Precision Engineering , 31, pp. 122-129.

Chern, G. L. (1993). Analysis of burr formation and breakout in metal cutting. Ph.D. Thesis, University of California at Berkeley, Berkeley. 
Cuba Ramos et al., A. (2012). Characterization of the transition from ploughing to cutting in micro machining and evaluation of the minimum thickness of cut. Journal of Materials Processing Technology, 212, pp. 594-600.

Davies, M. A., Buns, T. J., \& Evans, C. J. (1997). On the dynamics of chip formation in machining hard metals. Annals of the CIRP, 46, pp. 25-30.

Davim, J. P. (2010). Surface integrity in machining. New York: Springer.

Daymi, A. (2011). Surface integrity in high speed end milling of titanium alloy Ti-6Al-4V. Materails Science and Technology , 27, pp. 387-394.

Dimov et al., S. (2004). Micromilling strategies: optimization issues. Journal of Engineering Manufacture, 218, pp. 731-736.

Ding, H., Shen, N., \& Shin, Y. C. (2012). Thermal and mechanical modeling analysis of laserassisted micro-milling of difficult-to-machine alloys. Journal of Materials Processing Technology, 212, pp. 601-613.

Dornfeld et al., D. (2009). Burrs - analysis, control and removal. In J. C. Aurich, \& D. Dornfeld (Ed.), Proceedings of the CIRP International Conference on Burrs (p. 254). Springer.

Dornfeld, D., Min, S., \& Takeuchi, Y. (2006). Recent advances in mechanical micromachining. Annals of the CIRP, 55, pp. 745-768.

Enahoro, H. E., \& Oxley, P. L. (1961). An investigation of the transition from a continuous to a discontinuous chip in orthogonal machining. International Journal of Mechanical Sciences, 3, pp. 145-156.

Fang, N. (2003). Slip-line modeling of machining with a rounded-edge tool - Part II: analysis of the size effect and the shear strain-rate. Journal of the Mechanics and Physics of Solids, 51, pp. 743-762.

Fernández-Abia et al., A. I. (2011). Effect of very high cutting speeds on shearing, cutting forces and roughness in dry turning of austenitic stainless steels. The International Journal of Advanced Manufacturing Technology , 57, pp. 61-71.

Filiz et al., S. (2007). An experimental investigation of micro-machinability of cooper 101 using tungsten carbide micro-endmills. International Journal of Machine Tools \& Manufacture , 47, pp. 1088-1100.

Fleck et al., N. A. (1994). Strain gradient plasticity: theory and experiment. Acta Metallurgica et Materialia , 42, pp. 475-487.

Fleck, N. A., \& Hutchinson, J. W. (1993). A phenomenological theory for strain gradient effects in plasticity. Journal of the Mechanics and Physics of Solids ,41, pp. 1825-1857. 
Gillespie, L. K. (1975). The burrs produced by grinding. The Bendix Corporation, Department 822. Kansas City: Technical Communications.

Gillespie, L. K., \& Blotter, P. T. (1976). The formation and properties pf machining burrs. Journal of Engineering for Industry, 98, pp. 66-74.

Gillibrand, D. (1979). Micro-defects on machined carbon steel surfaces. Precision Engineering, pp. 89-94.

Hasnaoui et al., A. (2003). Dimples on nanocrystaline fracture surfaces as evidence for shear plane formation. Science, 300, pp. 1550-1552.

Huo, D., \& Cheng, K. (2010). Experimental investigation on micromilling of oxygen-free, highconductivity copper using tungsten carbide, chemistry vapour deposition, and single-crystal diamond micro tools. Proceedings of the Institution of Mechanical Engineers. Part B, Journal of engineering manufacture, 224, pp. 995-1003.

Jackson, M. J. (2006). Microfabrication and Nanomanufacturing. Taylor \& Francis Group LLC. Jahanmir, S. (2011). Surface Integrity in Ultrahigh Speed Micromachining. Procedia Engineering , 19, pp. 156-161.

Jin et al., C. (2009). The characteristics of cutting forces in the micro-milling of AISI D2 steel. Journal of Mechanical Science and Tech , 23, pp. 2823-2829.

Joshi, S. S., \& Melkote, S. N. (2004). An explanation for the size-effect in machining using strain gradient plasticity. Journal of Manufacturing Science and Engineering , 126, pp. 679684.

Kaczmarek, J. (1976). Machining by cutting, abrasion and erosion. Peter Peregrinus Limited.

Kang et al., I. S. (2007). A mechanistic model of cutting force in the micro end milling process. Journal of Materials Processing Technology, 187-188, pp. 250-255.

Kim, C., Mayor, J. R., \& Ni, J. (2004). A static model of chip formation in microscale milling. Transactions of the ASME, 126, pp. 710-718.

Kishawy, H. A., \& Elbestwi, M. A. (1999). Effects of process parameters on material side flow during hard turning. International Journal of Machine Tools \& Manufacture , 39, pp. 10171030.

Komanduri, R. (1971). Some aspects of machining with negative rake tools simulating grinding. Journal of Machine Tool Design and Research , 11, pp. 223-233.

Komanduri, R., \& Turkovich. (1981). New observations on the mechanism of chip formation when machining titanium alloys. Wear , 69, pp. 179-188. 
Komatsu et al., T. (2012). Effect of crystal grain size in stainless steel on cutting process in micromilling. 5th CIRP Conference on High Performance Cutting 2012. 1, pp. 150-155. Elsevier.

Lai et al., X. (2008). Modelling and analysis of micro scale milling considering size effect, micro cutter edge radius and minimum chip thickness. International Journal of Machine Tools \& Manufacture, 48, pp. 1-14.

Lee, K., \& Dornfeld, D. A. (2005). Micro-burr formation and minimization through process control. Precision Engineering , 29, pp. 246-252.

Lee, K., Stirn, B., \& Essel, I. (2000). Burr formation in micro-machining. Retrieved June 17, 2013, from www.graco.unb.br: http://graco.unb.br/alvares/DOUTORADO/omega.enm.unb.br/pub/doutorado/disco2/telem anufacturing1/berkeley/LMA.berkeley.edu/research/2000/2000_Lee_3/2000_Lee_3.pdf

Lee, W. B., \& Zhou, M. (1993). A theorical analysis of the effect of crystallographic orientation on chip formation in micromachining. International Journal of Machine Tools and Manufacture , 33, pp. 439-447.

Lekkala et al., R. (2011). Characterization and modeling of burr formation in micro-end milling. Precision Engineering , 35, pp. 625-637.

Li, H. Z., Liu, K., \& Li, X. P. (2001). A new method for determining the undeformed chip thickness in milling. Journal of Materials Processing Technology, 113, pp. 378-385.

Li, K., \& Chou, S. (2010). Experimental evaluation of minimum quantity lubrication in near micro-milling. Journal of Materials Processing Technology, 210, pp. 2163-2170.

Liu et al., X. (2004). The Mechanics of Machining at the Microscale: Assessment of the Current State of the Science. Journal of Manufacturing Science and Engineering , 126, pp. 666-679.

Liu, K., Li, X. P., \& Liang, S. Y. (2007). The mechanism of ductile chip formation in cutting of brittle materials. The International Journal of Advanced Manufacturing Technology , 33, pp. 875-884.

Machado et al., A. R. (2009). Teoria da usinagem dos materiais. São Paulo: Blucher.

Madhavan, V., Chandrasekar, S., \& Farris, T. N. (2002). Direct observations of the chip-tool interface in the low speed cutting of pure metals. Journal of Tribology, 124, pp. 617-626.

Masuzawa, T. (2000). State of the art of micromachining. CIRP Annals - Manufacturing TEchnology, 49, pp. 473-488. 
Masuzawa, T., \& Töshoff, H. K. (1997). Three-dimensional micromachining by machine tools. CIRP Annals - Manufacturing Technology, 46, pp. 221-228.

Mian, A. J., Driver, N., \& Mativenga, P. T. (2011). Identification of factors that dominate size effect in micro-machining. International Jounal of Machine Tools \& Manufature, 51, pp. 383-394.

Mian, A., Driver, N., \& Mativenga, P. T. (2010). A comparative study of material phase effects on micro-machinability of multiphase materials. The International Journal of Advanced Manufacturing Technology, 50, pp. 163-174.

Mocellin, F., Melleras, E., \& Guesser, W. L. (2004). Study of the machinability of compacted graphite iron for drilling process. Journal of the Brazilian Society of Mechanical Science \& Engineering, 26, pp. 22-27.

Nakayama, K., \& Tamura, K. (1968). Size effect in metal-cutting force. Journal of Engineering for Industry , pp. 119-126.

Ning, Y., Rahman, M., \& Wong, Y. S. (2001). Investigation of chip formation in high speed end milling. Journal of Materials Processing Technology, 113, pp. 360-367.

Okitsu, Y., Takata, N., \& Tsuji, N. (2009). A new route to fabricate ultrafine-grained structures in carbon steels without severe plastic deformation. Scripta Materialia , 60, pp. 76-79.

Özel, T., \& Altan, T. (2000). Determination of workpiece flow stress and friction at the chiptool contact for high-speed cutting. International Journal of Machine Tools \& Manufacturing , 40, pp. 133-152.

Popov et al., K. B. (2006). Micromilling: material microstructure effects. Journal of Engineering Manufacture , 220, pp. 1807-1813.

Porto et al., J. V. (2004). Usinagem de ultraprecisão. São Carlos: Rima.

Puls, H., Klocke, F., \& Lung, D. (2012). A new experimental methodology to analyse the friction behaviour at the tool-chip interface in metal cutting. Production Engineering , 6, pp. 349-354.

Rech, J., \& Moisan, A. (2003). Surface integrity in finish hard turning of case-hardened steels. International Journal of Machine \& Manufacture , 43, pp. 543-550.

Robinson, G. M., \& Jackson, M. J. (2005). A review of micro and nanomachining from a materials perspective. Materials Processing Technology, 167, pp. 316-337.

Rodrigues et al. (2012). Patent No. PI11072474. Brasil.

Rodrigues et al., A. R. (2012). Surface integrity analysis when milling ultrafine-grained steels. Materials Research, 15, pp. 125-130. 
Rodrigues et al., A. R. (2010). Effects of milling condition on the surface integrity of hot forged steel. Journal of the Brazilian Society of Mechanical Science \& Engineering, 32, pp. 37-43.

Rodrigues, J., \& Martins, P. (2005). Tecnologia mecânica: tecnologia da deformação plástica (1 1 Edição ed., Vol. II). Lisboa: Escolar Editora.

Saptaji, K., Subbiah, S., \& Dhupia, J. S. (2012). Effect of side edge angle and effective rake angle on top burrs in micro-milling. Precision Engineering , 36, pp. 444-450.

Schaller et al., T. (1999). Microstructure grooves with a width of less than $50 \mu \mathrm{m}$ cut with ground hard metal micro end mills. Precision Engineering , 23, pp. 229-235.

Schmidt, J., \& Tritschler, H. (2004). Micro cutting of steel. Microsystem Technologies , 10, pp. 167-174.

Schueler et al., G. M. (2009). Burr formation and surface characteristics in micro-end milling of titanium alloys. Proceedings of the CIRP International Conference on Burrs (pp. 129-138). Berlin: Springer.

Shaw, M. C. (1997). Metal cutting principles. New York: Oxford Science.

Simoneau, A., \& Elbestawi, M. A. (2006). Surface defects during microcutting. International Journal of Machine tools \& Manufacture , 46, pp. 1378-1387.

Simoneau, A., Ng, E., \& Elbestawi, M. A. (2006). Chip formation during microscale cutting of a medium carbon steel. Machine Tools \& Manufacture , 46, pp. 467-481.

Son, S. M., Lim, H. S., \& Ahn, J. H. (2005). Effects of the friction coefficient on the minimum cutting thickness in micro cutting. International Journal of Machine Tools and Manufacture , 45, pp. 529-535.

Sreejith, P. S., \& Ngoi, B. K. (2000). Dry machining: machining of the future. Journal of Materials Processing Technology, 101, pp. 287-291.

Suzuki et al., H. (2007). Precision Cutting of Aspherical Ceramic Molds with Micro PCD Milling Tool. CIRP Annals - Manufacturing Technology, 56, pp. 131-134.

Vázques et al., A. (2010). An experimental analisys of process parameters to manufacture metallic micro-channels by micro-milling. The International Journal of Advanced Manufacturing Technology, 51, pp. 945-955.

Vogler, M. P., DeVor, R. E., \& Kapoor, S. G. (2004). On the modeling and analysis of machining performance in micro-endmilling, Part I: surface generation. Journal of Manufacturing Science and Engineering , 126, pp. 685-694. 
Wang et al., T. S. (2008). A novel process to obtain ultrafine-grained low carbon steel with bimodal grain size distribution for potencially improving ductility. Materials Science \& Engineering A , 485, pp. 456-460.

Weng, Y. (2009). Ultra-fine grained steels. Beijing: China Iron \& Steel Research Institute Group.

Weule, H., Hüntrup, V., \& Tritschler. (2001). Micro-cutting of steel to meet new requirements in miniaturization. CIRP Annals - Manufacturing Technology. 50, pp. 61-64. Elsevier.

Wu, J. H., \& Liu, Z. Q. (2009). Modeling the minimum chip thickness in orthogonal microcutting. Advanced Materials Research , 69-70, pp. 203-208.

$\mathrm{Wu}$, J., \& Liu, Z. (2010). Modeling of flow stress in orthogonal micro-cutting process based on strain gradient plasticity theory. The International Journal of Advanced Manufacturing Technology, 46, pp. 143-149.

Zhou et al., M. (2001). The effect of material microstructure on microcutting processes. Materials and manufacturing processes, 16, pp. 815-828. 
APÊNDICE A Medição do raio de aresta das ferramentas 


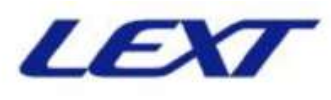

\section{Report Title}

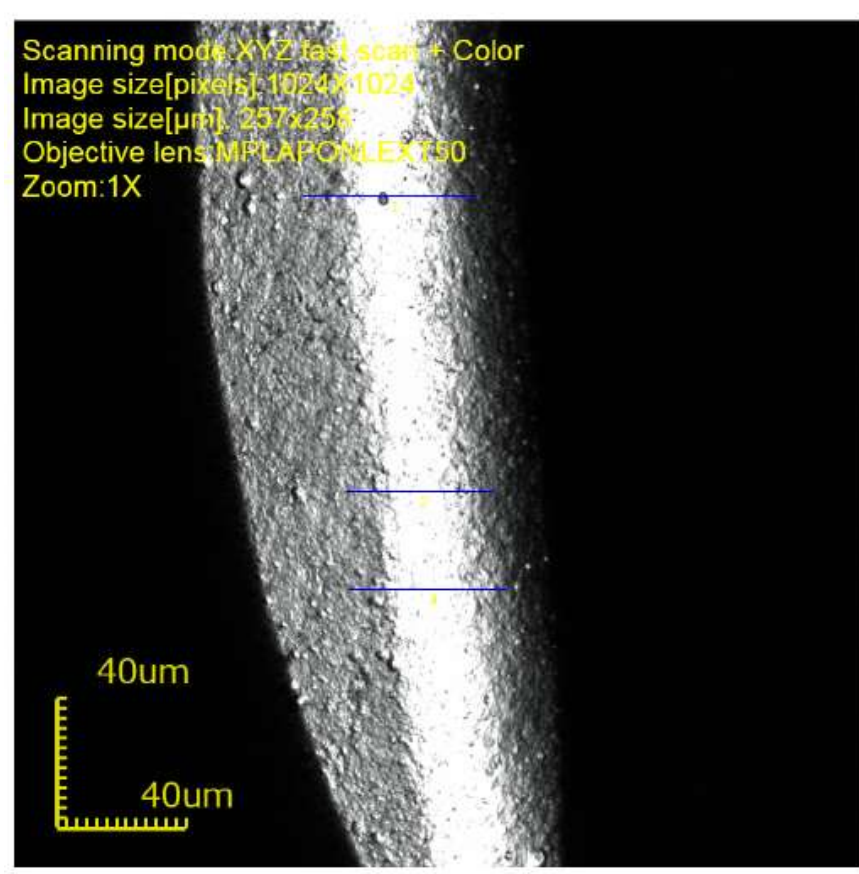

User ID: ADMIN

User name: Administrator

Description: FIRST ADMINISTRATOR

USER

111109_185951

[Acquisition parameters]

Scanning mode: $X Y Z$ fast scan + Color Image size[pixels]: 1024X1024

Image size[ $\mu \mathrm{m}]$ : $257 \times 258$

Objective lens: MPLAPONLEXT50x

Zoom: 1x

DIC: Off

Comment

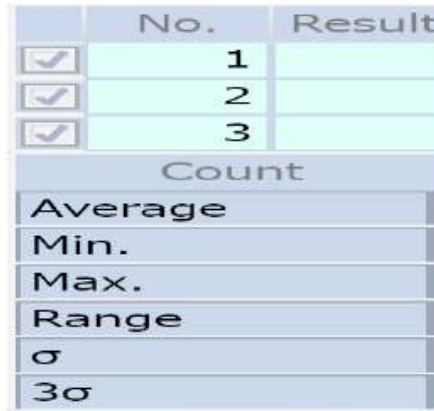

Radius[Hm] 26.316 22.545 24.009

Curvature[1/H

File name

Tolerance

24.290

22.545

26.316

3. $フ 1$

1.901

5.703

$0.038111109 \quad 1855$

$0.044111109-1855$

$0.042111109 \_1855$

3

0.041

0.038

0.044

0.006

0.003

0.009

Upper tolerance

Standard

Lower tolerance

O

o
Off

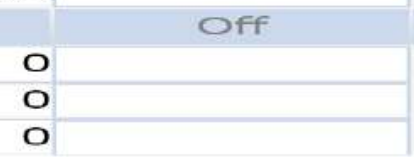

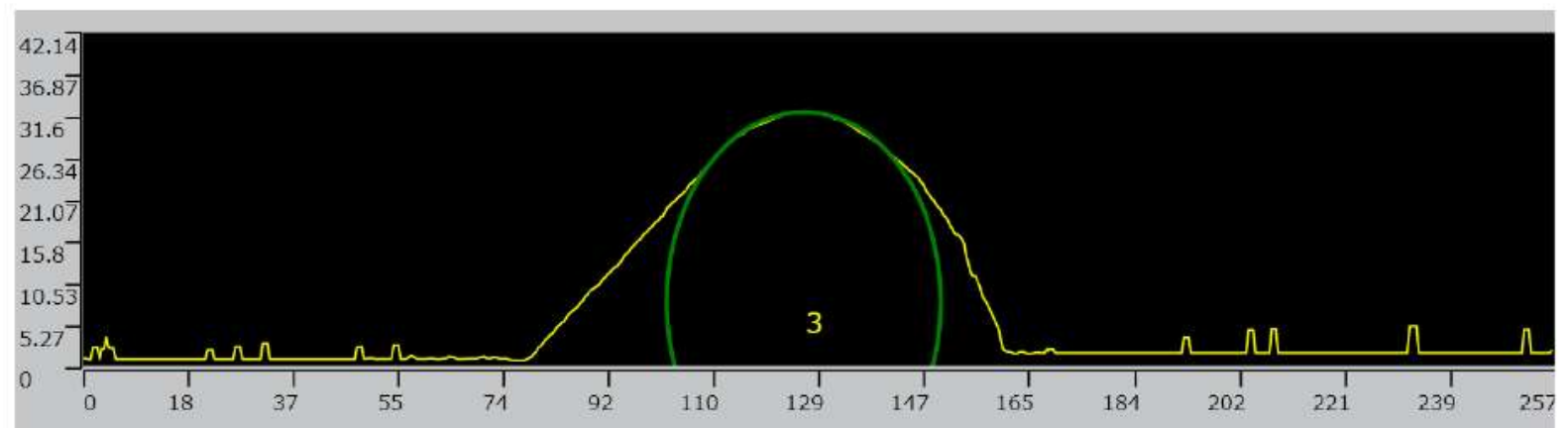

Figura A.1 - Medição do raio de aresta de uma das pastilhas utilizadas no macrofresamento. 


\section{$\angle E X$}

\section{Report Title}

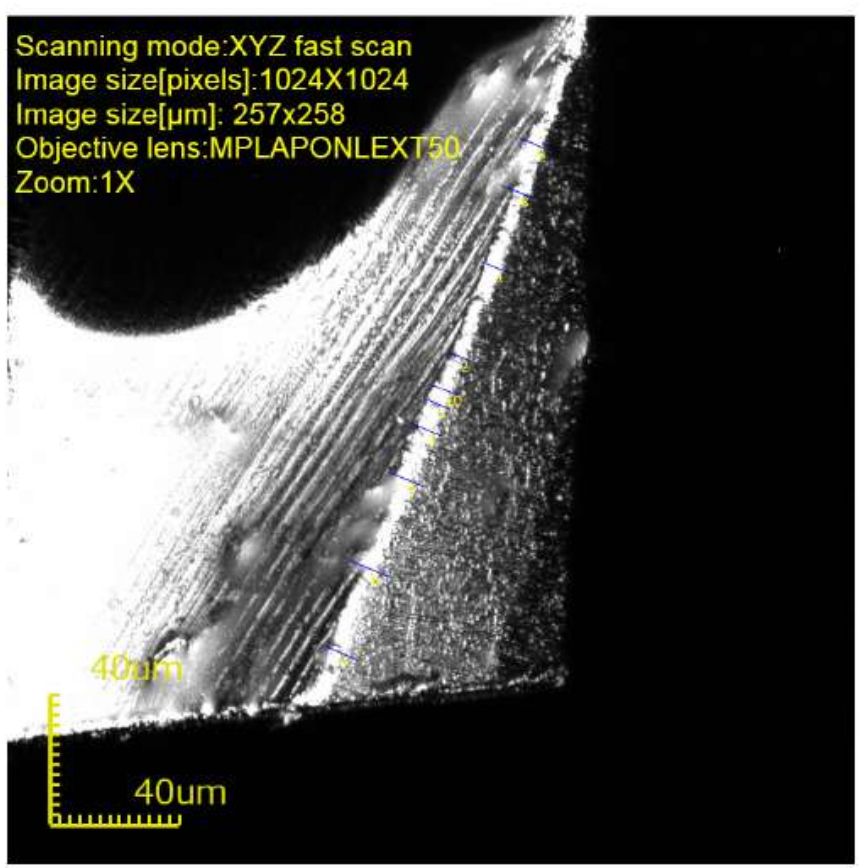

User ID: ADMIN

User name: Administrator

Description: FIRST ADMINISTRATOR USER

120314031531135

[Acquisition parameters]

Scanning mode: $X Y Z$ fast scan

Image size[pixels]: 1024X1024

Image size $[\mu \mathrm{m}]: 257 \times 258$

Objective lens: MPLAPONLEXT50x

Zoom: $1 \mathrm{x}$

DIC: Off

\section{Comment}
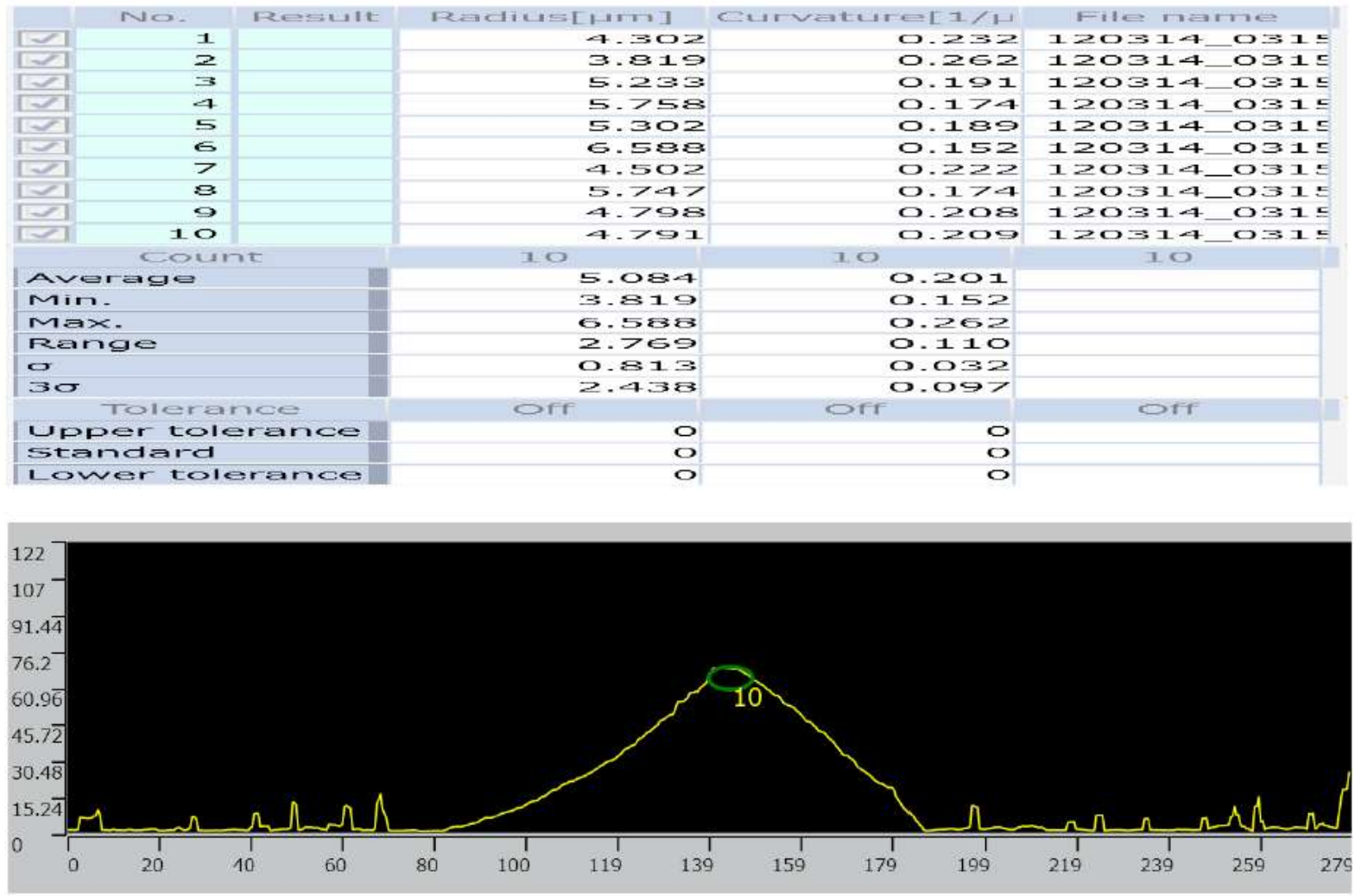

Figura A.2 - Medição do raio de aresta de uma das microfresas utilizadas no microfresamento. 